University of Texas at El Paso

\title{
DigitalCommons@UTEP
}

Open Access Theses \& Dissertations

2012-01-01

\section{On the Extraction of Volatiles from Lunar Regolith Using Solar Power}

Jorge Alberto Frias

University of Texas at El Paso, jafrias@miners.utep.edu

Follow this and additional works at: https://digitalcommons.utep.edu/open_etd

Part of the Mechanical Engineering Commons

\section{Recommended Citation}

Frias, Jorge Alberto, "On the Extraction of Volatiles from Lunar Regolith Using Solar Power" (2012). Open Access Theses \& Dissertations. 1821.

https://digitalcommons.utep.edu/open_etd/1821

This is brought to you for free and open access by DigitalCommons@UTEP. It has been accepted for inclusion in Open Access Theses \& Dissertations by an authorized administrator of DigitalCommons@UTEP. For more information, please contact lweber@utep.edu. 


\title{
ON THE EXTRACTION OF VOLATILES FROM LUNAR REGOLITH USING SOLAR POWER
}

\author{
JORGE ALBERTO FRIAS
}

Department of Mechanical Engineering

\section{APPROVED:}

Evgeny Shafirovich, Ph.D., Chair

Norman Love, Ph.D.

Jose M. Hurtado, Ph.D.

Benjamin C. Flores, Ph.D.

Dean of the Graduate School 


\section{Copyright (C)}

by

Jorge Alberto Frias

2012 
This thesis is dedicated to my parents

for their love, endless support

and encouragement 


\title{
ON THE EXTRACTION OF VOLATILES FROM LUNAR REGOLITH USING SOLAR POWER
}

\author{
by \\ JORGE ALBERTO FRIAS, BSME
}

\author{
THESIS \\ Presented to the Faculty of the Graduate School of \\ The University of Texas at El Paso \\ in Partial Fulfillment \\ of the Requirements \\ for the Degree of
}

MASTER OF SCIENCE

Department of Mechanical Engineering

THE UNIVERSITY OF TEXAS AT EL PASO

December 2012 


\section{Acknowledgements}

I would first like to thank my advisor Dr. Evgeny Shafirovich for his help, patience, motivation and guidance provided during my Masters of Science degree. Secondly, I acknowledge the members of my committee, Dr. Norman Love and Dr. Jose M. Hurtado for their insight in the process of completing this thesis.

I would also like to thank Armando Delgado, Ashvin Kumar, Francisco Alvarez, Marco Machado, Israel Lopez, Shakil Alam and Daniel Rodriguez as part of the In-Situ Resource Utilization (ISRU) team from the Center for Space Exploration Technology Research (cSETR) for their cooperation during this research project. Thanks to all the students of the cSETR at UTEP for their help through my graduate career. I would also like to extend my thanks to Angel Lerma and Jesus Hinojos for their support and aid in manufacturing the parts for my experiment. Special thanks to ExoTerra's president Michael VanWoerkom for his support during this thesis. Also, to the Texas Space Grant Consortium program who awarded me twice as a fellowship recipient during my graduate school and aided towards my tuition.

Finally, I would like to thank Dr. Ahsan Choudhuri from the Department of Mechanical Engineering, Nathaniel Robinson and Laura Barnum, for their continuing support during my involvement as a research assistant in the NASA University Research Center (cSETR) at UTEP. 


\begin{abstract}
Recent lunar missions have confirmed the presence of water and miscellaneous volatiles within the craters of the Moon's South Pole. If harvested, these resources have the potential to provide an incredible budget saving to the human space exploration program by dropping the total mass that astronauts need to carry from the Earth. The area that develops these technologies is called In-Situ Resource Utilization (ISRU). ISRU allows reducing the payload, and consequently reduces the energy consumption and cost of space exploration. The present thesis investigates methods for the extraction of volatiles from regolith within the shadowed craters of the Moon using solar power. Topics that are to be discussed within this thesis will include heat transfer calculations, experimental studies using a $\mathrm{CO}_{2}$ laser, and lastly the design of the process schematic to validate the extraction of volatiles.
\end{abstract}




\section{Table of Contents}

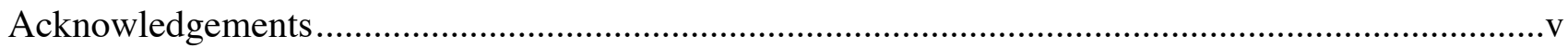

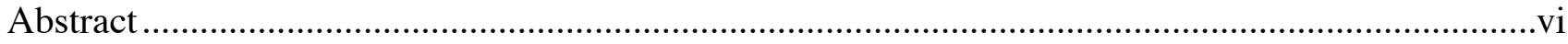

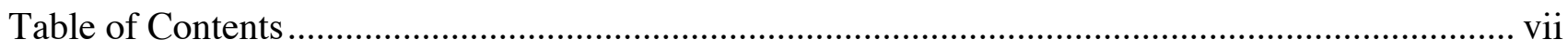

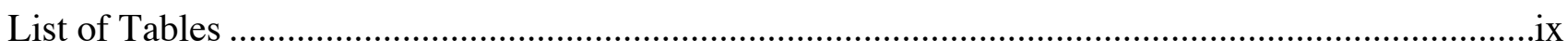

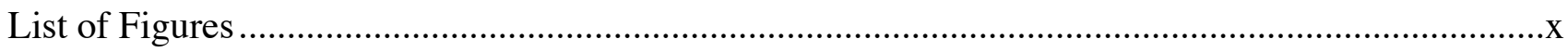

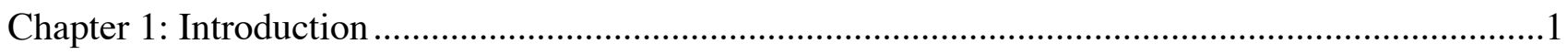

1.1 Lunar In-Situ Resource Utilization ..............................................................4

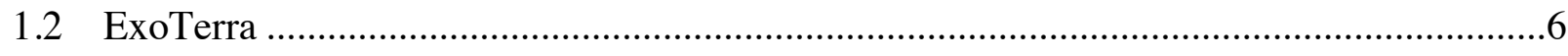

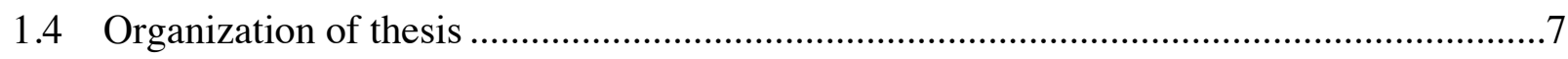

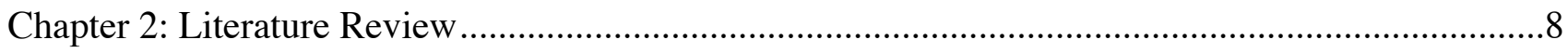

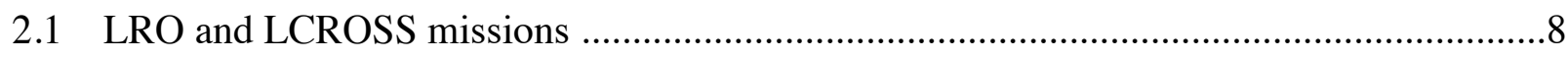

2.2 Lunar Regolith Simulant JSC-1A .................................................................14

2.3 Solar Thermal Power System for Oxygen Production from Lunar Regolith ..................17

2.4 Sublimation of Water Ice to Water Vapor ............................................................26

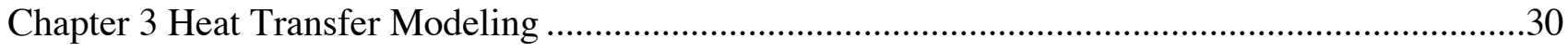

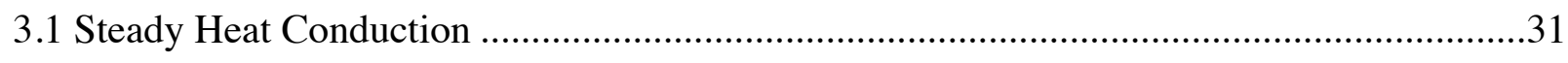

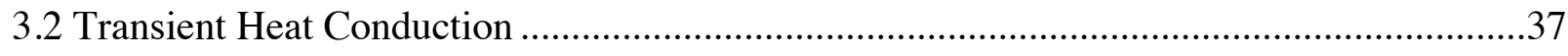




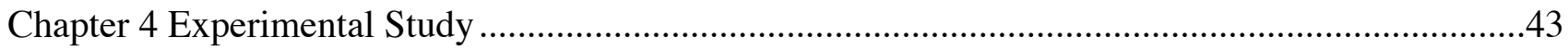

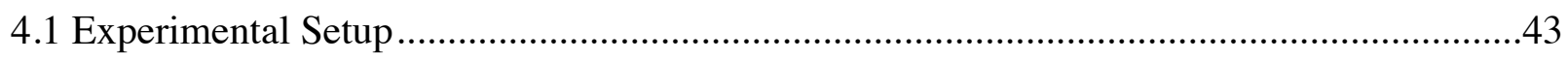

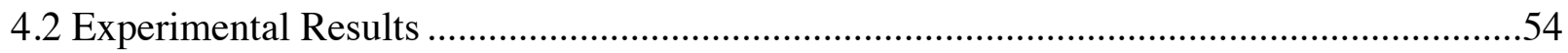

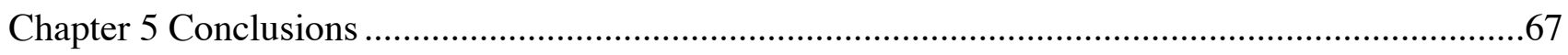

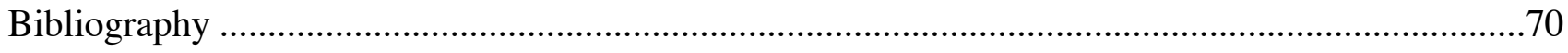

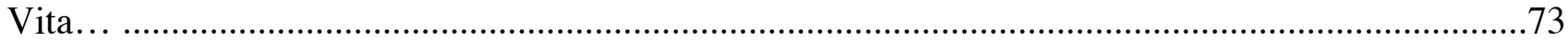




\section{List of Tables}

Table 2.1.1-Elemental contributions to the plume spectrum observed by the LAMP (Gladstone 2010) 12

Table 2.2.1 - Mineral compositions of JSC simulants and some Apollo samples 15

Table 2.2.2 - Compositions (wt \%) of the mayor constituents of JSC -1, JSC-1A, JSC-1AF and Apollo

17 samples 15

Table 2.2.3 - Mineral composition of lunar regolith simulant JSC-1A ....................................... 16

Table 2.3.1 - Surface temperature of lunar regolith simulant melt vs. heat flux (T. Nakamura 2011) .... 20

Table 2.4.1 - Specific isobaric heat capacity data of water vapor (Woolley 1980) ............................ 28

Table 3.1.1 - Values used for simulation analysis performed …............................................... 32

Table 3.2.1.1 - Engineering Equation Solver solutions for a transient heat conduction in a semi-infinite

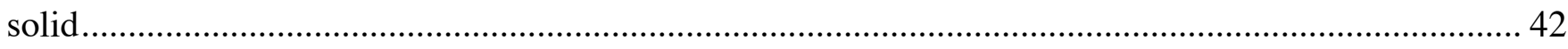

Table 4.2.1 - Results from experimental testing summarized ................................................... 55

Table 4.2.2 Comparison between heat transfer simulation and experimental testing ......................... 56

Table 5.1 - Comparison of modeling with experimental results .................................................. 67

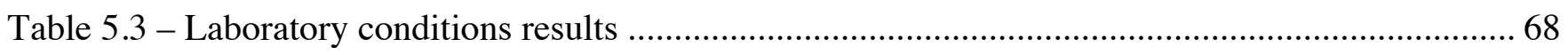

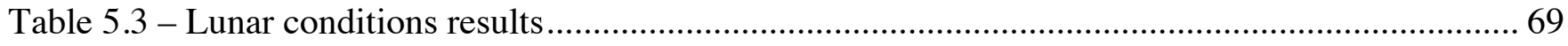




\section{List of Figures}

Figure 1.1 - Lunar volatiles extraction architecture ......................................................................... 1

Figure 1.2 - Volatile extraction and processing system .................................................................. 3

Figure 1.3 - Initial schematic for the condensation system............................................................ 3

Figure 1.1.1 - Composition of lunar regolith (Landis 2007) ..............................................................

Figure 2.1.1 - Diviner pre-impact brightness temperature map from nadir data (Hayne 2010) ................ 9

Figure 2.1.2 - Short wave infrared (SWIR) cameras helped determine the presence of water in the moon

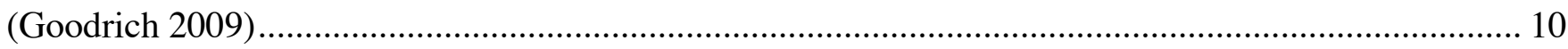

Figure 2.3.1 - Solar thermal system for oxygen production from lunar regolith (Takashi Nakamura 2008)

Figure 2.3.2 - (a) Focus heating with imaging optics (b) and with non-imaging optics (Takashi

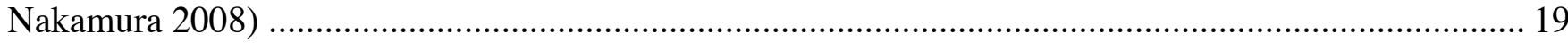

Figure 2.3.3 - Vitrified JSC-1 melt (T. Nakamura 2010) ………………………………....................... 21

Figure 2.3.4 - Solar concentrator array tracking the sun (T. Nakamura 2010) ........................................ 23

Figure 2.3.5 - Solar sintering of the 15 in x 15 in Tephra surface (T. Nakamura 2011) .......................... 24

Figure 2.3.6 - Illustration of thermal wadis and its function (R. Balasubramaniam 2009) ...................... 25

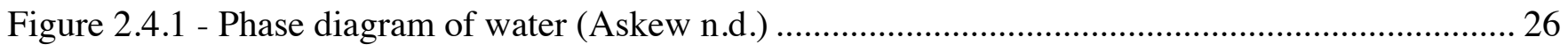

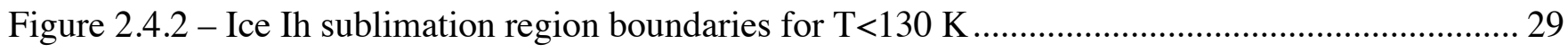

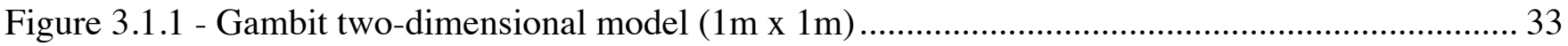

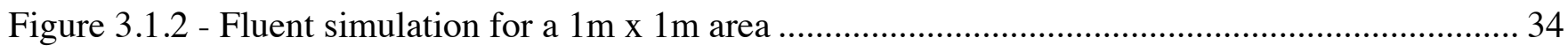

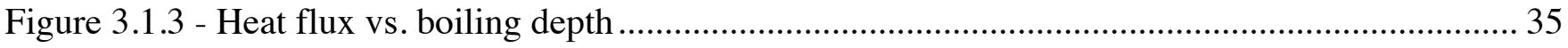

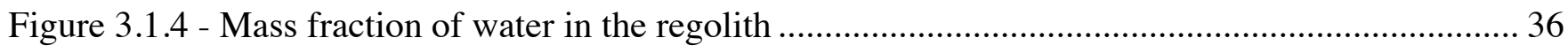

Figure 3.2.1 - Fluent analysis for transient heat conduction performed during 30 minutes ...................... 38

Figure 3.2.2 - Close-up image of the heating section in the transient heat conduction analysis .............. 39 
Figure 3.2.1.1 - Results obtained from the Engineering Equation Solver software for the specific surface heat flux equation

Figure 4.1.1 - Schematic diagram of experimental setup for extraction of water from wet regolith using

$\mathrm{CO}_{2}$ laser

Figure 4.1.2 - Firestar-Ti60 $\mathrm{CO}_{2}$ laser 44

Figure 4.1.3 - Power Wizard readings ...... 45

Figure 4.1.4 - CAD design for Teflon part to hold the zinc selenide window 46

Figure 4.1.5 - Heater chamber apparatus a) front view b) top view 46

Figure 4.1.6 - Bioengineering INVERSINA 47

Figure 4.1.7 - Preliminary test 48

Figure 4.1.8 - Thermocouple setup 49

Figure 4.1.9 - Thermocouple setup placement 50

Figure 4.1.10 - Experiment a) without heating tape b) with heating tape . 51

Figure 4.1.11 - Final water extraction system 52

Figure 4.2.1 - Test 4 picture 54

Figure 4.2.2 - Test 1.20\% power for 2 minutes 56

Figure 4.2.3 - Initial thermocouple setup 57

Figure 4.2 .4 - Test 2.50\% power for 2 minutes 58

Figure 4.2 .5 - Test $3.50 \%$ power for 10 minutes 58

Figure 4.2.6 - Test $4.60 \%$ power for 10 minutes 59

Figure 4.2.7 - Test 5. 60\% power for 15 minutes 59

Figure 4.2.8 - Thermocouple setup testing 60

Figure 4.2.9 - Test $8.60 \%$ power for 20 minutes 61

Figure 4.2.10 - Test $9.80 \%$ power for 20 minutes 61 


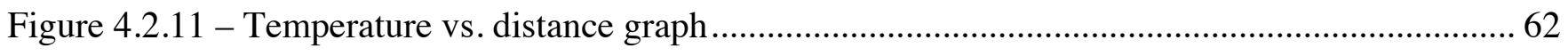

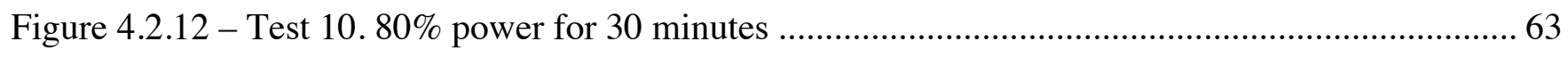

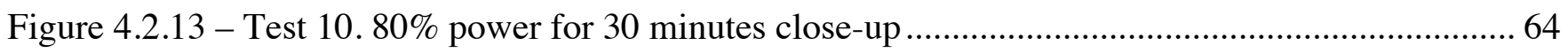

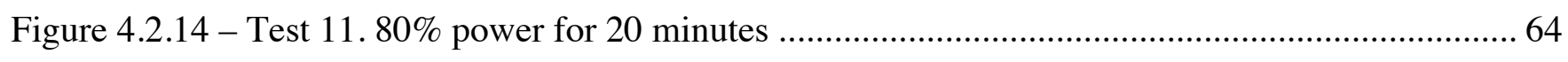

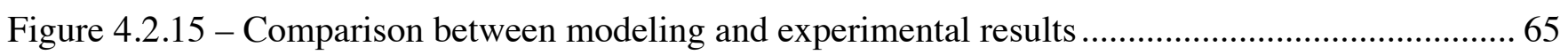

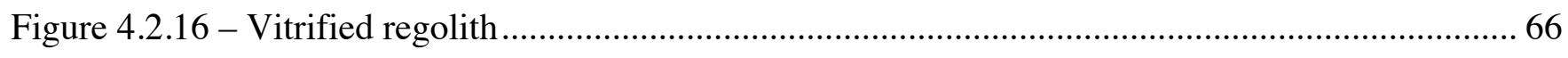




\section{Chapter 1: Introduction}

The objective of this paper is to study extraction methods of volatiles from lunar regolith within the shadowed craters of the Moon using solar power. Extreme conditions, such as low temperatures of $40 \mathrm{~K}$ and the lack of an atmosphere in the surface of the moon are factors to be considered in this challenging study. Volatiles are trapped in the shadowed areas in the moon, leaving no solar power source for rovers and processing equipment. Since energy is required for the extraction of these volatiles, beamed power to the shadowed crater is being contemplated. Two options are being considered to beam the solar energy into the crater. The first option to take into account would be to have a satellite orbiting the Moon and concentrate a beam power to the shadowed crater as shown in Figure 1.1. However, for simplicity reasons, the most promising method would be option two which is to have ground-based reflectors to power into the shadowed area where the designed equipment would be extracting volatiles.

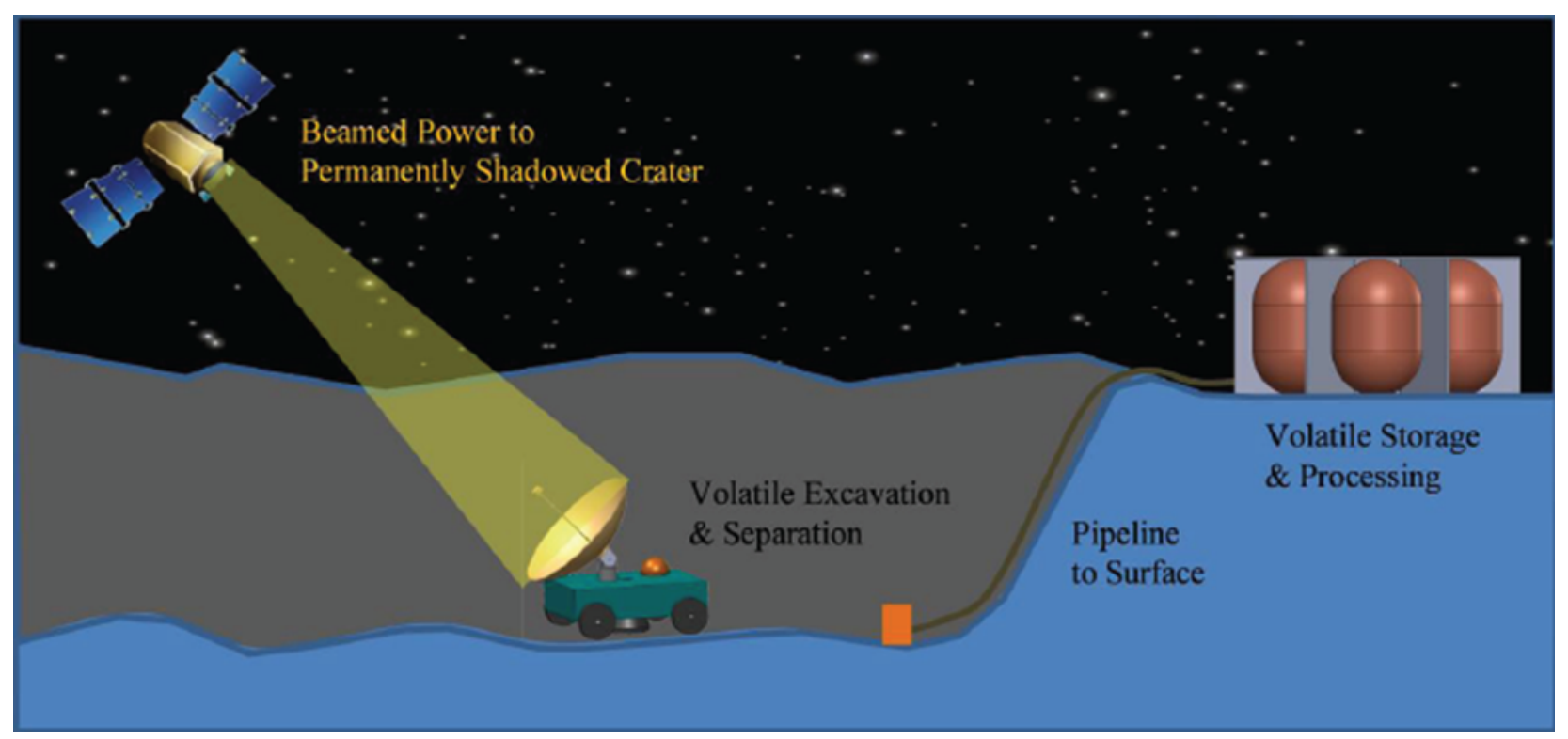

Figure 1.1 - Lunar volatiles extraction architecture 
As mentioned before, the absence of atmosphere and the low temperatures present a crucial challenge in the experiment. In order to better understand the behavior of volatiles under these extreme conditions, we first conducted research on the phase diagram of water. "The sublimation of water in the region of extremely low pressures and temperatures meets increasing interest for the exploration of icy cosmic bodies" (Rainer Feistel 2007). Temperature and atmospheric pressure in the craters of the moon are known to be $40 \mathrm{~K}$ and $10^{-7} \mathrm{~Pa}$. respectively. Therefore, the pressure and temperature at which solid water sublimates into water vapor was determined and is shown later in this report.

In order to estimate the amount of energy needed to extract volatiles from the lunar regolith, heat transfer calculations on the regolith when a heat flux is being applied should be performed. A preliminary design for the extraction system includes an oven heated by solar power that is transferred by the fiber optics from the solar concentrator (Fig 1.2). Note that the feasibility of transferring concentrated solar energy by the fiber optics has been demonstrated in successful tests of the optical waveguide solar thermal power system for ISRU applications (T. a. Nakamura 1996). The regolith is heated to temperatures that exceed the boiling points of the contained volatiles at the atmospheric pressure of the Moon. As each volatile reaches its liquefaction point and condenses out of the gas mixture, it is pumped into a separate storage tank. Initial schematics shown in Figure 1.3 envision tanks for water, carbon monoxide and nitrogen with separate tanks for various volatiles such as hydrogen sulfide, chlorine, ammonia and any other traces of volatiles obtained during the process. 


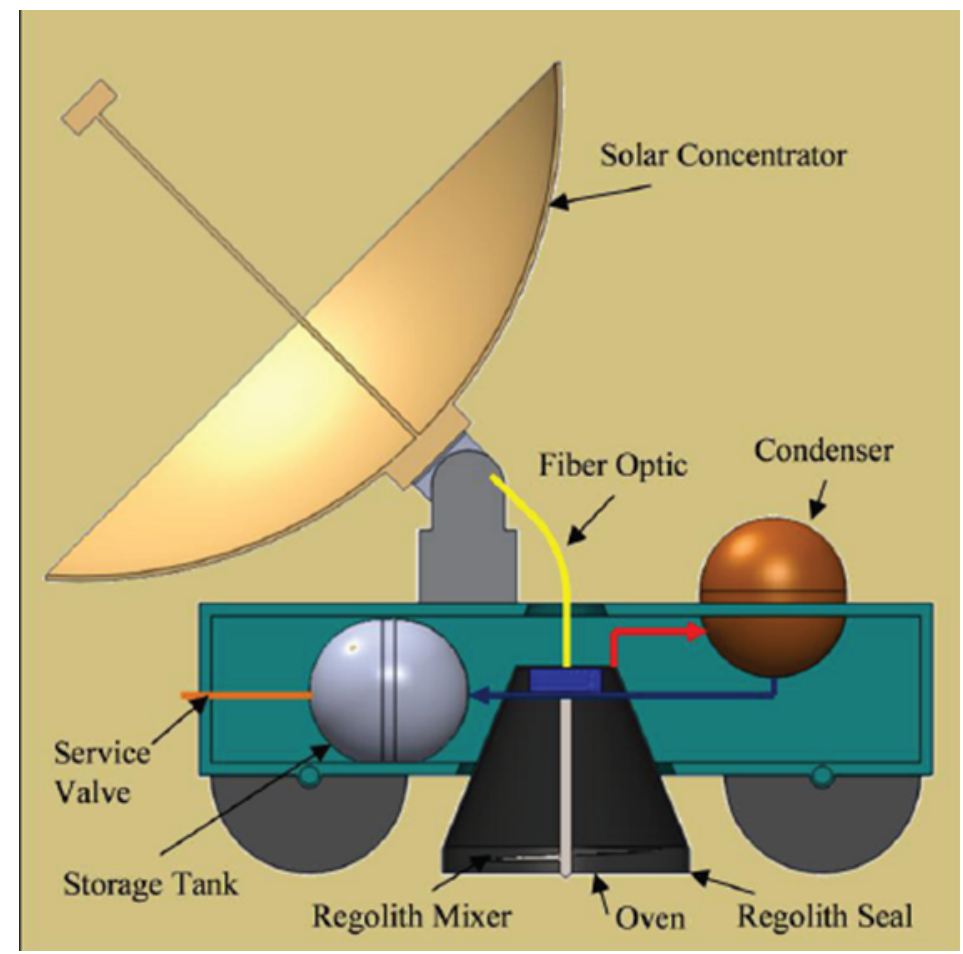

Figure 1.2 - Volatile extraction and processing system

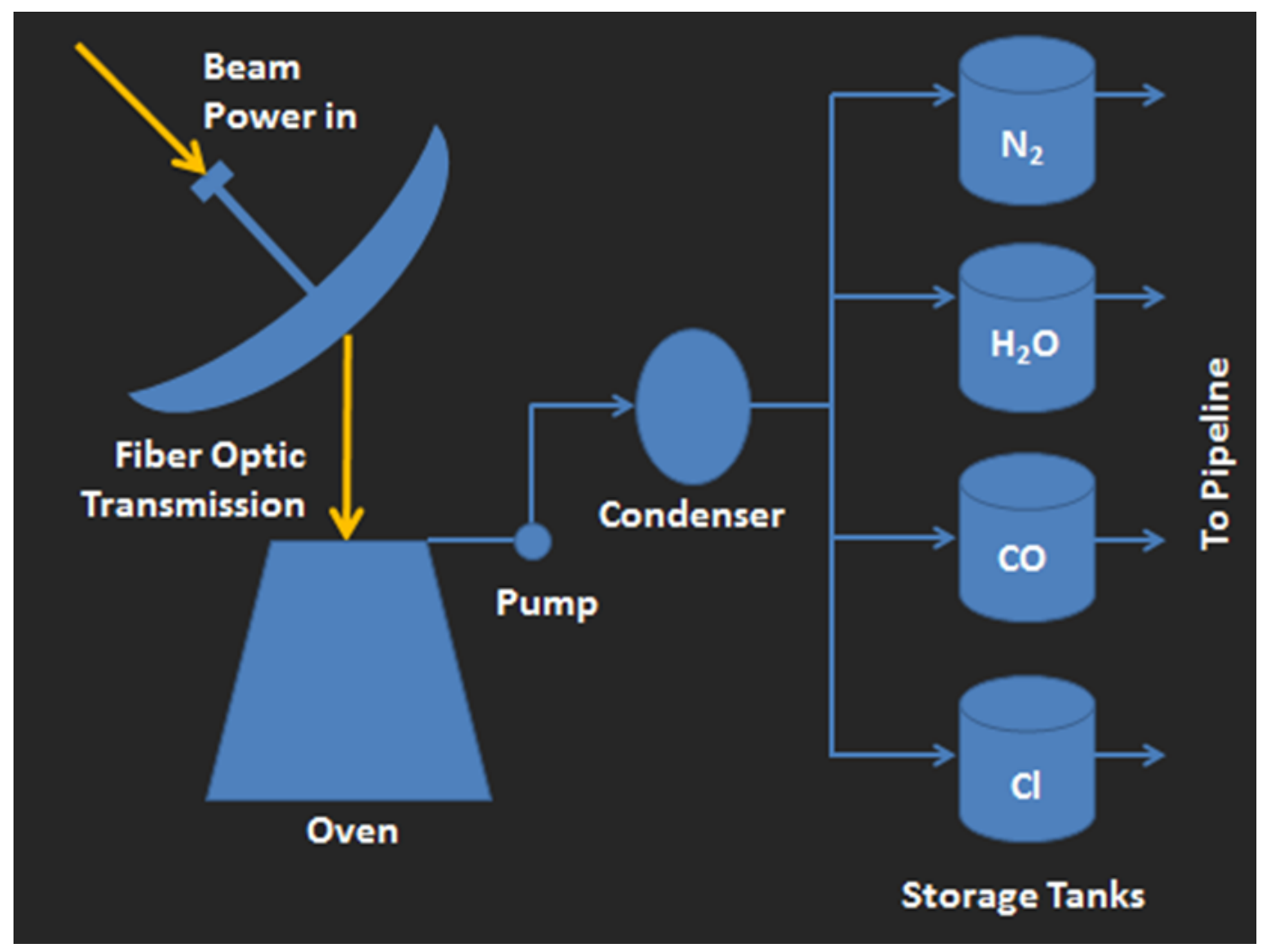

Figure 1.3 - Initial schematic for the condensation system 
To develop the extraction equipment, it is necessary to determine the amount of power that is required for the sublimation of frozen volatiles located in the lunar regolith. This thesis focuses on the analysis and experimental results of heat transfer starting from the top surface of regolith, irradiated by the light beam, down to the underlying layers. This analysis is needed for the determination of required solar power. Analysis and experimental results obtained in the laboratory are then compared to validate analysis performed under lunar conditions.

\subsection{LUNAR IN-SiTU RESOURCE UTILIZATION}

NASA is currently planning on expanding human space exploration, and with the Space Launch System and the Orion Multi-Purpose Crew Vehicle, humans will soon have the opportunity to travel beyond low Earth orbit. This will open a solar system of opportunities for humans to explore near-Earth objects such as the Moon, Mars and asteroids. However, in order to reach these space destinations, researchers have started to perform experiments in analog sites on Earth with similar conditions. Examples include analog site in Hawaii to simulate the regolith in the moon and excavation being performed in the north poles to study excavation techniques in extreme conditions.

In-Situ Resource Utilization (ISRU) is the concept of using indigenous resources on space bodies to produce propellants, water, oxygen, and other materials required for space exploration missions. The production of oxygen is not only vital for human survival, but is also used fro propulsion purposes. Figure 1.1.1 shows the composition of the lunar regolith. Because the Moon is $42 \%$ oxygen (Landis 2007), methods to extract the oxygen from the mineral form have been studied. It is important to note that the main elemental component of lunar regolith after oxygen is silicon. Silicon is the main component for the production of solar panels, and the extraction of silicon from the regolith is important for the production of photovoltaic components to collect solar energy. 


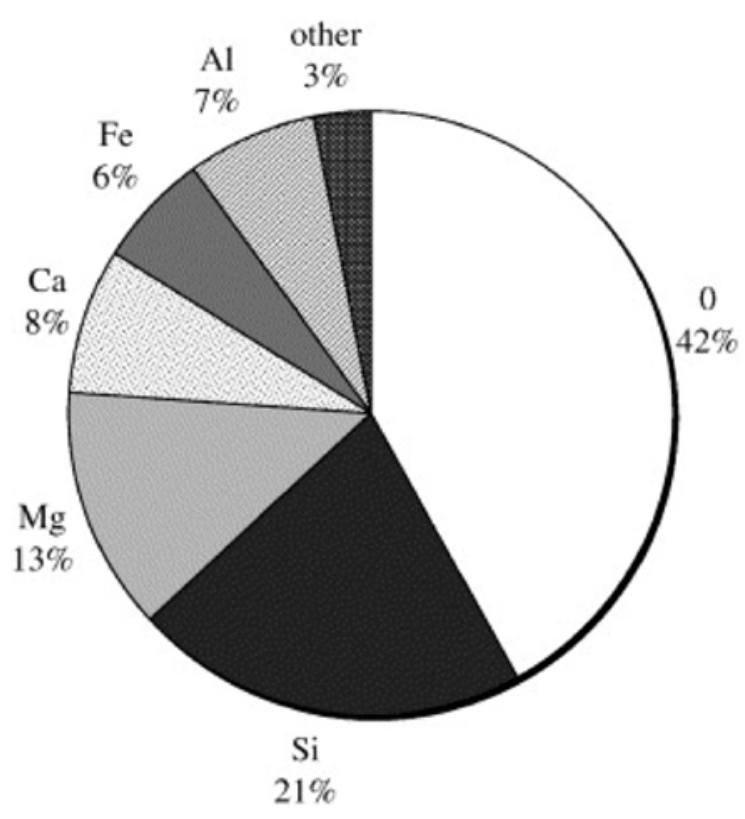

Figure 1.1.1 - Composition of lunar regolith (Landis 2007)

Since long duration missions can cause resupply efforts to be expensive and can put the crew at risk, ISRU has become increasingly more and more important. NASA is currently conducting mission simulations, known as analog missions, at extreme and often isolated locations on Earth to prepare for robotic and human missions to extraterrestrial destinations. The two main tests for the 2012 ISRU missions are the Regolith and Environment Science and Oxygen and Lunar Volatile Extraction (RESOLVE) and the Moon Mars Analog Mission Activities (MMAMA).

RESOLVE is an experiment package designed to find, characterize and map the presence of ice and other volatiles in almost permanently shadowed areas at the lunar poles. To demonstrate this concept, RESOLVE will perform a small-scale oxygen extraction from a layer of regolith found on the volcanic deposits of Hawaii, just as it could with regolith found on the moon. The multiple science instruments used include: 
- A neutron spectrometer and near-infrared spectrometer (NIR) to help locate volatiles and identify the minerals in the regolith, such as hydrogen and water vapor.

- A one-meter drill system to take samples from below the lunar surface for evaluation.

- An oven used to bake the samples, separating the elements of interest from the soil itself.

- A volatile characterization mass spectrometer/gas chromatograph to identify the type and amount of volatiles present.

\subsection{EXOTERRA}

The ISRU team at UTEP's Center for Space Exploration Technology Research is currently working with ExoTerra Resource and its president Michael VanWoerkom who had the idea of harvesting these resources and providing high savings to the space program. ExoTerra Resource has the intent of providing space infrastructure systems that make lunar exploration cheaper and safer. ExoTerra initially envisions tanks for water $\left(\mathrm{H}_{2} \mathrm{O}\right)$, carbon monoxide $(\mathrm{CO})$, and nitrogen $(\mathrm{N})$, with separate tank for miscellaneous volatiles such as hydrogen sulfide $\left(\mathrm{H}_{2} \mathrm{~S}\right)$, chlorine $(\mathrm{Cl})$, ammonia $\left(\mathrm{NH}_{3}\right)$ and any other traces of volatiles. The UTEP team has decided to investigate the feasibility of extracting water from Lunar South Pole regolith (assuming that the water content corresponds to LCROSS data) through modeling of heat transfer from the concentrated sunlight beam to the regolith and demonstrating experiments under laboratory conditions. 


\subsection{ORganization OF THESIS}

A literature review is presented in Chapter 2. First, we review prior studies performed to confirm the presence of water on the Moon, presented in six journal articles published in Science in 2012. Also in this chapter, we review prior studies on the solar thermal power system for oxygen production from lunar regolith, where solar concentrators were tested to heat the lunar regolith simulant. Finally, the data on sublimation of water ice to water vapor under extreme conditions such as low pressure and low temperature on the Moon are presented. Chapter 3 details the results obtained from the heat transfer

modeling. The experimental setup and results obtained are presented in Chapter 4. Summary and conclusions are presented in Chapter 5. 


\section{Chapter 2: Literature Review}

\subsection{LRO AND LCROSS MISSIONS}

Initial missions performed in the past, such as Clementine in January 1994, had the objective to test lightweight miniature sensors and had the task of mapping the moon for the first time. Clementine was able to deliver more than 1.8 million digital images of the moon and allowed scientists to discover possible existence of ice within some of the Moon craters (Spudis 2004). In March of 1998, Lunar Prospector (LP) mission was executed. It was designed to map the Moon's surface and confirm the possibility of ice in the polar regions of the moon by measuring magnetic and gravity fields as well as to study lunar outgassing events. The neutron spectrometer instrument onboard LP detected hydrogen, which was assumed to be in the form of water ice. Data acquired indicated that a large quantity of water ice was mixed into the regolith at each pole. By March $5^{\text {th }} 1998$, LP announced the discovery of a signal for water ice on both of the lunar poles.

Lunar Crater Observation and Sensing Satellite (LCROSS) mission was performed in 2009 to confirm the presence of water ice in permanently shadowed craters at the Moon's South Pole. LCROSS mission consisted of impacting a Centaur rocket at a speed of more than 1.5 miles per second to the lunar surface of the Moon to create a plume to be analyzed. Figure 2.1.1 shows an image of the exact location in the crater where the impact took place. Impact happened near the center of one of the coldest regions on the Cabeus crater. 


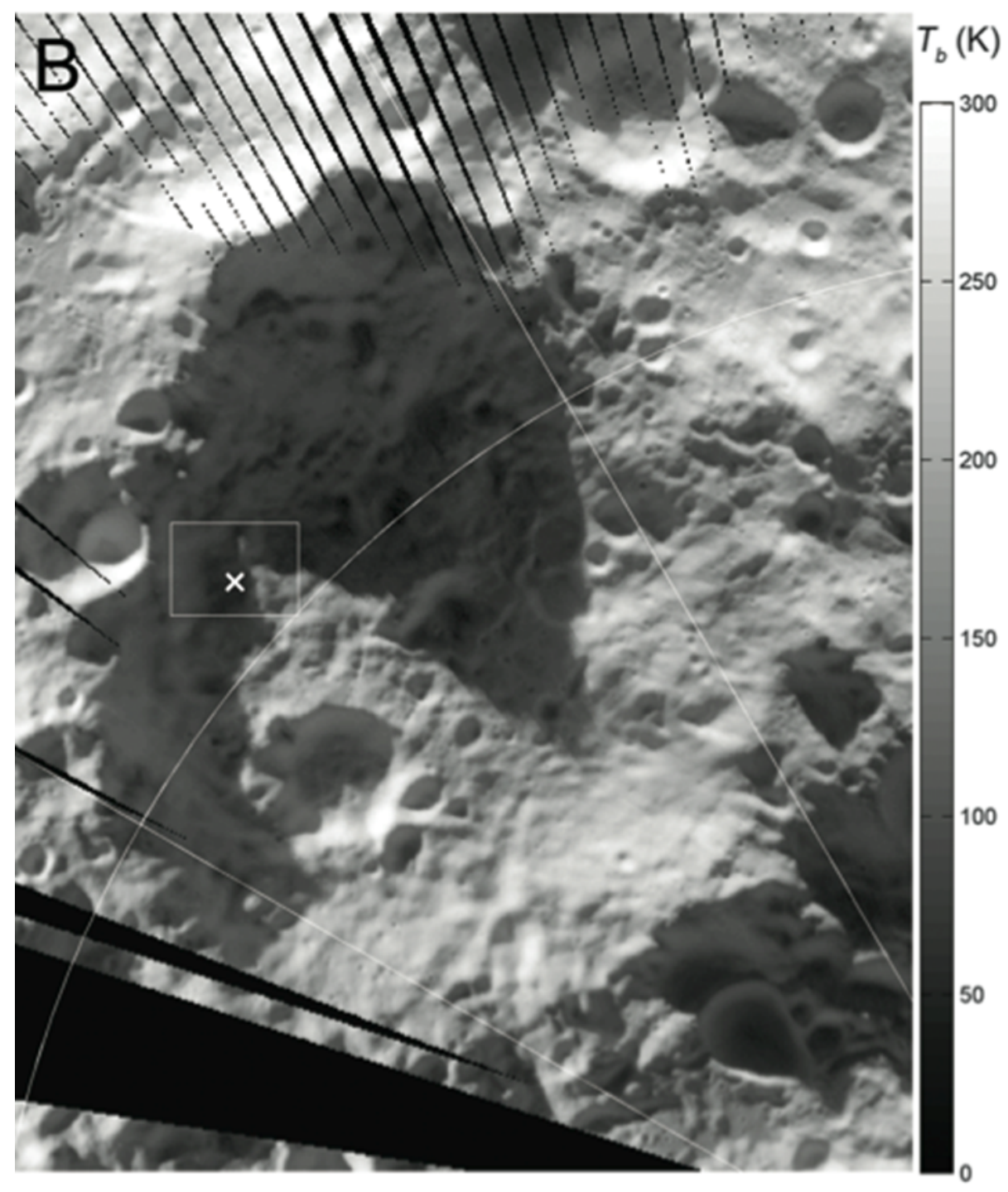

Figure 2.1.1 - Diviner pre-impact brightness temperature map from nadir data (Hayne 2010)

Before the impact, the Centaur rocket was being followed by NASA's LCROSS spacecraft, which analyzed the plume by using several instruments that include four near-infrared and mid-infrared cameras, two near-infrared spectrometers, a visible light spectrometer and a visible radiometer to measure the flash of light created by the Centaur impact. LCROSS instruments are shown in Figure 2.1.2. Approximately 9 hours before impact, the LCROSS Shepherding Spacecraft separated from the Centaur rocket and performed a breaking burn to build a 4-minute separation between itself and the Centaur at impact. About 1 hour before impact, the nine LCROSS instruments were powered and began 
taking data to generate a reference spectrum against which post-impact spectra could be compared to. The impact generated by the rocket heated a region of approximately 30 to $200 \mathrm{~m}^{2}$ to temperatures of at least $950 \mathrm{~K}$, providing enough energy to sublimate approximately $300 \mathrm{~kg}$ of water ice during the 4 minutes of the LCROSS and LRO post-impact observations (Hayne 2010).

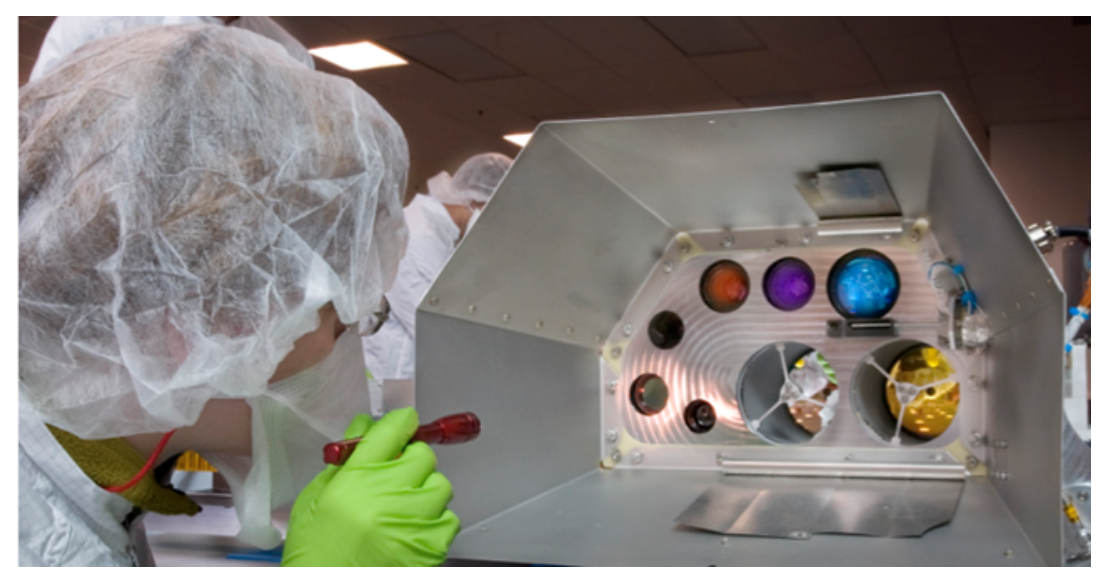

Figure 2.1.2 - Short wave infrared (SWIR) cameras helped determine the presence of water in the moon (Goodrich 2009)

NASA's Lunar Reconnaissance Orbiter (LRO) was orbiting the Moon at that moment, both to help pick the location of the impact and to observe the resulting debris and vapor cloud resulted from the impact. The LCROSS target site was selected using a variety of criteria; the two most important were the altitude at which ejecta would be illuminated by sunlight and evidence of elevated levels of hydrogen from previous measurements. Topographic data and its orientation to the Sun indicated that Cabeus crater was the most compelling target (Mitrofanov 2010). "The Lyman Alpha Mapping Project (LAMP) ultraviolet spectrograph onboard the LRO observed the plume generated by the LCROSS impact as far-ultraviolet emissions from the florescence of sunlight by molecular hydrogen and carbon monoxide" (Gladstone 2010). LRO was also designed to map the lunar surface and characterize landing sites for future missions. LRO has revealed that in Polar Regions of the Moon, deep and long shaded craters can act as cold storage, capable of accumulating and preserving volatile material like water ice. 
LCROSS mission results were issued in six papers that were published in the October 22 issue of Science magazine (Mitrofanov 2010) (Paige 2010) (Hayne 2010) (Gladstone 2010) (Schultz 2010) (Colaprete 2010). The mission found evidence that lunar regolith, especially in the shadowed areas, is rich in useful materials and that if extracted, can be utilized by explorers. The area selected for impact showed temperatures less than $50 \mathrm{~K}$ making it a likely cold trap for volatiles materials (Paige 2010). If mined, these resources could be an indispensable source of life support for astronauts exploring the Moon.

Volatiles are compounds that freeze and are trapped in the cold lunar craters and are vaporized when warmed by the sun. LCROSS and LRO determined as much as $20 \%$ of the material in the plume to be volatiles. Diversity and abundance of volatiles in the plume suggest a variety of sources such as comets, solar wind, and asteroids (Colaprete 2010). "The diverse mixture of water and high-volatility compounds detected in the LCROSS ejecta plume is strong evidence for the impact delivery and coldtrapping of volatiles derived from primitive outer solar system bodies" (Paige 2010). Elemental contribution to the plum spectrum observed by the LAMP is shown in Table 2.1.1. Pertinent information on each element's brightness is given, including wavelength, oscillation strength, and g-factor. The weight percentage of element thermally desorbed in atomic form was estimated, assuming that 10,000 $\mathrm{kg}$ of soil was impact-heated to a temperature of $1000 \mathrm{~K}$. 
Table 2.1.1-Elemental contributions to the plume spectrum observed by the LAMP (Gladstone 2010)

\begin{tabular}{|c|c|c|c|c|c|c|}
\hline Element & Type & $\begin{array}{l}\text { Wavelength } \\
(\mathrm{nm})\end{array}$ & $\begin{array}{l}\text { Oscillator } \\
\text { strength }\end{array}$ & $\begin{array}{c}g \text {-factor } \\
\left(\text { photons } \mathrm{s}^{-1} \text { ) }\right.\end{array}$ & $\begin{array}{l}\text { Least-squares fit } \\
\text { column density } \\
\left(\mathrm{cm}^{-2}\right)\end{array}$ & $\begin{array}{c}\text { Soil mass } \\
\text { abundance* } \\
(\%)\end{array}$ \\
\hline \multirow[t]{2}{*}{ H } & LTV & 102.57 & 0.07906 & $3.84 \times 10^{-06}$ & $<4.3 \times 10^{9}$ & (See $\mathrm{H}_{2}$ ) \\
\hline & & 121.57 & 0.41588 & $2.88 \times 10^{-03}$ & & \\
\hline \multirow[t]{2}{*}{ B } & LTV & 182.59 & 0.14893 & $9.14 \times 10^{-05}$ & $<3.2 \times 10^{11}$ & $<0.04$ \\
\hline & & 182.64 & 0.13550 & $8.15 \times 10^{-05}$ & & \\
\hline \multirow[t]{2}{*}{ C } & LTV & 156.03 & 0.07603 & $3.67 \times 10^{-06}$ & $<6.2 \times 10^{11}$ & $<0.09$ \\
\hline & & 165.69 & 0.13397 & $1.97 \times 10^{-05}$ & & \\
\hline \multirow[t]{2}{*}{ N } & LTV & 119.96 & 0.12940 & $9.30 \times 10^{-07}$ & $<3.9 \times 10^{13}$ & $<6.6$ \\
\hline & & 120.02 & 0.08569 & $5.55 \times 10^{-07}$ & & \\
\hline \multirow[t]{2}{*}{0} & LTV, SIL & 130.49 & 0.04818 & $8.01 \times 10^{-06}$ & $<8.3 \times 10^{10}$ & $<0.02$ \\
\hline & & 130.60 & 0.04786 & $8.08 \times 10^{-06}$ & & \\
\hline $\mathrm{Mg}$ & SIL & 182.79 & 0.05495 & $3.20 \times 10^{-05}$ & $1.3 \times 10^{12} \pm 5.3 \times 10^{9}$ & 0.4 \\
\hline \multirow[t]{2}{*}{ Al } & $\mathrm{CON}$ & 176.64 & 0.72101 & $2.03 \times 10^{-04}$ & $<2.8 \times 10^{10}$ & $<0.009$ \\
\hline & & 176.91 & 0.15415 & $4.91 \times 10^{-05}$ & & \\
\hline \multirow[t]{2}{*}{$\mathrm{Si}$} & SIL & 169.62 & 0.25170 & $3.32 \times 10^{-05}$ & $<6.0 \times 10^{10}$ & $<0.02$ \\
\hline & & 184.55 & 0.27353 & $1.60 \times 10^{-04}$ & & \\
\hline \multirow[t]{2}{*}{$\mathbf{P}$} & MET & 177.50 & 0.15415 & $5.05 \times 10^{-05}$ & $<9.3 \times 10^{10}$ & $<0.04$ \\
\hline & & 178.28 & 0.10208 & $3.85 \times 10^{-05}$ & & \\
\hline \multirow[t]{2}{*}{$S$} & HTV & 180.73 & 0.12051 & $6.61 \times 10^{-05}$ & $<1.5 \times 10^{11}$ & $<0.06$ \\
\hline & & 182.62 & 0.10965 & $6.63 \times 10^{-05}$ & & \\
\hline \multirow[t]{2}{*}{$\mathrm{al}$} & LTV & 116.72 & 0.20321 & $4.06 \times 10^{-07}$ & $<4.7 \times 10^{11}$ & $<0.2$ \\
\hline & & 133.57 & 0.02500 & $7.38 \times 10^{-06}$ & & \\
\hline \multirow[t]{2}{*}{$\mathrm{Ca}$} & $\mathrm{CON}$ & 178.63 & 0.01016 & $3.99 \times 10^{-06}$ & $3.3 \times 10^{12} \pm 1.3 \times 10^{10}$ & 1.6 \\
\hline & & 188.32 & 0.01698 & $1.62 \times 10^{-05}$ & & \\
\hline \multirow[t]{2}{*}{ Sc } & $\mathrm{CON}$ & 173.90 & 0.10494 & $1.93 \times 10^{-05}$ & $<1.7 \times 10^{11}$ & $<0.09$ \\
\hline & & 174.47 & 0.10136 & $2.24 \times 10^{-05}$ & & \\
\hline v & $\mathrm{CON}$ & 192.94 & 0.00310 & $4.11 \times 10^{-06}$ & $<4.0 \times 10^{12}$ & $<2.4$ \\
\hline \multirow[t]{2}{*}{$\mathrm{Mn}$} & HTV & 178.53 & 0.01236 & $4.83 \times 10^{-06}$ & $<1.9 \times 10^{12}$ & $<1.3$ \\
\hline & & 178.55 & 0.00912 & $3.57 \times 10^{-06}$ & & \\
\hline \multirow[t]{2}{*}{$\mathrm{Fe}$} & MET & 185.17 & 0.02222 & $1.24 \times 10^{-05}$ & $<7.6 \times 10^{11}$ & $<0.5$ \\
\hline & & 190.34 & 0.00706 & $8.21 \times 10^{-06}$ & & \\
\hline \multirow[t]{2}{*}{ Co } & MET & 181.42 & 0.01072 & $5.57 \times 10^{-06}$ & $<1.5 \times 10^{12}$ & $<1.0$ \\
\hline & & 182.24 & 0.02234 & $1.36 \times 10^{-05}$ & & \\
\hline \multirow[t]{2}{*}{$\mathrm{Zn}$} & HTV & 145.76 & 0.02897 & $2.09 \times 10^{-07}$ & $<4.0 \times 10^{12}$ & $<3.1$ \\
\hline & & 158.96 & 0.12190 & $3.77 \times 10^{-06}$ & & \\
\hline \multirow[t]{2}{*}{ As } & MET & 188.20 & 0.00250 & $2.24 \times 10^{-06}$ & $<2.0 \times 10^{10}$ & $<0.02$ \\
\hline & & 189.04 & 0.79057 & $8.67 \times 10^{-04}$ & & \\
\hline \multirow[t]{2}{*}{$\mathrm{Au}$} & MET & 169.93 & 0.05000 & $6.87 \times 10^{-06}$ & $<6.8 \times 10^{11}$ & $<1.6$ \\
\hline & & 187.98 & 0.02506 & $2.18 \times 10^{-05}$ & & \\
\hline $\mathrm{Hg}$ & LTV & 184.95 & 1.15080 & $6.29 \times 10^{-04}$ & $5.0 \times 10^{11} \pm 2.9 \times 10^{8}$ & 1.2 \\
\hline $\mathrm{H}_{2}$ & LTV & $110-170$ & $\mathrm{~N} / \mathrm{A}$ & $\mathrm{N} / \mathrm{A}$ & $5.8 \times 10^{13} \pm 1.0 \times 10^{11}$ & 1.4 \\
\hline CO & LTV & $139-181$ & $\mathrm{~N} / \mathrm{A}$ & N/A & $1.7 \times 10^{13} \pm 1.5 \times 10^{11}$ & 5.7 \\
\hline
\end{tabular}


Given the estimated total excavated mass of regolith that reached sunlight, and hence was observable, the concentration of water ice in the regolith at the LCROSS impact site is estimated to be $5.6 \pm 2.9 \%$ by mass. The total hydrogen sensed by the Lunar Exploration Neutron Detector (LEND) would logically not only include the water measured by LCROSS's spectrometers, but also $\mathrm{H}_{2}$ measured by LRO LAMP and any other hydrogen-containing volatiles such as methane measured by LCROSS.

Using parameters obtained from the heat flow experiments performed at the Apollo 15 and 17 landing sites, an estimate at the LCROSS impact site temperatures at a depth of 2 meters should be $6 \mathrm{~K}$ higher than the average surface temperatures (Paige 2010). Colder surface areas in the South Polar Region also have the ability to cold-trap super volatiles species that have higher volatility than water, which include compounds such as sulfur dioxide, carbon dioxide, formaldehyde, ammonia, and methanol.

In conclusion, the Centaur impact produced a crater about 25 to 30 meters across, with about 4000 and $6000 \mathrm{~kg}$ of ejecta reaching sunlight and sublimated. The impact released a variety of volatiles besides water, which suggests a variety of possible sources for future space exploration missions. 


\subsection{LunAR REgolith Simulant JSC-1A}

In the decades passed after Apollo missions, the composition of lunar regolith has been extensively investigated. Apollo missions landed and collected lunar soil samples from different regions of the Moon and delivered them to Earth. Similar to Earth, the mineral and chemical composition of the soil is different in different regions. Of course, the number of samples of actual lunar regolith is very limited and is not available for researchers to conduct experiments. However, several Earth sites with similar soil compositions to the lunar regolith have been mined to simulate the regolith. Although these soils are chemically similar, they are not exactly the same and, consequently, have different physical properties. Nonetheless, lunar simulants are the best option available for researchers on Earth to conduct lunar-oriented experiments.

Currently, one of the most used regolith simulants is JSC-1A. This regolith simulant comes from an ash deposit located near Flagstaff, Arizona and closely resembles the actual composition of the lunar soil (C. Ray 2010). JSC-1A lunar regolith simulant is commercialized by ORBITEC. Table 2.2.1 shows the mineral compositions of JSC simulants and some Apollo samples (C. Schrader 2008). For the present studies the lunar regolith simulant used was JSC-1A purchased from ORBITEC. 
Table 2.2.1 - Mineral compositions of JSC simulants and some Apollo samples

\begin{tabular}{|c|c|c|c|c|c|}
\hline $\begin{array}{c}\text { Minerals (wt. } \\
\text { \%) }\end{array}$ & Apollo 16 & $\begin{array}{c}\text { Apollo 11 } \\
\mathbf{\&} \mathbf{1 2}\end{array}$ & JSC-1 & JSC-1A & JSC-1AF \\
\hline Plagioclase & $43-44$ & $11-15$ & 32.47 & 37.83 & 48.47 \\
\hline Clinopyroxene & $0.6-0.7$ & & 14.67 & 18.77 & 21.15 \\
\hline Orthopyroxene & $\sim 2.5$ & & 0.65 & 0.66 & 1.62 \\
\hline Total Pyroxene & $\sim 3$ & $25-37$ & 15.32 & 19.43 & 22.77 \\
\hline Olivine & $0.8-0.9$ & $2-10$ & 18.29 & 12.44 & 9.22 \\
\hline Glass & $44-46$ & $31-45$ & 30.86 & 26.67 & 15.68 \\
\hline
\end{tabular}

Table 2.2.2 shows a comparison of the constituent oxides (oxides that form the minerals) in one sample of Apollo 17 and in the JSC simulants (C. Ray 2010). It is presented that the chemical composition is very similar for the simulants and the Apollo 17 sample.

Table 2.2.2 - Compositions (wt \%) of the mayor constituents of JSC -1, JSC-1A, JSC-1 AF and Apollo 17 samples

\begin{tabular}{|c|c|c|c|}
\hline $\begin{array}{c}\text { Constituent } \\
\text { oxides }\end{array}$ & JSC-1A & $\begin{array}{c}\text { Apollo 17 } \\
\text { Sample }\end{array}$ & $\begin{array}{c}\text { JSC- } \\
\mathbf{1 A} / \text { JSC- } \\
\mathbf{1 A F}\end{array}$ \\
\hline $\mathrm{SiO}_{2}$ & 47.2 & 42.2 & 45.7 \\
\hline $\mathrm{Al}_{2} \mathrm{O}_{3}$ & 15 & 15.7 & 16.2 \\
\hline $\mathrm{CaO}$ & 10.4 & 11.5 & 10 \\
\hline $\mathrm{MgO}$ & 9 & 10.3 & 8.7 \\
\hline $\mathrm{FeO}$ & 7.4 & 12.4 & - \\
\hline $\mathrm{Fe}_{2} \mathrm{O}_{3}$ & 3.4 & - & 12.4 \\
\hline $\mathrm{Na}_{2} \mathrm{O}$ & 2.7 & 0.2 & 3.2 \\
\hline $\mathrm{K}_{2} \mathrm{O}$ & - & 0.1 & 0.8 \\
\hline $\mathrm{TiO}_{2}$ & 1.6 & 5.1 & 1.9 \\
\hline $\mathrm{P}_{2} \mathrm{O}_{5}$ & - & - & 0.7 \\
\hline $\mathrm{MnO}$ & - & 0.2 & 0.2 \\
\hline
\end{tabular}

The chemical and mineral composition of regolith simulant JSC-1A is available from a variety of sources (C. Schrader 2008) (E. Hill 2007) (ORBITEC 2006) and is summarized in Table 4. Although, 
some properties are different from the actual lunar regolith, the simulant composition will be used for these studies. However, for simplicity, lunar simulant will be called regolith from now on.

Table 2.2.3 - Mineral composition of lunar regolith simulant JSC-1A

\begin{tabular}{|c|c|c|c|}
\hline \multicolumn{2}{|c|}{ Mineral } & Formula & $\begin{array}{c}\text { JSC-1A } \\
\text { composition }\end{array}$ \\
\hline \multirow{3}{*}{ Plagioclase } & Anorthite & $\mathrm{CaAl}_{2} \mathrm{Si}_{2} \mathrm{O}_{8}$ & 26.48 \\
\hline & Albite & $\mathrm{NaAlSi}_{3} \mathrm{O}_{8}$ & 11.35 \\
\hline & $\begin{array}{l}\text { Orthoclase } \\
\text { (K feldspar) }\end{array}$ & $\mathrm{KAISi}_{3} \mathrm{O}_{8}$ & 0.07 \\
\hline \multirow{3}{*}{ Pyroxene } & Wollastonite & $\mathrm{CaSiO}_{3}$ & 7.77 \\
\hline & Enstatite & $\mathrm{MgSiO}_{3}$ & 7.38 \\
\hline & Ferrosilite & $\mathrm{FeSiO}_{3}$ & 4.28 \\
\hline \multirow{2}{*}{ Olivine } & Forsterite & $\mathrm{Mg}_{2} \mathrm{SiO}_{4}$ & 9.09 \\
\hline & Fayalite & $\mathrm{Fe}_{2} \mathrm{SiO}_{4}$ & 3.36 \\
\hline & Glass & & 26.67 \\
\hline & $\begin{array}{l}\text { MgFeAl } \\
\text { Silicate }\end{array}$ & & 3.06 \\
\hline & Trolite & FeS & 0.17 \\
\hline & Ilminite & $\mathrm{FeTiO}_{3}$ & 0.11 \\
\hline & Calcite & $\mathrm{CaCO}_{3}$ & 0.11 \\
\hline & Magnetite & $\mathrm{Fe}_{3} \mathrm{O}_{4}$ & 0.01 \\
\hline & Quartz & $\mathrm{SiO}_{2}$ & 0.01 \\
\hline & Other & & 0.07 \\
\hline & Total & & 99.98 \\
\hline
\end{tabular}




\subsection{Solar Thermal Power System for Oxygen Production from Lunar Regolith}

For ISRU applications, solar energy is the best source of energy readily available on the surface of the Moon. For this reason, solar thermal power systems for oxygen production from lunar regolith have been widely studied in the past (T. a. Nakamura 1996) (Takashi Nakamura 2008) (T. Nakamura, Solar Thermal System for Lunar ISRU Applications: Development and Field OPerations at Mauna Kea, HI 2011) (T. Nakamura 2010). In this solar thermal system, solar heat radiation is collected by an arrangement of solar concentrators, which transfers the concentrated solar radiation to the optical waveguide line made of low loss fiber optics. The optical waveguide transmission line directs the solar heat radiation to the desired surface on the Moon and heats the regolith for processing and extracting useful resources.

This method is a promising technique to save power in sites on the Moon surface where energy is very limited. Instead of excavating the regolith in the crater and transferring it out to be processed, this method will extract the resources at their original location and save the energy that would be required for moving them. By utilizing this solar furnace concept and concentrating solar heat by parabolic reflectors, heating to high temperatures in a specific spot is achieved and vaporization of useful materials is accomplished.

Physical Science Inc. (PSI) conducted this program in collaboration with Lockheed Martin Space System Company (LMSSC) and Orbital Technologies Corporation (ORBITEC). Figure 2.3.1 shows the schematics of how the solar radiation is collected by the concentrator array and transferred by the optical waveguide to the processing unit for extraction of oxygen from lunar regolith. 


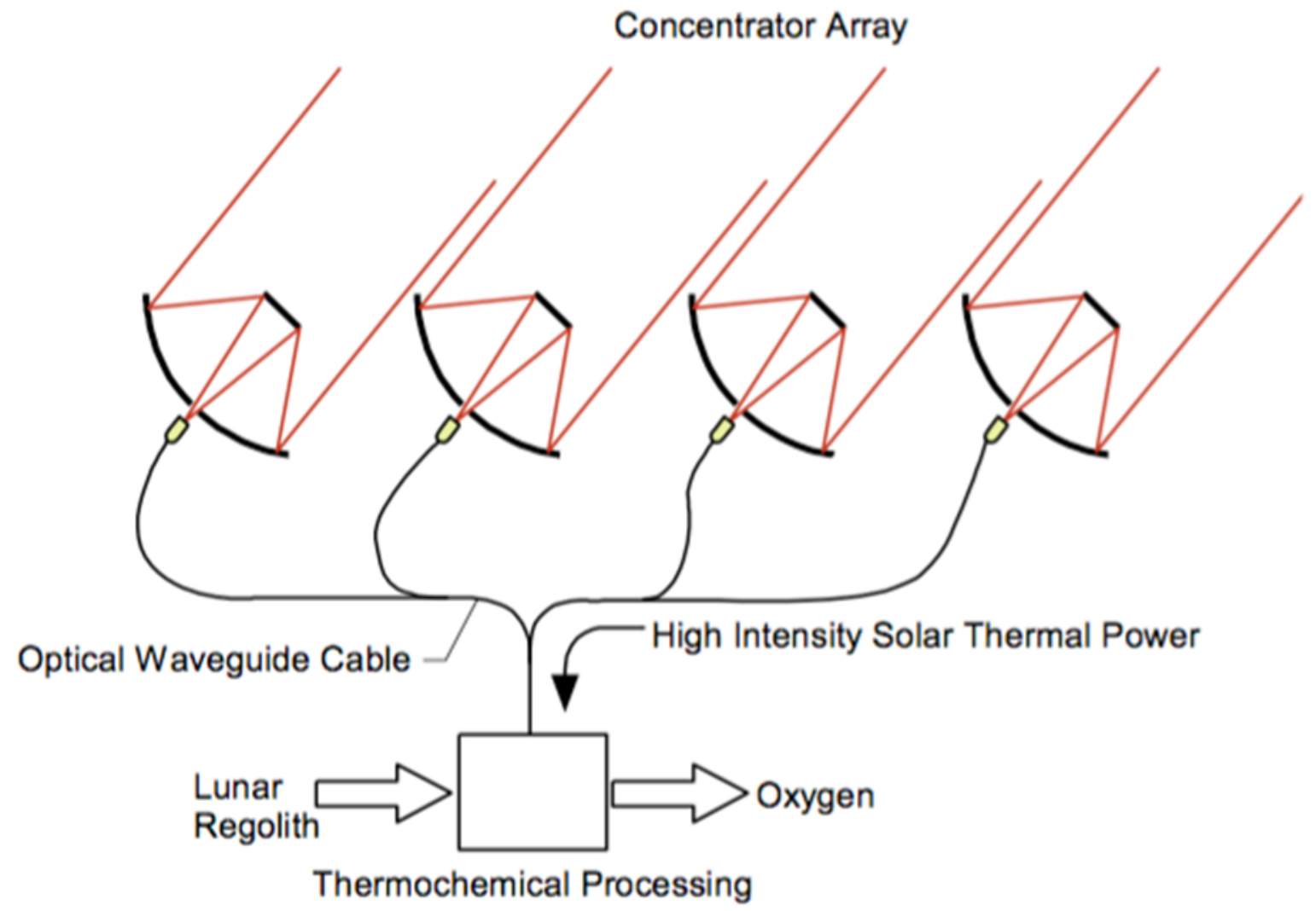

Figure 2.3.1 - Solar thermal system for oxygen production from lunar regolith (Takashi Nakamura 2008)

Some of the key features of this system are:

- Concentrated solar radiation can be transmitted via the flexible optical waveguide directly to a specific point on the surface of the Moon.

- Power scale-up of the system can be accomplished by incrementing the number of concentrator units used.

- The system can be stationary or mobile depending on the requirements and can easily be transported and deployed on the lunar surface.

- The system can be applied to a variety of oxygen production processes such as carbothermal extraction of oxygen or be utilized to extract other useful resources (volatiles). 
The optical waveguide solar thermal system was initially developed for lunar material processing with NASA/JSC funding support from 1994 to 1996 (T. a. Nakamura 1996). The system consisted of three major components: the concentrator, the solar power transmission line, and the thermal reactor.

Several tests have been performed on the regolith melting capability (Takashi Nakamura 2008).

Figure 2.3.2 shows the imaging focus heating and the non-imaging heating of the lunar regolith simulant. Tests were performed in order to measure the melt temperature of the regolith simulant. The radiation flux of about $70 \mathrm{~W} / \mathrm{cm}^{2}$ was directed from the quartz rod to the regolith simulant surface. At the edge of the melt zone, the heat propagates into the regolith simulant powder via heat conduction causing the temperature gradient to become steeper.

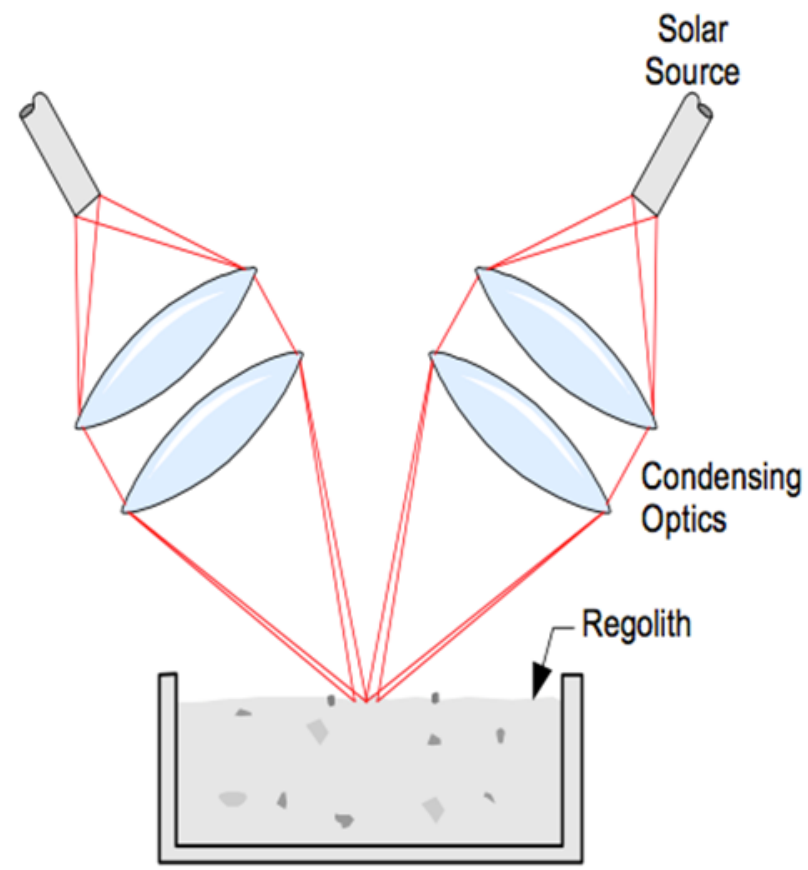

(a) Heating with Imaging Optics

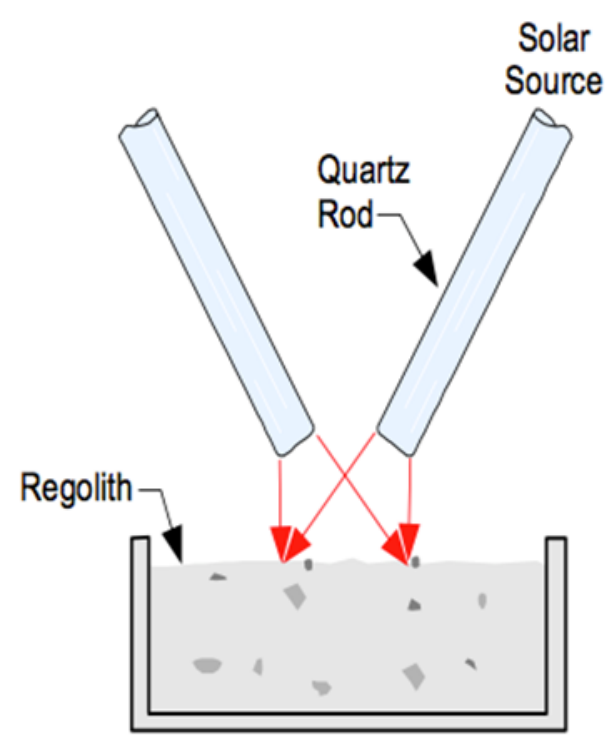

(b) Heating with Non-Imaging Optics

Figure 2.3.2 - (a) Focus heating with imaging optics (b) and with non-imaging optics (Takashi Nakamura 2008) 
When surface temperature exceeded $1150 \mathrm{C}$, a molten slag was formed. This molten slag was also observed on our experiments and is shown in chapter 4 . There is a very narrow temperature range of $\sim 1000{ }^{\circ} \mathrm{C}$ and $1100{ }^{\circ} \mathrm{C}$ where regolith appears to be sintered. When surface temperatures exceeded $1150{ }^{\circ} \mathrm{C}$, a molten slag was formed (Figure 2.3.3). In these regolith-melting experiments, the temperature of the melt was measured using type-C thermocouples. The thermocouple was set at various locations within the melt, and then selected the highest temperature as the surface temperature. Table 2.3.1 summarizes the results obtained for the temperature measurements. It is important to note that these temperature readings were taken without radiation shielding. With a radiation shielding, the melt zone becomes more thermally homogenous and creates a larger melt. Both experiments were conducted at the ISRU analog test, Mauna Kea, HI during January - February 2010 (T. Nakamura 2011).

Table 2.3.1 - Surface temperature of lunar regolith simulant melt vs. heat flux (T. Nakamura 2011)

\begin{tabular}{|c|c|c|}
\hline $\begin{array}{c}\text { Power } \\
\text { Source } \\
\text { (Date) }\end{array}$ & $\begin{array}{c}\text { Heat } \\
\text { Flux } \\
\left(\mathbf{W} / \mathbf{c m}^{2}\right)\end{array}$ & $\begin{array}{c}\text { Temperature } \\
\left.\mathbf{~}^{\circ} \mathbf{C}\right)\end{array}$ \\
\hline $\begin{array}{c}\text { PSI Xe Arc } \\
(1 / 25 / 07)\end{array}$ & 63.4 & 1368 \\
\hline $\begin{array}{c}\text { PSI Xe Arc } \\
\text { (10/19/06) }\end{array}$ & 71.8 & 1450 \\
\hline $\begin{array}{c}\text { PSI Solar } \\
\text { Concentrator } \\
\text { (4/13/07) }\end{array}$ & 84.39 & 1556 \\
\hline $\begin{array}{c}\text { PSI Solar } \\
\text { Concentrator } \\
\text { (5/8/07) }\end{array}$ & 117.4 & 1728,1800 \\
\hline $\begin{array}{c}\text { PSI Solar } \\
\text { Concentrator } \\
\text { (5/8/07) }\end{array}$ & $\sim 127$ & $\begin{array}{c}1900 \\
\text { (unsteady) }\end{array}$ \\
\hline
\end{tabular}




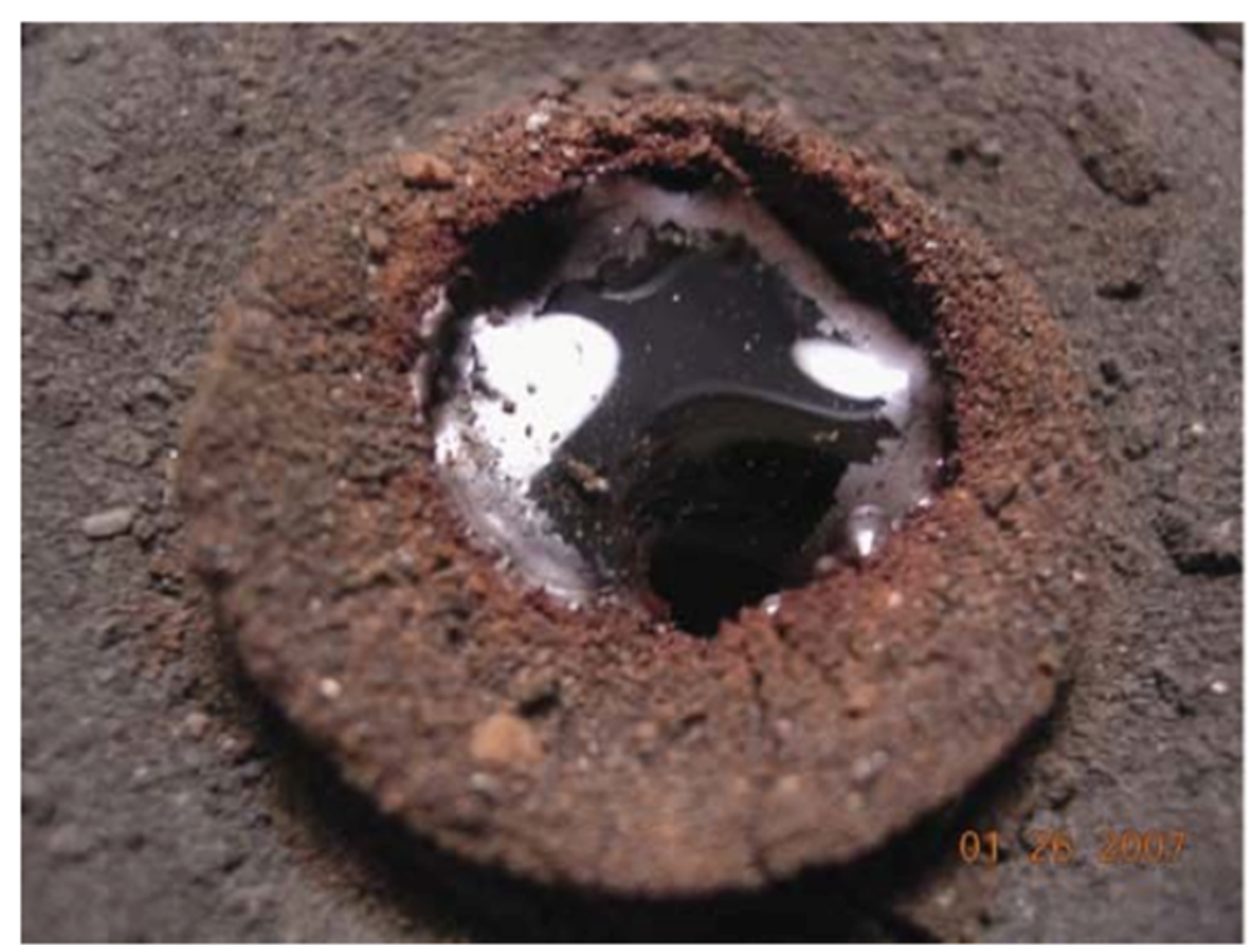

Figure 2.3.3 - Vitrified JSC-1 melt (T. Nakamura 2010)

The solar concentrator array consisted of seven 27-inch parabolic reflectors mounted on a single platform. The concentrators use the secondary reflectors to focus the solar image at the inlet of the optical fiber cables. Figure 2.3.4 shows the schematics of the concentration method. The concentrator array is equipped with a sun sensor and a two-axis tracking system to follow the sun as it sets during experiments. The optical fiber used for this experiment is the hard polymer-clad fused silica fiber manufactured by CeramOptec Industries, Inc. (T. Nakamura, Solar Power System for Lunar ISRU Aplications 2010) 


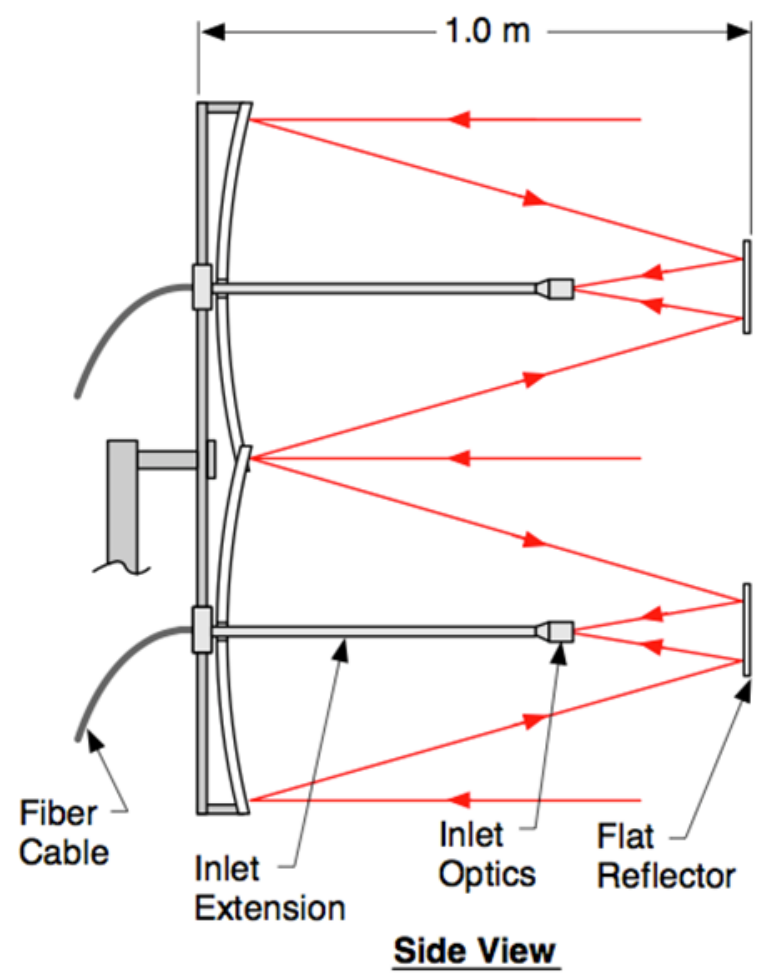

Figure 2.3.4 - Schematics of the concentration method (T. Nakamura 2010)

Figure 2.3.5 shows an image where seven solar concentrators are accommodated by the conical section which receives the solar radiation and concentrates the energy into a single point using the quarts rod. Each of the seven reflectors is connected in the back part of the system to a single optical fiber cable in which length can be modified according to requirements. The quartz rod directs the high concentration solar flux onto the regolith surface for oxygen production or extraction of useful resources. This thesis will focus on the heat transfer in the regolith when the heat flux is being applied to the lunar surface. 


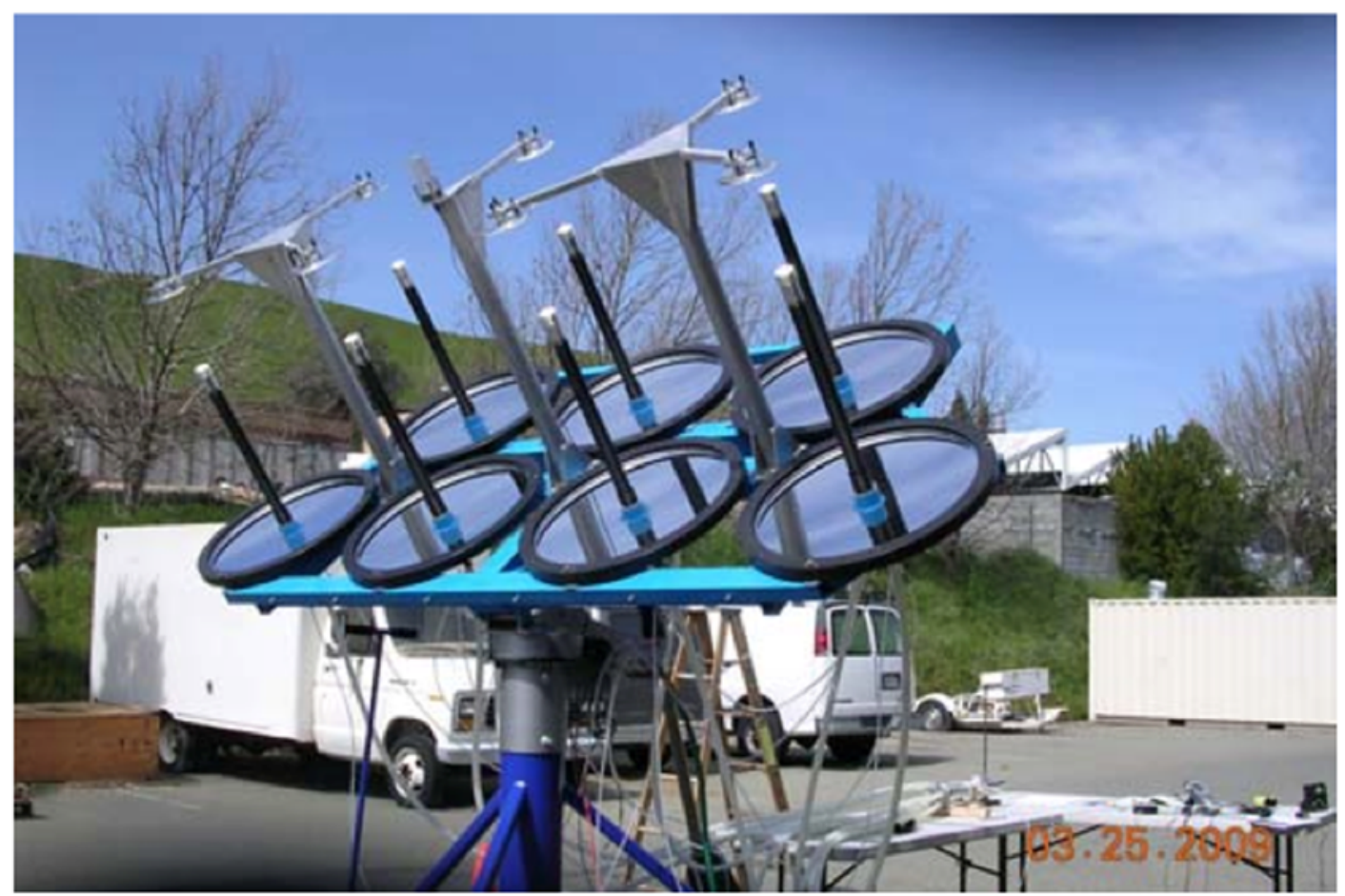

Figure 2.3.4 - Solar concentrator array tracking the sun (T. Nakamura 2010)

The ambient solar flux intensity at the time of the experiment was measured to be $880 \mathrm{~W} / \mathrm{m}^{2}$. With seven concentrator mirrors the power output from the optical fiber cables is about $800 \mathrm{~W}$ (T. Nakamura 2010). A comparison of output energy was made between the optical fiber cables and from the quartz rod using the same solar flux conditions. Results showed that the two outputs are almost identical indicating that there is no noticeable heat loss in the mechanism within the long quartz rod. Experimental data show that the measured heat flux intensity will heat the regolith up to temperatures of $1800{ }^{\circ} \mathrm{C}$.

Actual lunar regolith is very fine and, when landing and taking off, the dust may start to float and damage the hardware and instrumentation. One way to stabilize the lunar surface is to thermally process the regolith to form a stable surface layer with a higher load bearing as well as dust containing capabilities. Steadiness of the lunar surface can be accomplished by sintering the lunar regolith, which 
takes place at lower temperatures than regolith melting. The sintering process is shown in Figure 2.3.5 and it takes place at temperatures around $\sim 1000{ }^{\circ} \mathrm{C}$.
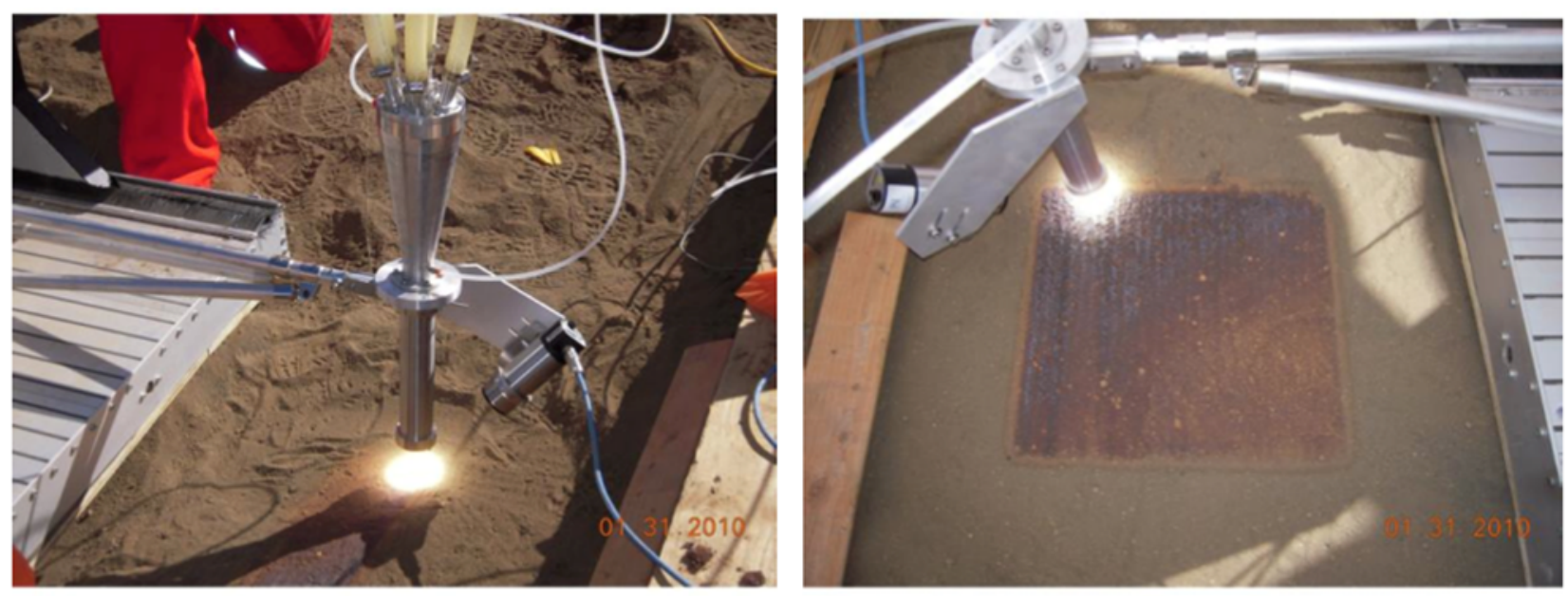

Figure 2.3.5 - Solar sintering of the 15 in x 15 in Tephra surface (T. Nakamura 2011)

Finally, an interesting concept that was developed in 2009 to protect space hardware during the lunar night is the so-called thermal wadis (R. Balasubramaniam 2009). The thermal wadis consists of a thermal mass that accumulates the solar energy collected by a series of radiant energy reflectors during the lunar day, while the rovers operate on the lunar surface and do their respective jobs. During the night, the rover goes back to the thermal wadis and is kept warm by the accumulated energy to avoid damage to the equipment due to extreme low temperatures during lunar dark periods. If regolith is sintered using solar energy, a higher thermal diffusivity will be achieved in the surface due to the better contact between the grains in the sintered material as compared to a loose powder. Experiments have also been made in which regolith is mixed with magnesium and ignited to create a structural material from lunar regolith (Alvarez, et al. 2012). The higher diffusivity of the thermal mass (Figure 2.3.6) should enhance the heat transfer to the hardware. 

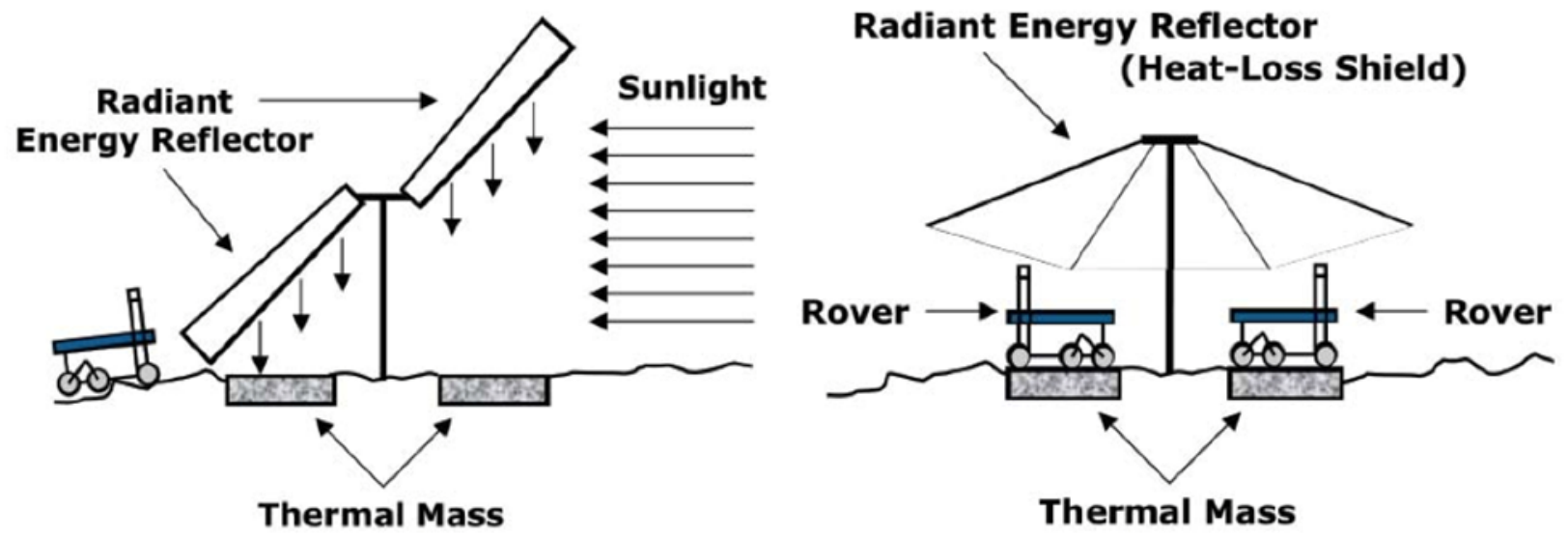

Figure 2.3.6 - Illustration of thermal wadis and its function (R. Balasubramaniam 2009) 


\subsection{Sublimation OF WATER ICE TO WATER VAPOR}

Earth is the only known location in the solar system where liquid water exists. Only water in solid state (ice) can be present on the Moon. Temperatures across the large part of the Moon surface are extremely low during nighttime and high during daytime because of its distance from the Sun and lack of atmosphere. Effects of temperature and pressure imply that water sublimates in sunlight and drifts off into space. Thus, water ice exists only in areas near poles, especially in permanently shadowed areas such as bottom of a crater.

The sublimation of water in regions of extremely low pressures and low temperatures meets increasing interest for future explorers of icy cosmic bodies. Studies have been made with sublimation pressure and sublimation enthalpy of water ice at low temperatures (Rainer Feistel 2007). Water is one of the most fundamental geochemical substances on earth and to better understand the behavior of it at lunar conditions the phase diagram of water (Fig. 2.4.1) has to be understood.

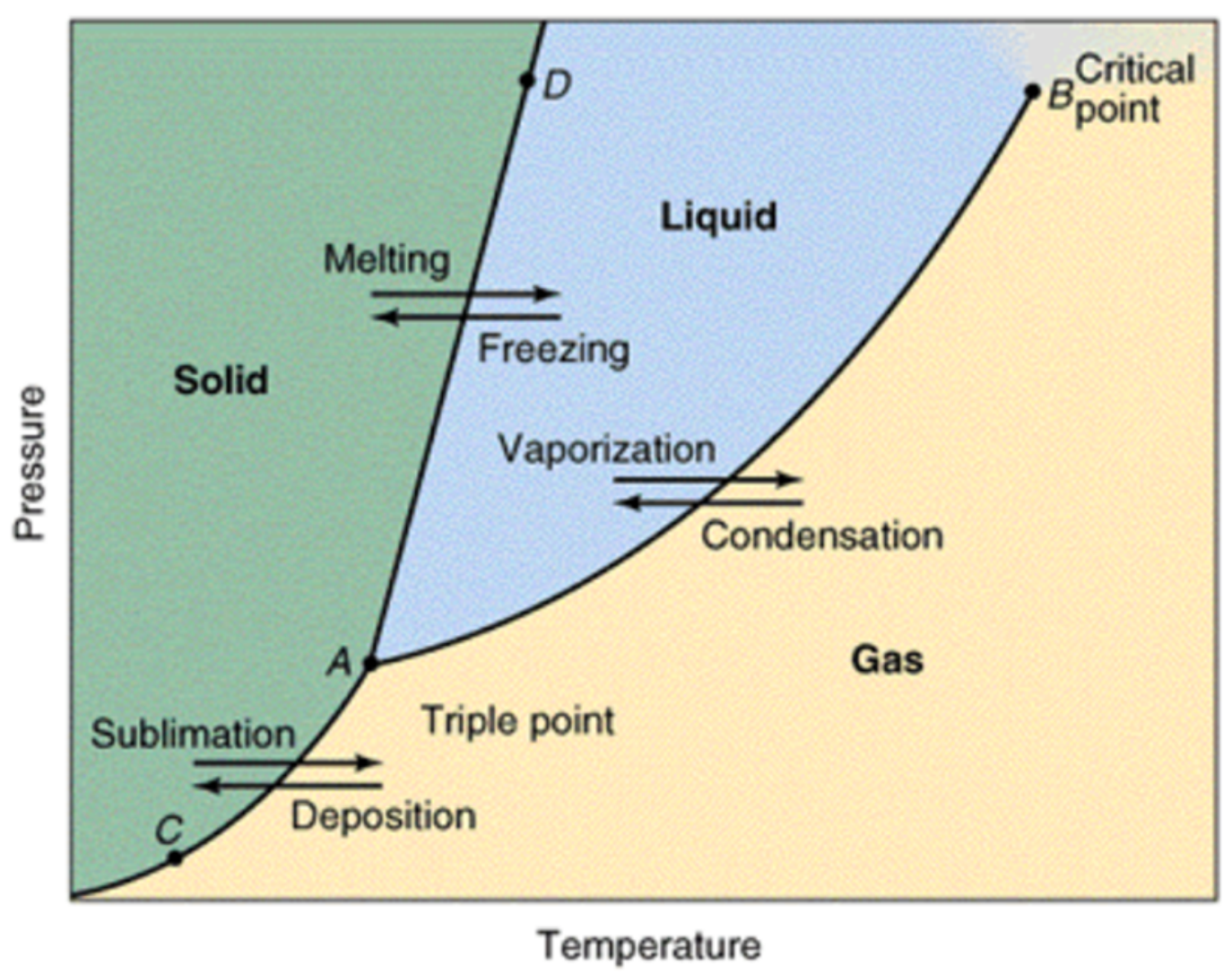

Figure 2.4.1 - Phase diagram of water (Askew n.d.) 
At temperatures below $130 \mathrm{~K}$, the shape of the sublimation curve of water is not known; neither theoretical treatments nor experimental data exist for this area. Since a comprehensive Gibbs energy function for hexagonal ice has recently become available, a new, consistent and accurate way to find the sublimation properties become possible by equating the chemical potentials of ice (Rainer Feistel 2007). This method is limited because the heat capacity of water vapor is undefined for temperatures below 130 K. Experimental sublimation pressure data are only available above $130 \mathrm{~K}$. Assumptions were made at lower pressures, especially because of its minor pressure dependence in this region. Quantum theory predicts that specific heat capacity of an ideal gas will decrease monotonously and exponentially as temperatures decrease due to the subsequent disappearance of excited molecular rotational and vibrational quantum states. (Landau 1966)

An investigation was performed to show how computed sublimation temperature below $130 \mathrm{~K}$ might depend on this uncertainty of vapor heat capacity. Using linear interpolation of heat capacities between these points, an approximate sublimation curve was developed for the pressure range between $10 \mathrm{nPa}$ and $10^{-250} \mathrm{~Pa}$. Heat capacity numbers for the low temperature range are presented on table 2.4.1. These data were derived from infrared spectra of vapor, and therefore do not require any temperature scale conversion. 
Table 2.4.1 - Specific isobaric heat capacity data of water vapor (Woolley 1980)

\begin{tabular}{|c|c|}
\hline Ti (K) & $\begin{array}{c}\mathbf{C}_{\mathbf{i}} \text { (Heat } \\
\text { capacity) }\end{array}$ \\
\hline 130 & 4.00709 \\
\hline 120 & 4.00667 \\
\hline 110 & 4.00611 \\
\hline 100 & 4.00517 \\
\hline 90 & 4.00323 \\
\hline 80 & 3.99878 \\
\hline 70 & 3.98847 \\
\hline 60 & 3.96553 \\
\hline 50 & 3.91803 \\
\hline 40 & 3.82947 \\
\hline 30 & 3.68197 \\
\hline 20 & 3.43043 \\
\hline 10 & 2.95277 \\
\hline 0 & 1.5 \\
\hline
\end{tabular}

It was determined that below a temperature of $130 \mathrm{~K}$, the sublimation pressure is smaller than $10^{-}$ ${ }^{8} \mathrm{~Pa}$ (Rainer Feistel 2007). Temperatures and atmospheric pressure in the craters of the Moon are $40 \mathrm{~K}$ and $10^{-7} \mathrm{~Pa}$, respectively. Note that at $40 \mathrm{~K}$, ice sublimates if pressure is lower than $10^{-52} \mathrm{~Pa}$, which explains the existence of ice in the lunar craters. To extract volatiles on the Moon, the regolith should be heated to the boiling point at $10^{-7} \mathrm{~Pa}$. For example, the boiling point of water at this pressure is estimated to be $134 \mathrm{~K}$. Regolith containing water in the crater of the Moon would need to be heated up to temperatures exceeding $134 \mathrm{~K}$ in order to sublimate the ice and extract water from the regolith. This temperature was taken into account to make the heat transfer calculations shown in chapter 3.

It was demonstrated that sublimation temperature is a monotonically decreasing function of water vapor heat capacity. Based upon this data, it was found that the region of possible locations of the sublimation curve is a narrow stripe in the temperature and pressure. Using available heat capacity data and the manifold of possible interpolation functions between them, this region further shrinks considerably, making interpolations almost equivalent. A new sublimation curve based on interpolation 
of heat capacity is proposed and shown in Figure 2.4.2. Gibbs function, which is the thermodynamic potential that measures the work obtained from a thermodynamic system at a constant temperature and pressure was used to calculate these values. Equation 2.4.1- 2.4.3 show that at a given pressure $P$, the intersection points of these three Gibbs functions with the Gibbs function of ice Ih, $g^{\mathrm{Ih}}(\mathrm{T}, \mathrm{P})$, define the true and two approximate sublimation temperatures. (Rainer Feistel 2007)

$$
\begin{gathered}
g_{A}\left(T_{A}, P\right)=g^{I h}\left(T_{A}, P\right) \\
g\left(T_{\text {subl }}, P\right)=g^{I h}\left(T_{\text {subl }}, P\right) \\
g_{B}\left(T_{B}, P\right)=g^{I h}\left(T_{B}, P\right)
\end{gathered}
$$

a

Sublimation Region

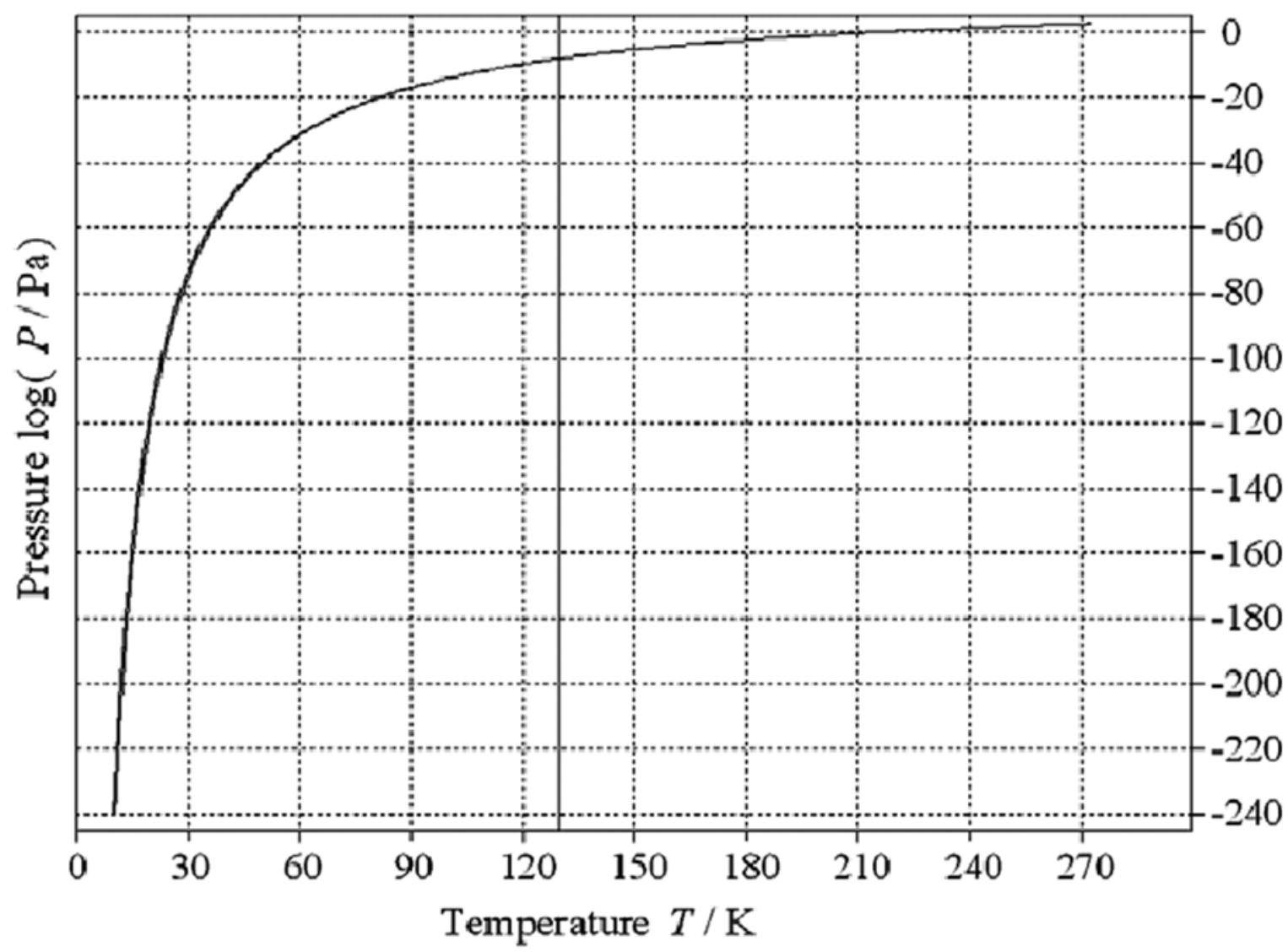

Figure 2.4.2 - Ice Ih sublimation region boundaries for $\mathrm{T}<130 \mathrm{~K}$ 


\section{Chapter 3 Heat Transfer Modeling}

Heat transfer calculations were performed to determine the amounts of energy that would be necessary to extract certain amounts of water at specific time under lunar and laboratory conditions. Steady and non-steady calculations when a heat flux is being applied to a surface were conducted using engineering software and verified experimentally in chapter 4 .

Heat transfer problems are classified as being steady (steady state) or transient (unsteady). The term "steady" implies no change with time at any point within the medium, while transient implies variation with time. Heat conduction measurements were conducted where a heat flux was applied to a solid surface that has the properties of the lunar regolith. In the Moon, thermal conductivity is extremely low $\left(0.01 \mathrm{~W} / \mathrm{mK}\right.$ ) (B. Dabrowski 2006). The density, was taken to be $1600 \mathrm{~kg} / \mathrm{m}^{3}$ for the regolith (Lucas 1972) and the specific heat to be $840 \mathrm{~J} /(\mathrm{kgK})$ (Lluís Acero n.d.).

The rate of heat conduction through a medium in a specific direction (say, in the y-direction) is proportional to the temperature difference across the medium and the area normal to the direction of heat transfer, but is inversely proportional to the distance in that direction. We may express this in the differential form by Fourier's law of heat conduction (Eq. 3.1) for one-dimensional heat conduction.

$$
\dot{Q}_{\text {cond }}=-k A \frac{d T}{d x}
$$

where $k$ is the thermal conductivity, and $d \mathrm{~T} / \mathrm{dx}$ is the temperature gradient. We know that the heat flux and the temperature distribution in a medium depend on the conditions at the surface; description of a heat transfer scenario is not complete without a full description of the thermal conditions at the bounding surface. For this reason, we needed thermal conditions at the boundaries and they are called boundary conditions. Heat transfer in a body or adjacent bodies in thermal contact is physically modulated by several material parameters, including thermal conductivity, specific heat, mass density, thermal 
diffusivity, viscosity, etc. These parameters have a significant impact on the amount of thermal energy lost or gained by a body when subjected to different boundary conditions.

\subsection{STEAdy Heat Conduction}

To be able to perform a steady heat conduction analysis, an assumption on a two-dimensional area needs to be implemented. Knowing the initial temperature to be $40 \mathrm{~K}$ (temperature in the lunar craters) and properties of the lunar regolith, different areas sizes were taken into consideration to start the analysis. Table 3.1.1 shows the different values used for several simulations performed. A twodimensional model was designed in Gambit software to simulate the heat transfer produced when applied different heat fluxes. As shown in Test number 1, a square of 1x1 meters with a mesh size of $.002 \mathrm{~m}$ was designed to simulate the regolith (Fig. 3.1.1). All four sides of the squares, were defined as walls with a temperature of $40 \mathrm{~K}$. while the inside area was defined as the Lunar Regolith. After the Gambit model was created, it was imported into Fluent, where boundary conditions were assigned to the simulation. Analyses were also made under laboratory conditions to estimate the penetration depth at which temperatures would exceed the boiling point of water. After obtaining an estimated number, an experimental test was performed to validate the data obtained from the analysis. Two experimental tests were performed and are later explained in chapter 4. First, experimental test consisted of having an arrangement of six thermocouples placed vertically to measure the temperature distribution; and second experiment consisted of adding water to the regolith simulant and using a $\mathrm{CO}_{2}$ laser, we would prove the extraction process. Steady and transient heat conduction analysis needed to be performed prior to conducting experimental testing. 
Table 3.1.1 - Values used for simulation analysis performed

\begin{tabular}{|c|c|c|c|}
\hline \multicolumn{5}{|c|}{ Gambit \& Fluent Simulations } \\
\hline Test & $\begin{array}{c}\text { Mesh Size } \\
(\mathbf{m})\end{array}$ & $\begin{array}{c}\text { Length of } \\
\text { simulation } \\
(\mathbf{m})\end{array}$ & $\begin{array}{c}\text { Diameter of } \\
\text { laser (m) }\end{array}$ \\
\hline 1 & 0.002 & 1 & 0.02 \\
\hline 2 & 0.001 & 0.5 & 0.01 \\
\hline 3 & 0.001 & 0.5 & 0.02 \\
\hline 4 & 0.001 & 0.25 & 0.02 \\
\hline 5 & 0.001 & 0.02 & 0.02 \\
\hline 6 & 0.001 & 0.125 & 0.02 \\
\hline 7 & 0.001 & 0.06 & 0.02 \\
\hline 8 & 0.001 & 0.03 & 0.02 \\
\hline 9 & 0.003 & 2 & 0.02 \\
\hline 10 & 0.006 & 4 & 0.02 \\
\hline 11 & 0.02 & 8 & 0.02 \\
\hline 12 & 0.005 & 3 & 0.02 \\
\hline 13 & 0.03 & 16 & 0.02 \\
\hline 14 & 0.02 & 10 & 0.02 \\
\hline & & & \\
\hline
\end{tabular}




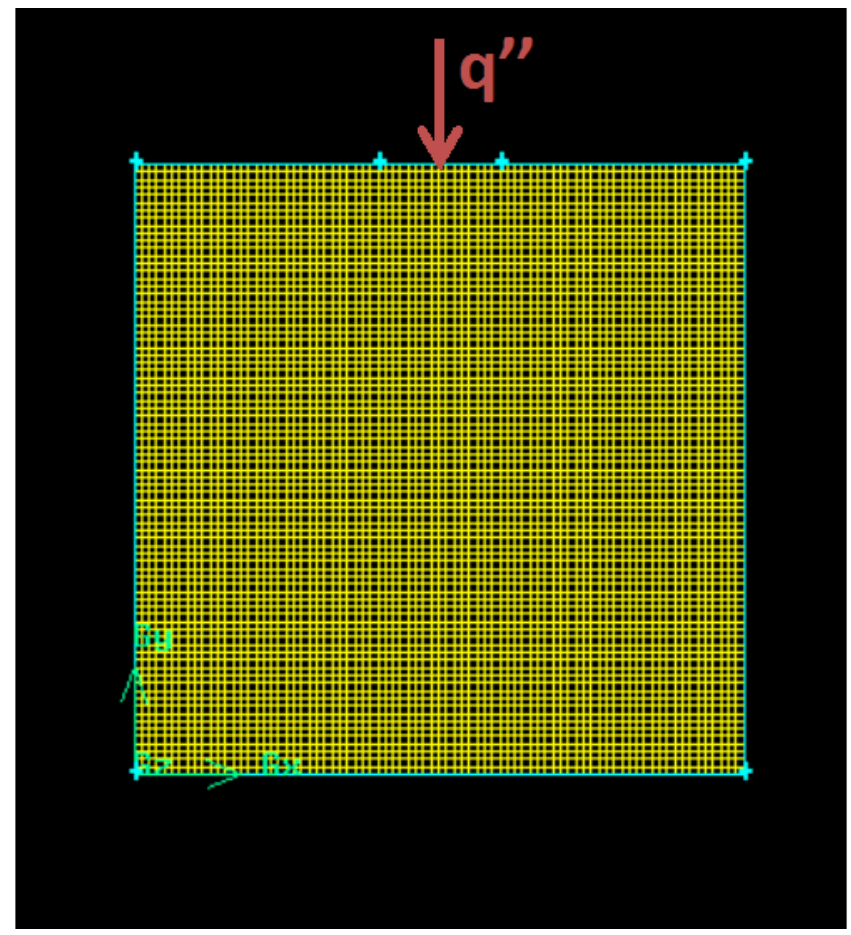

Figure 3.1.1 - Gambit two-dimensional model (1m x 1m)

Properties such as density, specific heat, and thermal conductivity of regolith were defined. Different heat fluxes were tested in order to estimate how deep the temperature would be sufficient for sublimating the solid water in the Moon. Preliminary tests started with a heat flux of $1000 \mathrm{~W} / \mathrm{m}^{2}$ followed by experiments with a higher heat flux. Heat flux is applied to the models by enabling the energy equation dialog box which contains inputs related to the modeling of energy. Under boundary conditions, a thermal heat flux input in the top surface will simulate the laser radiated into the body. The purpose of these experiments was to estimate the penetration depth at which we would reach the boiling point of water, temperatures we estimated to be $134 \mathrm{~K}$ for lunar conditions and $370 \mathrm{~K}$ in laboratory conditions. Figure 3.1.2 shows results for a steady heat conduction simulation obtained from Fluent software when a heat flux of $1000 \mathrm{~W} / \mathrm{m}^{2}$ is being applied to a $1 \mathrm{~m} \times 1 \mathrm{~m}$ area. It is shown that we reach a penetration depth of $0.06 \mathrm{~m}$ where we exceed the boiling point of water under lunar conditions. 

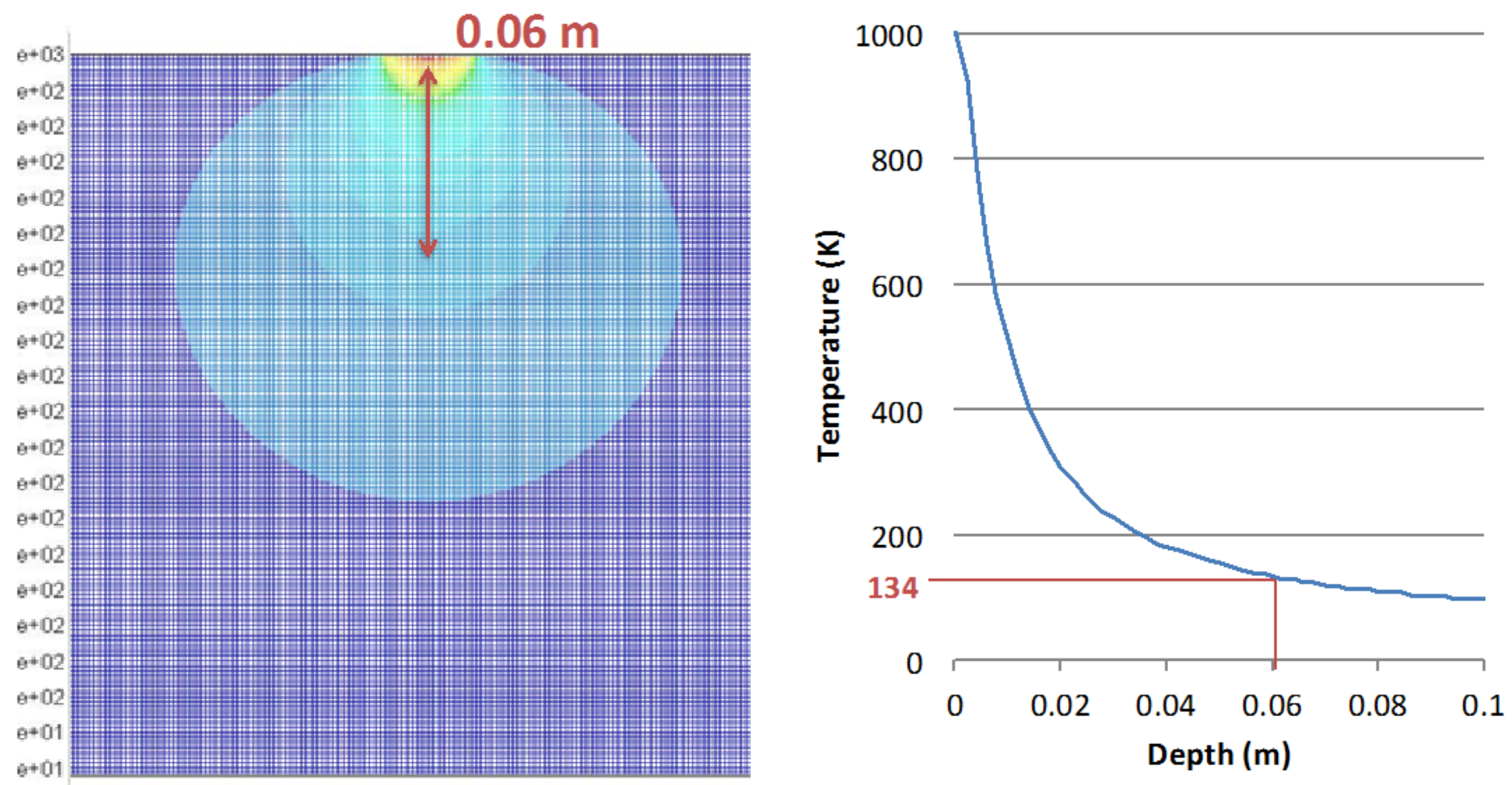

Figure 3.1.2 - Fluent simulation for a $1 \mathrm{~m} \times 1 \mathrm{~m}$ area

Different heat fluxes were applied to the same area simulation of $1 \mathrm{~m}$ x $1 \mathrm{~m}$ to study the effect of heat flux versus the penetration depth (also known as boiling depth). Results showed that in a steady state problem, when we increase the heat flux, we reach a larger penetration depth. Figure 3.1.3 shows a heat flux versus boiling depth graph explaining these results. 


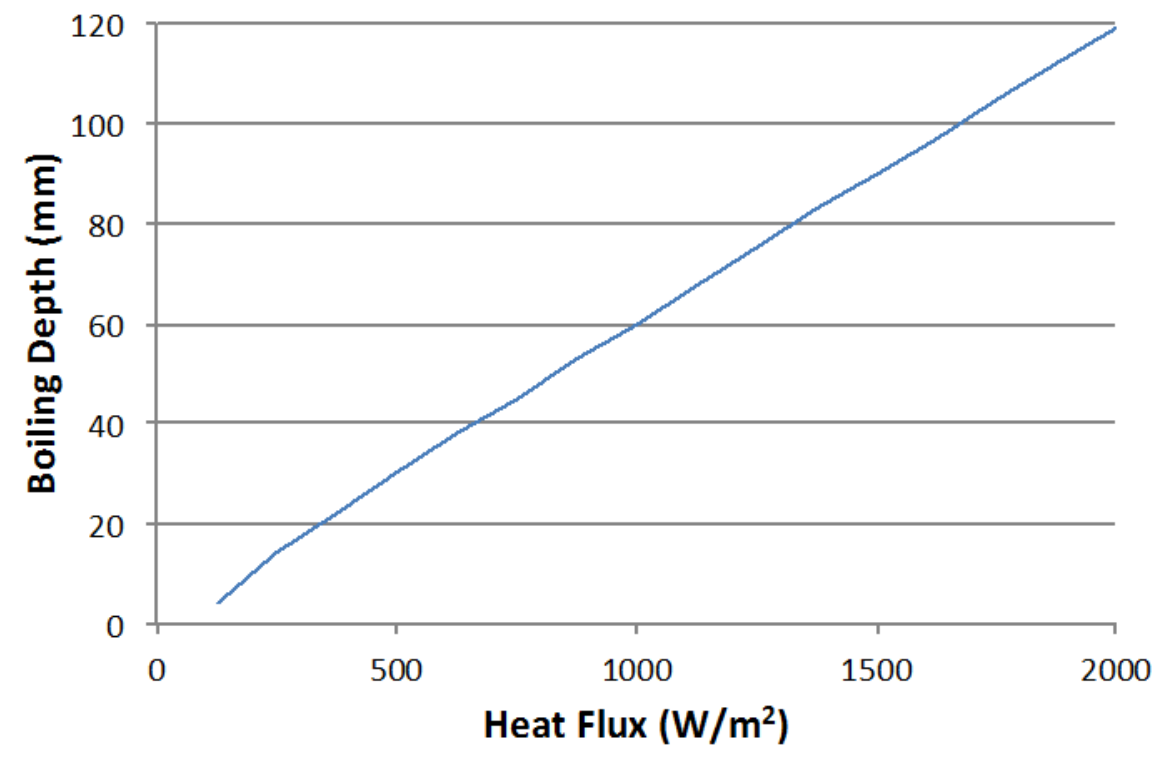

Figure 3.1.3 - Heat flux vs. boiling depth

Calculating the boiling (penetration) depth gives us an estimate of the amount of water that we can extract by heating the regolith. In order to estimate, we initially took the $0.06 \mathrm{~m}$ to be our penetration depth. By knowing this, we estimated that by heating a top layer surface of $0.5 \mathrm{~m} \times 0.5 \mathrm{~m}$ we could obtain a heated volume of $0.015 \mathrm{~m}^{3}(0.5 \mathrm{~m} \times 0.5 \mathrm{~m} \times 0.06 \mathrm{~m})$. Since the density of regolith is known to be $1600 \mathrm{~kg} / \mathrm{m}^{3}$, we calculated a heated mass of $24 \mathrm{~kg}$ of regolith exceeding our boiling temperature. Using data presented on chapter 2 from the LCROSS mission on the mass fraction of water in the regolith, the mass of water that can be extracted using the simulation was calculated to be $1.34 \mathrm{~kg}$ (Figure 3.1.4). 


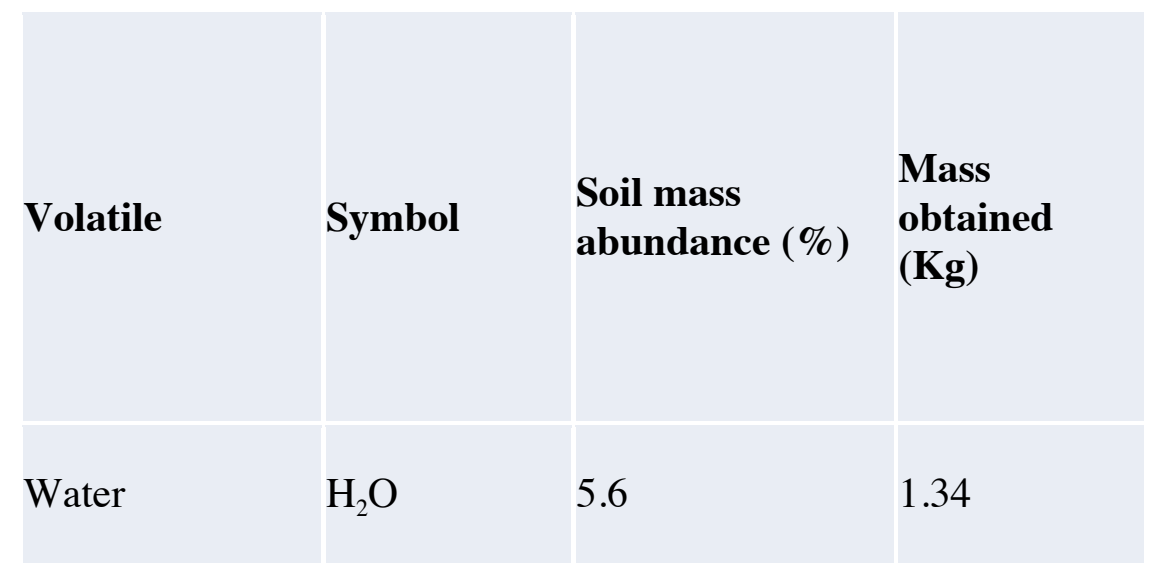

Figure 3.1.4 - Mass fraction of water in the regolith

Steady-state simulations showed that the length scale of the model influences the penetration depth. More specifically, the larger the size of the selected area (at the boundary of which the temperature is $40 \mathrm{~K}$ ), the larger the penetration depth. In reality, however, time is limited and the time factor determined the volume of regolith that can be heated. We concluded that a transient simulation has to be performed. 


\subsection{Transient Heat Conduction}

The temperature of a surface, in general, varies with time as well as with a position. Transient heat conduction is the variation of temperature with time as well as position in one- and multidimensional systems. After performing several steady state simulations for lunar and laboratory conditions, we moved into transient simulations using laboratory conditions for comparison with the results obtained from experiments performed. A $30 \mathrm{~cm}$ x $30 \mathrm{~cm}$ model was created in Gambit to simulate the area of a sample to be used in the experiment. Ambient temperatures $\left(297 \mathrm{~K}\right.$ or $\left.24{ }^{\circ} \mathrm{C}\right)$ and regolith properties were used to conduct the simulations. Heat flux for the model was increased when

purchased a $\mathrm{CO}_{2}$ laser presented on experimental setup shown in chapter 4 . The laser has a maximum of $60 \mathrm{~W}$ of power to be radiated into an area of $0.000038 \mathrm{~m}^{2}$ (the diameter of the collimated laser beam is known to be $7 \mathrm{~mm}$ in diameter). Assuming that $80 \%$ of the power in the laser is being utilized, we can estimate a heat flux of $1,200,000 \mathrm{~W} / \mathrm{m}^{2}$ being applied into the regolith. A mesh size of $1 \mathrm{~mm}$ was implemented into the simulation to precisely estimate the penetration depth at which water would evaporate.

Transient simulations involve time into the equations. After the model was created, it was imported into the software Fluent, where a time frame of 20 minutes (1200 sec.) and 30 minutes (1800 sec.) were analyzed. Figure 3.2.1 shows the results of the simulation for the 30 minutes parameters. 


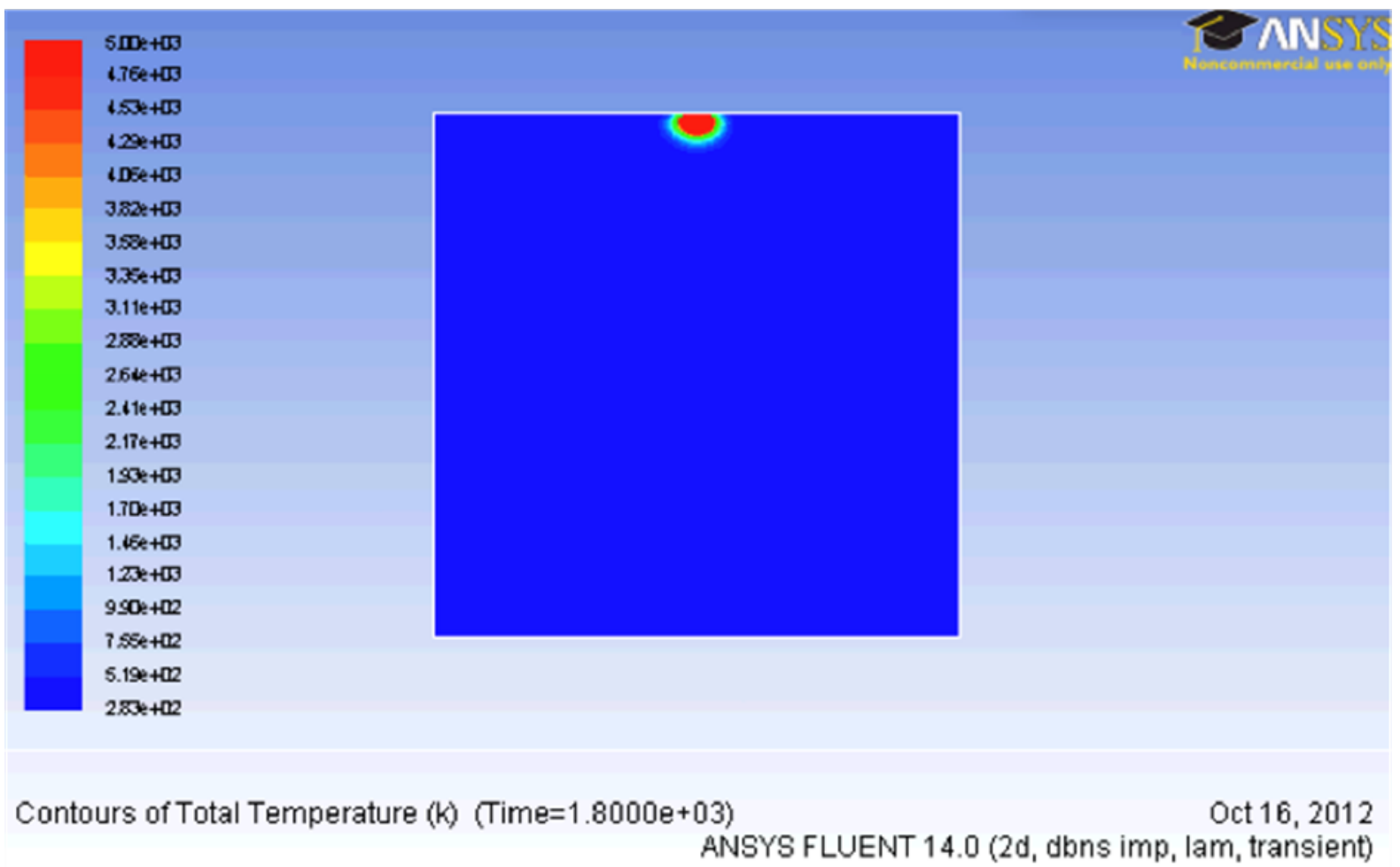

Figure 3.2.1 - Fluent analysis for transient heat conduction performed during 30 minutes

Figure 3.2.2 shows a close up of the section being heated. An imaginary vertical line was created in the simulation to calculate the temperature distribution exactly at the center of the heat flux. Software allowed us to plot this information and calculate the penetration depth. Using these data, we were able to estimate a penetration depth of $0.026 \mathrm{~m}(2.6 \mathrm{~cm})$ at which we would exceed the boiling point of water at room temperature $\left(373 \mathrm{~K}\right.$ or $\left.100^{\circ} \mathrm{C}\right)$. These results are similar to the ones obtained from our experimental examination and presented in chapter 5. 


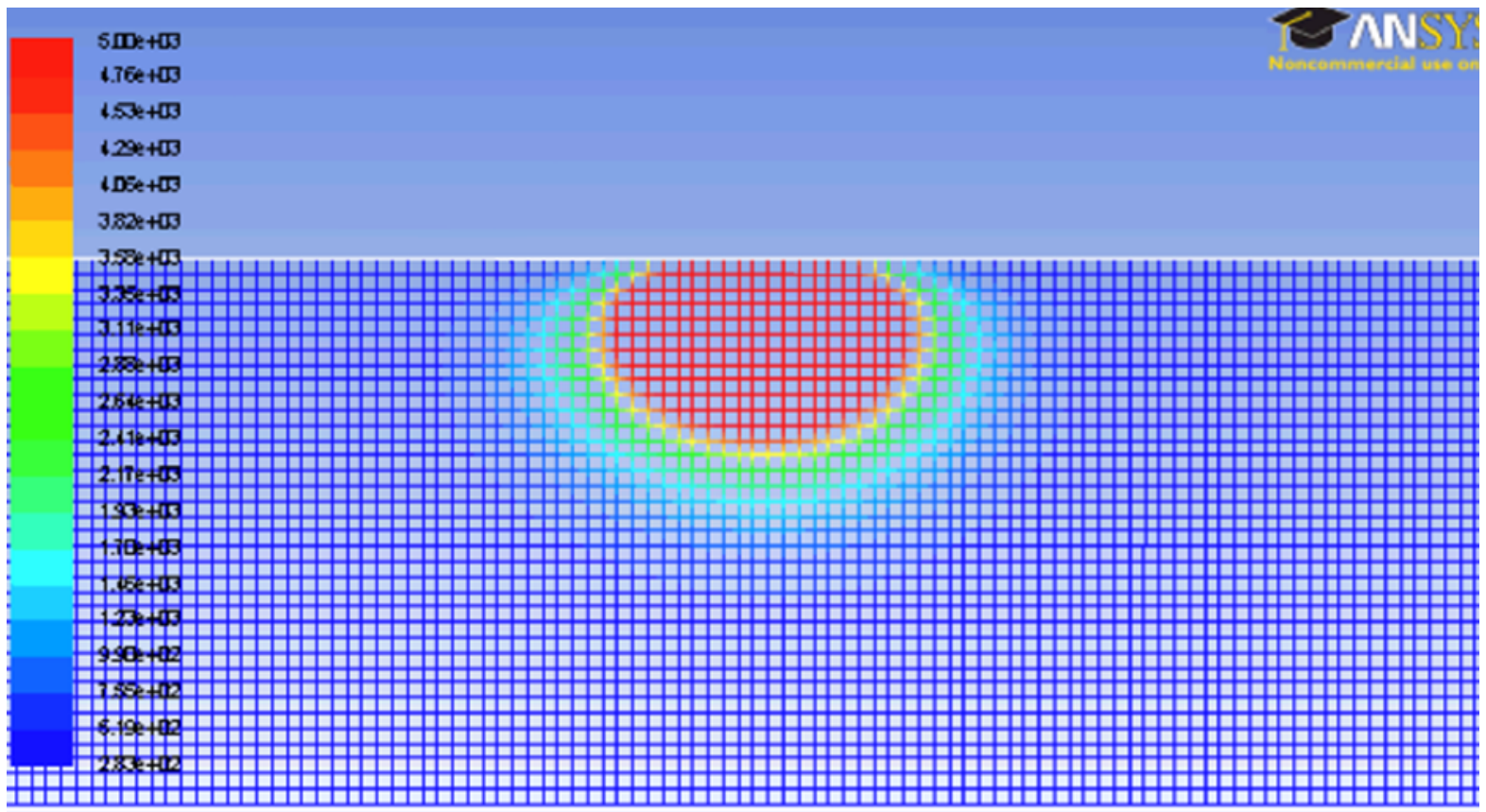

Figure 3.2.2 - Close-up image of the heating section in the transient heat conduction analysis

After performing the simulation under laboratory conditions and comparing similar results with the experimental testing, another simulation using lunar conditions was performed. Same properties for the regolith and same heat flux were used, however different temperatures were used (40 K). Using a heat flux of $1,200,000 \mathrm{~W} / \mathrm{m}^{2}$ for the same 30 minutes $(1800 \mathrm{sec}$.), we obtained a slightly lower penetration depth $(2.3 \mathrm{~cm})$. It is important to note that in laboratory conditions, regolith needed to be heated from room temperature $\left(297 \mathrm{~K}\right.$ or $\left.24^{\circ} \mathrm{C}\right)$ to the boiling point of water at room temperature $(373$ $\mathrm{K}$ or $100^{\circ} \mathrm{C}$ ) while for the Lunar conditions, regolith was heated from $40 \mathrm{~K}$ to $134 \mathrm{~K}$. Thus, for the Moon we have a delta $\mathrm{T}=94$, while for the laboratory delta $\mathrm{T}=76 \mathrm{~K}$. This is the reason why we have a slightly difference in penetration depths for lunar and laboratory conditions and the reason of our study. 


\subsubsection{Transient Heat Conduction in Semi-infinite Solids}

In heat transfer, the surface of the Moon is contemplated to be a semi-infinite solid. A semiinfinite solid is considered to be a body that has a single plane surface and extends to infinity in all directions. This term is used to indicate the temperature change in the part of the body that we are interested in (region close to the surface) and is due to thermal conditions on a single interface. For short intervals of time, most bodies can be modeled as semi-infinite solids since heat does not have sufficient time to penetrate deep into the body. Thickness of the body goes to infinity and does not influence the heat transfer investigation. Heat conduction in a semi-infinite solid is managed by the thermal conditions imposed on the exposed surface and on the properties of the material and thus, the solution depends on the boundary conditions at $\mathrm{x}=0$.

Using the Laplace transform technique, analytical solutions can be obtained for our specific boundary condition that involves heat flux in the surface. Eq. 3.2.1 shows the analytical solution when a specified surface heat flux is being applied (heat flux is constant). Equations were used to solve the transient heat conduction simulation and the given parameters included; heat flux of 1,200,000 W/ $\mathrm{m}^{2}$, thermal conductivity of the regolith $\left(0.01 \mathrm{~W} / \mathrm{m}^{2}\right)$ ' and the regolith thermal diffusivity that was calculated. Thermal diffusivity is a material property that appears in the transient heat conduction analysis, which represents how fast heat diffuses through a material. The thermal diffusivity equation is shown in Eq. 3.2.2 and was calculated to be approximately $7 \times 10^{-9} \mathrm{~m}^{2} / \mathrm{s}$ using available data for the regolith. These results match up with available data from Apollo missions that determined the thermal diffusivity to be $6.6 \times 10^{-9} \mathrm{~m}^{2} / \mathrm{s}$ (Heiken 1993).

$$
\begin{gathered}
T(x, t)-T_{i}=\frac{\dot{q}_{s}}{k}\left[\sqrt{\frac{4 \alpha t}{\pi} \exp \left(-\frac{x^{2}}{4 \alpha t}\right)-x \operatorname{erfc}\left(\frac{x}{2 \sqrt{\alpha t}}\right)}\right] \\
\alpha=\frac{k}{\rho c_{p}}
\end{gathered}
$$

Engineering Equation Solver (EES) is a program that solves systems of linear or nonlinear algebraic or differential equations numerically. It has a large built in library of thermo physical properties functions as well as mathematical functions, and allows the user to input additional property 
data. Figure 3.2.1.1 shows results obtained from the EES software when the specific surface heat flux equation is used. It is important to note that the model calculated values for a one directional axis; therefore we only have one coordinate system and no two dimensional model was displayed as previous representations. Using the available data, it was determined that for the time of 30 min a penetration depth at which water would evaporate would be approximately $0.018 \mathrm{~m}(1.8 \mathrm{~cm})$. A difference of $0.8 \mathrm{~cm}$ was observed between the transient heat conduction in a specific surface and the transient heat conduction in a semi-infinite solid for the same interval time (30 min).

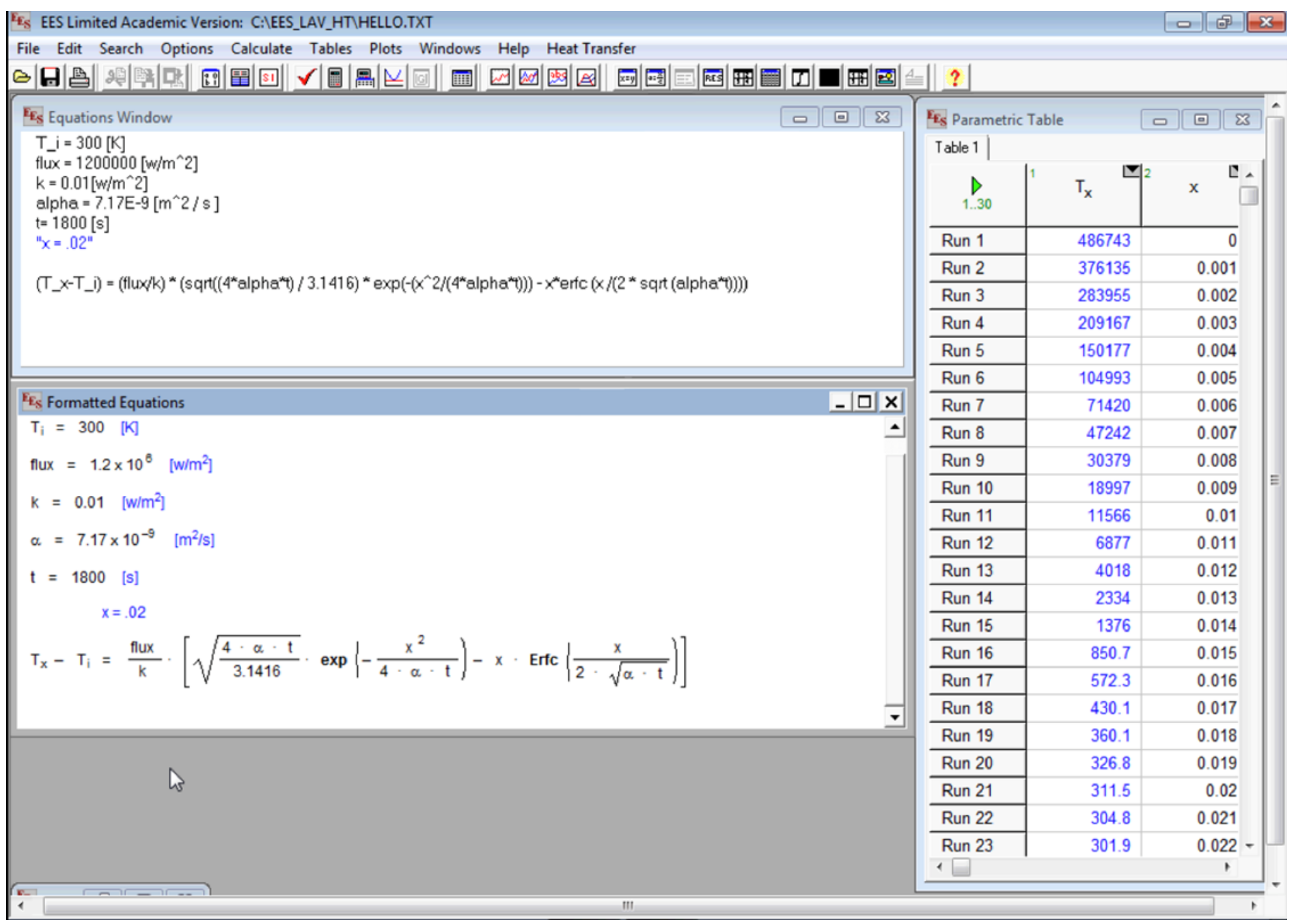

Figure 3.2.1.1 - Results obtained from the Engineering Equation Solver software for the specific surface heat flux equation 
For a simulation being performed for 20 minutes using laboratory conditions (300 K) a penetration depth of $1.5 \mathrm{~cm}$ was observed. For both time frames of 20 and 30 minutes using lunar condition $(40 \mathrm{~K})$, penetration depths calculated were $1.4 \mathrm{~cm}$ and $1.7 \mathrm{~cm}$ respectively. Summary of results are shown in table 3.2.1.1. This information is later compared to the experimental results presented in Chapter 4.

Table 3.2.1.1 - Engineering Equation Solver solutions for a transient heat conduction in a semi-infinite solid

\begin{tabular}{|c|c|c|c|}
\hline & $\begin{array}{c}\text { Heat Flux } \\
\left(\mathrm{W} / \mathrm{m}^{2}\right)\end{array}$ & $\begin{array}{l}\text { Time } \\
\text { (min) }\end{array}$ & $\begin{array}{l}\text { Penetration } \\
\text { Depth }(\mathrm{cm})\end{array}$ \\
\hline $\begin{array}{c}\text { EES } \\
\text { (laboratory } \\
\text { conditions) }\end{array}$ & 1200000 & 20 & 1.5 \\
\hline $\begin{array}{l}\text { EES } \\
\text { (laboratory } \\
\text { conditions) }\end{array}$ & 1200000 & 30 & 1.8 \\
\hline $\begin{array}{c}\text { EES } \\
\text { (lunar conditions) }\end{array}$ & 1200000 & 20 & 1.4 \\
\hline $\begin{array}{c}\text { EES } \\
\text { (lunar conditions) }\end{array}$ & 1200000 & 30 & 1.7 \\
\hline
\end{tabular}




\section{Chapter 4 Experimental Study}

\subsection{EXPERIMENTAL SETUP}

After completing the heat transfer calculations, an experimental study was performed in the laboratory of the Center for Space Exploration Technology Research at UTEP. Regolith simulant, mixed with 6\% deionized water, was placed in a container and heated by an infrared beam of a $\mathrm{CO}_{2}$ laser. Deionized water is a type of purified water with mineral ions (salts) removed. The experimental setup allowed monitoring the amount of water extracted with certain energy beamed into the regolith. Another experiment performed using the same laser was to measure the heat distribution in the heated regolith by using a series of thermocouples. Figure 4.1.1 shows a schematic of the extraction system used. The laser includes a beam bender mirror to change the direction of the laser downwards to allow a direct vertical contact with the regolith and a collimator to expand the beam from $2.3 \mathrm{~mm}$ to about $7 \mathrm{~mm}$. The setup was enclosed and connected to an exhaust hood to prevent leakage of gases to the lab environment.

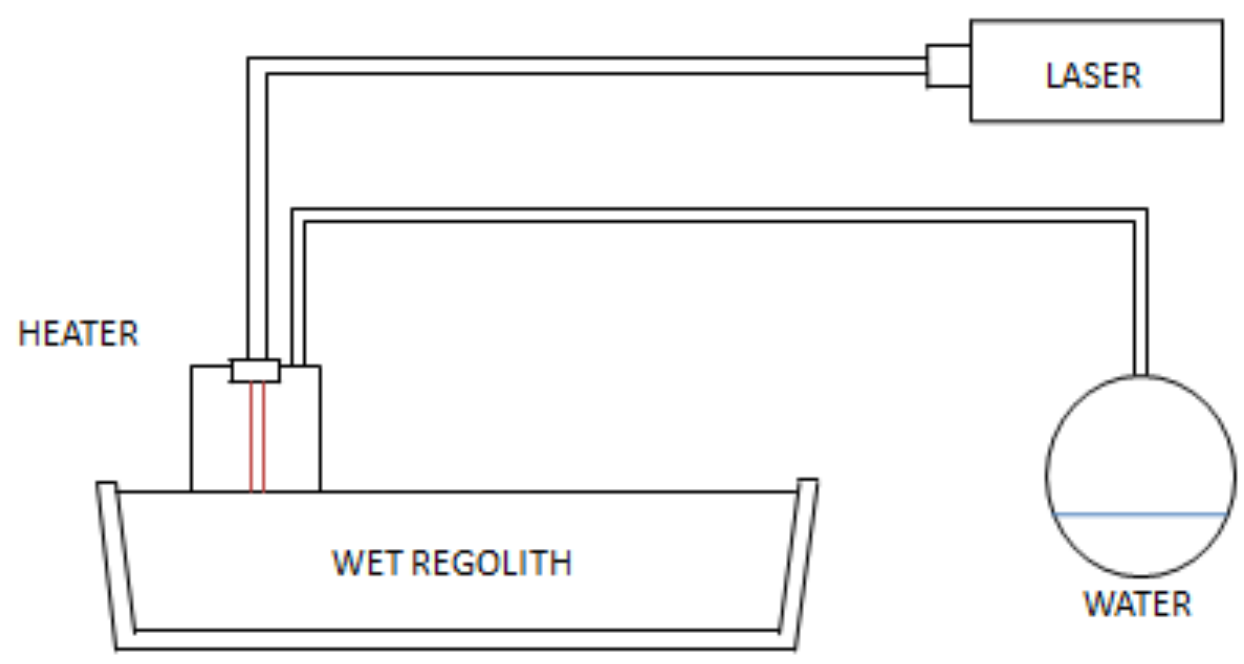

Figure 4.1.1 - Schematic diagram of experimental setup for extraction of water from wet regolith using $\mathrm{CO}_{2}$ laser 
The heat source was intended to heat part of the wet regolith up to the temperatures exceeding the boiling point of water, so that the water vapor can be collected in a glass beaker. A Firestar-Ti60 $\mathrm{CO}_{2}$ laser from Synrad was used as a heat source for the experiment (Fig. 4.1.2). The laser has a maximum output power of 60 watts and has excellent beam quality and pulsing characteristics. The beam diameter was optimized using a collimator that increased the laser beam diameter from $2.0 \pm 0.3 \mathrm{~mm}$ to $7.0 \pm 0.3 \mathrm{~mm}$. "Power Wizard" power meter from Synrad was used to measure the laser power. A comparison of values between the percentage of the maximum power (set by the laser controller) and the power meter readings is plotted in a graph shown in Figure 4.1.3. It is shown that the laser delivers a small amount of energy increase with respect to the ideal energy that it is supposed to supply. It is important to take this small increase into consideration when calculating the heat source that is being utilized.

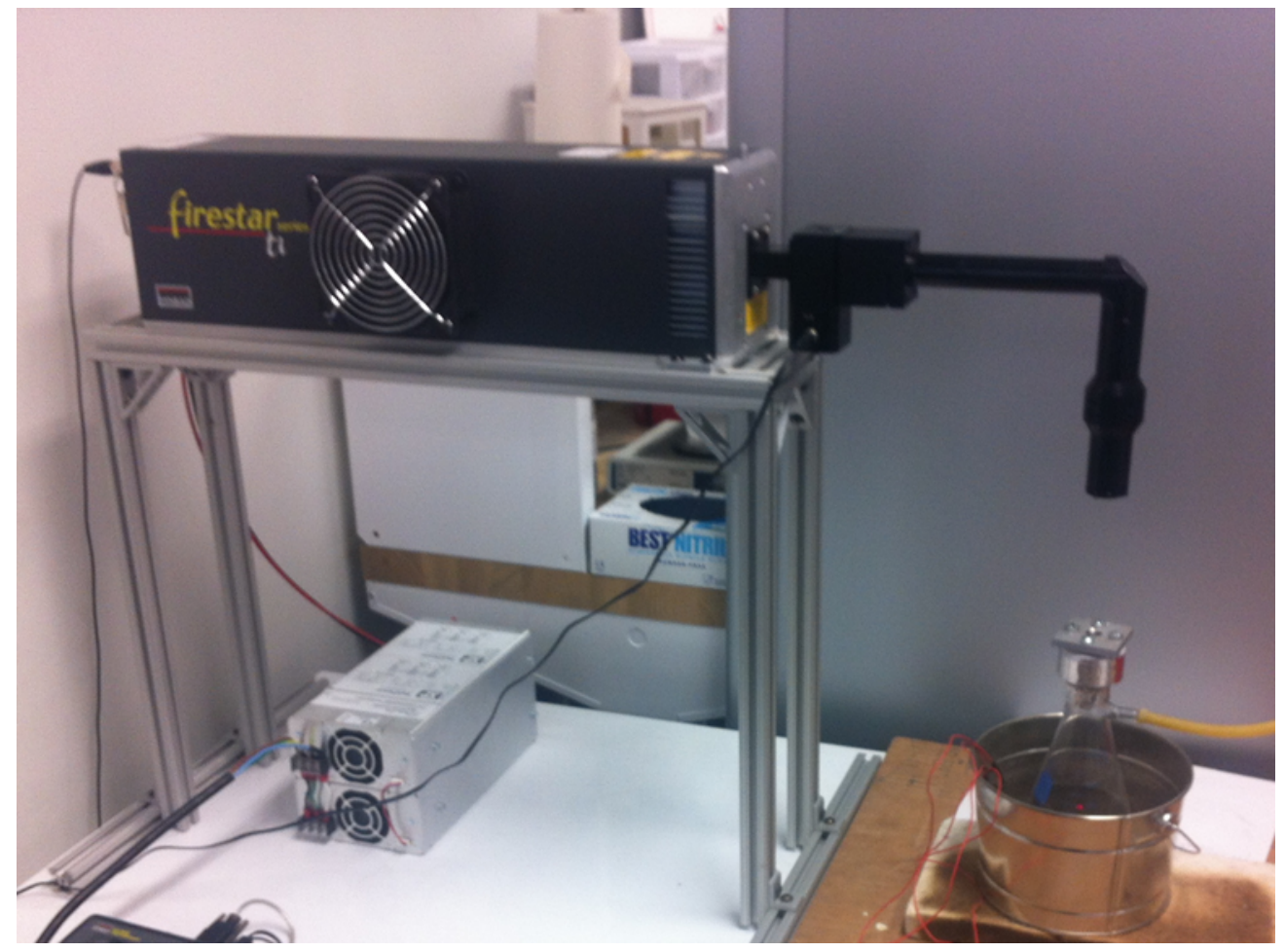

Figure 4.1.2 - Firestar-Ti60 $\mathrm{CO}_{2}$ laser 


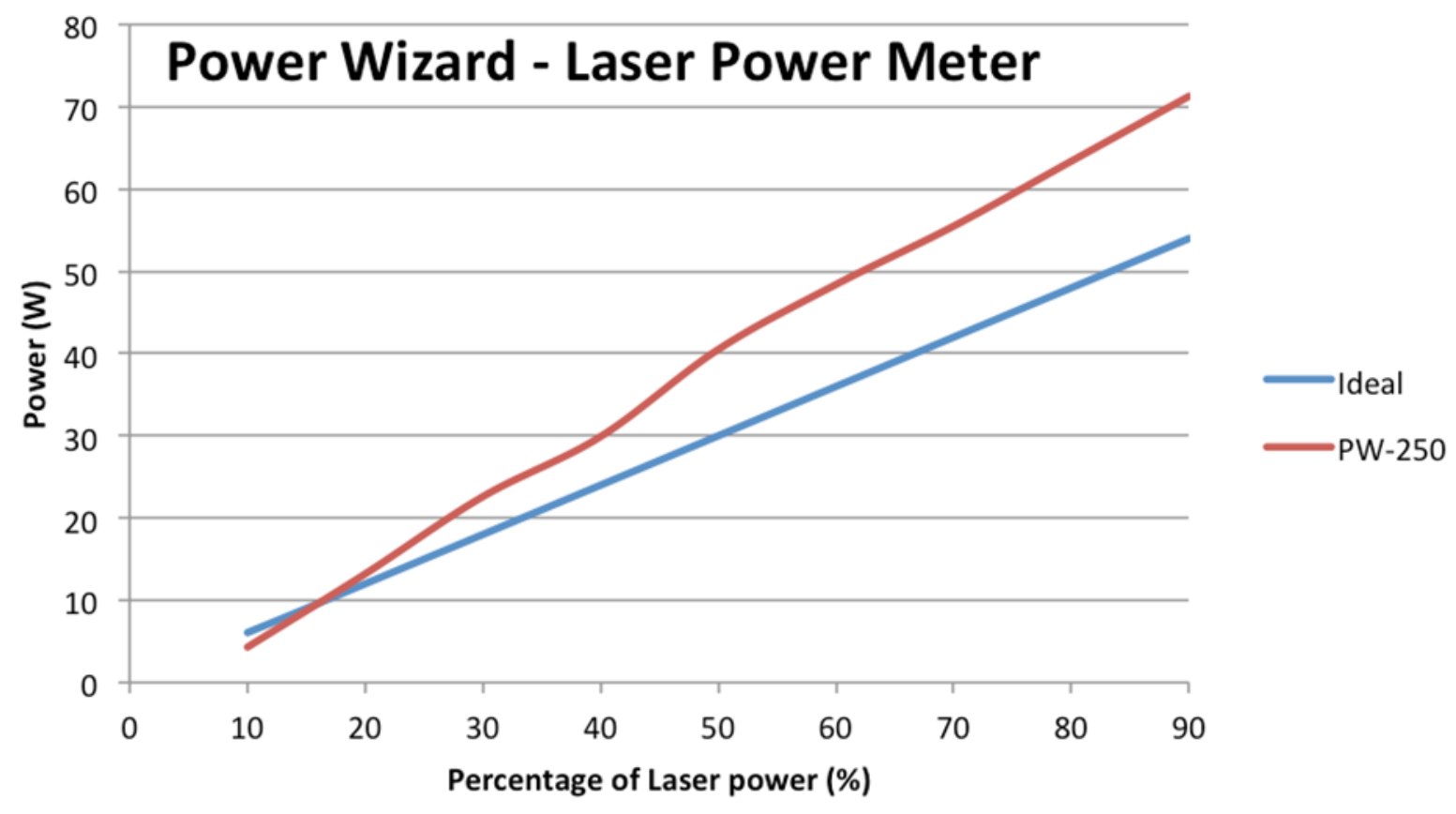

Figure 4.1.3 - Power Wizard readings

A heater chamber apparatus with a zinc selenide window integrated was designed to enclose the vapors produced from the heating. Several designs were discussed including a stainless steel container to withstand high temperatures. The final design of the heater apparatus consisted of a glass $250 \mathrm{~mL}$ filter flask without a bottom part to allow contact with the wet regolith. The glass filter flask was cut using a diamond saw. A Teflon part was designed and manufactured to integrate the zinc selenide window where the laser was going to pass through (Fig. 4.1.4). A front and top views of the final heater apparatus are shown in figure 4.1.5. 


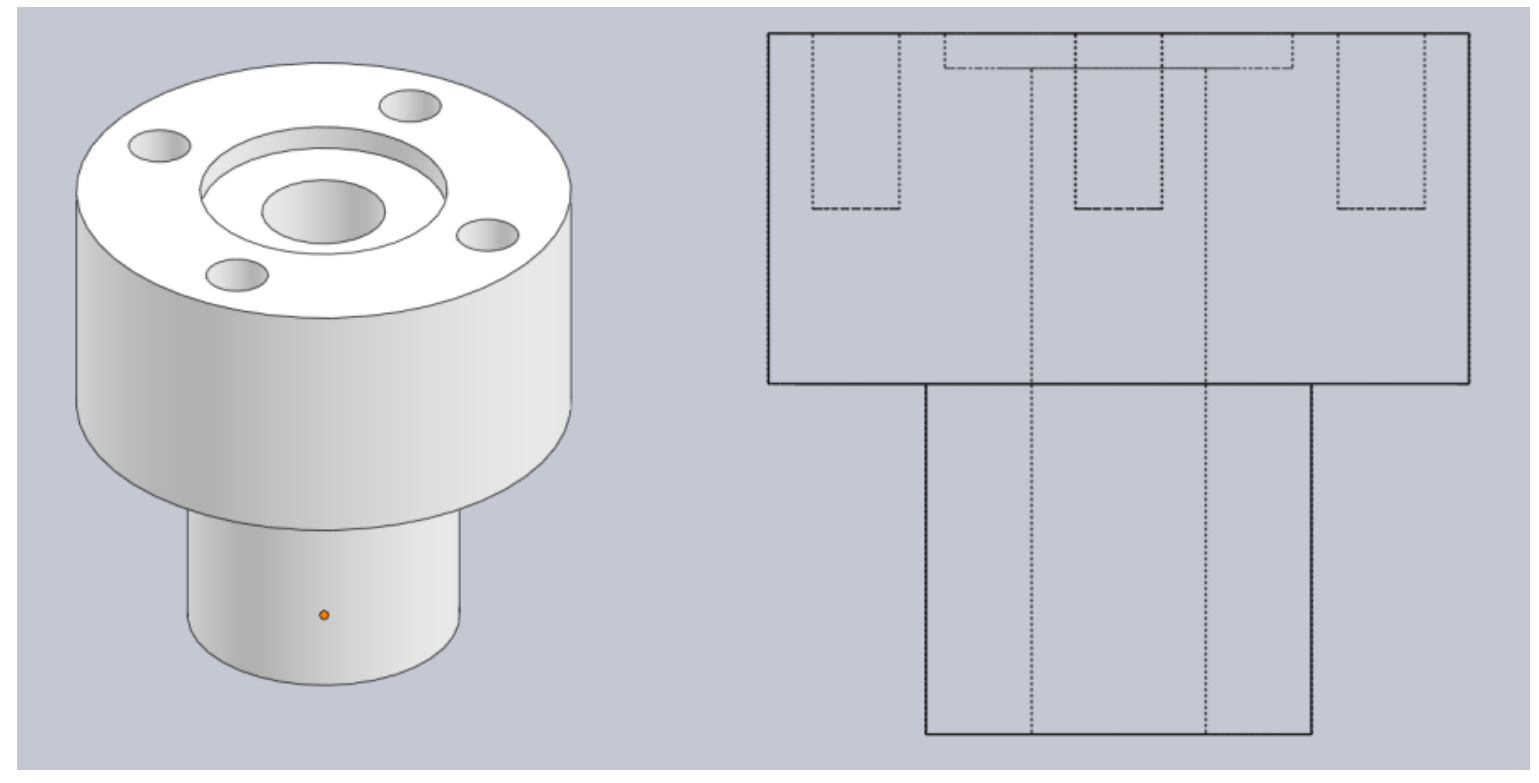

Figure 4.1.4 - CAD design for Teflon part to hold the zinc selenide window
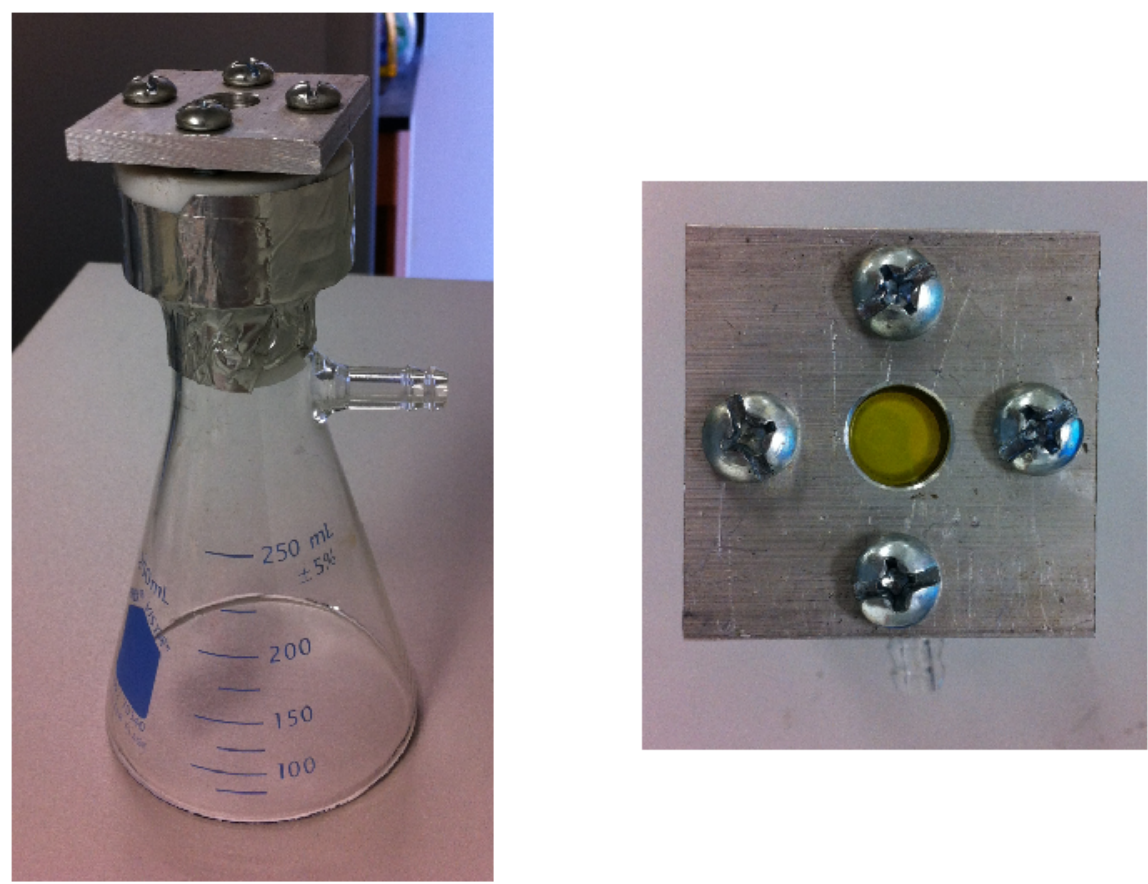

a)

b)

Figure 4.1.5 - Heater chamber apparatus a) front view b) top view 
It is important to have a homogeneous composition in the powder of JSC-1A simulant mixed with deionized water to obtain accurate results. Figure 4.1.6 shows the tumbler mixer (Inversina, Bioengineering), which was used to mix the regolith powder. The device uses three-dimension inversion kinematics, also known as the Paul Schatz principle to homogeneously mix solid, liquids, and suspensions. It has a knob setting from 1 to 10 to maintain a continuous rpm setting. The mixer can hold containers of different sizes using a rubber-ring holder. It is also designed for automatic shut-off on opening of the hood. The regolith samples were mixed for 30 minutes at a knob speed of 8 before adding the deionized water and another 30 minutes after adding the water.

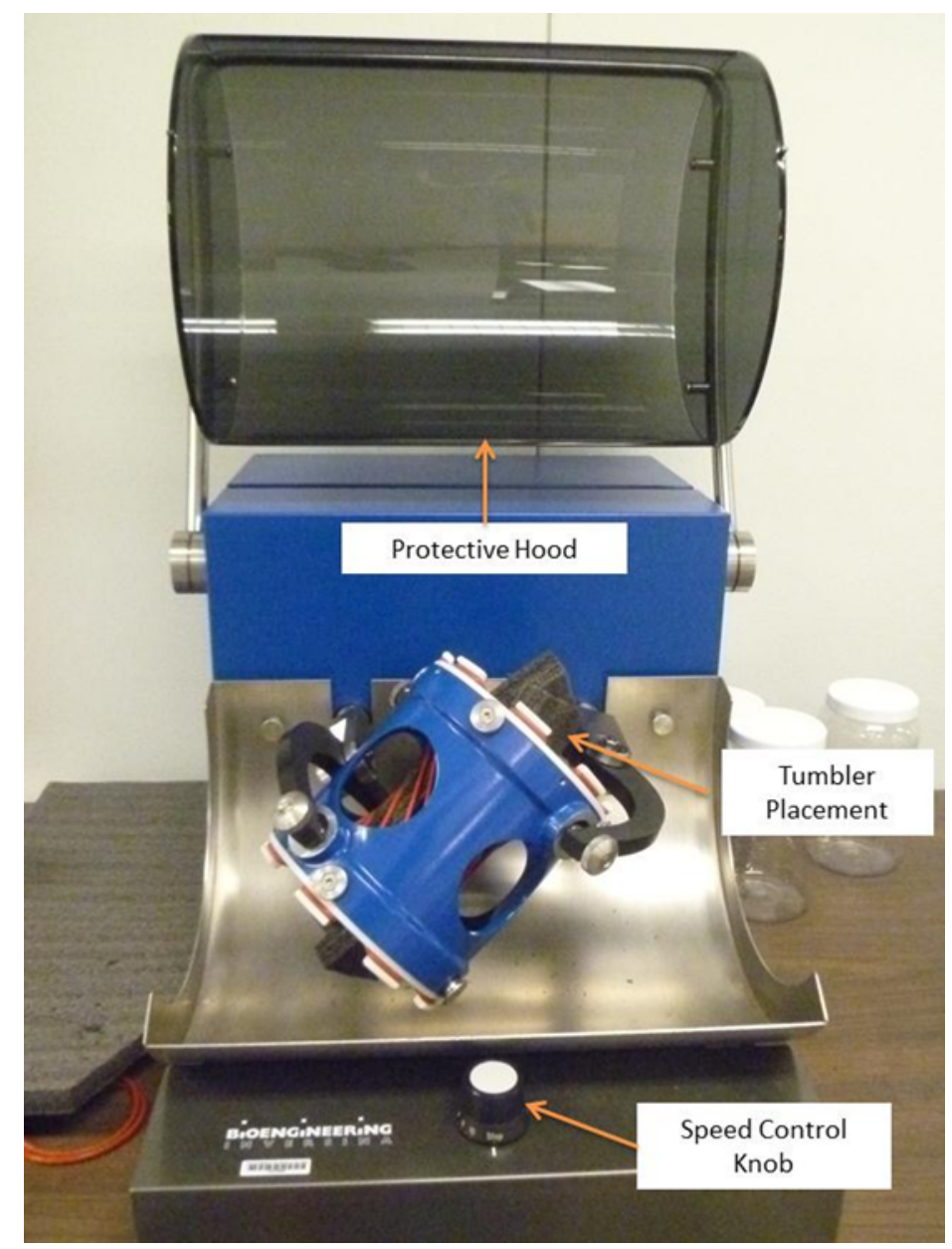

Figure 4.1.6 - Bioengineering INVERSINA 
Initial experiments consisted of having a bucket with dry regolith with two thermocouples placed inside at random distances to measure the temperature increase. The flask was connected to a separate container using rubber tubing to transfer water vapor and condense it separately. Initial results are presented in chapter 4.2. Figure 4.1.7 shows a picture with the operating laser while readings are taken inside the regolith. No vapors were observed while performing this preliminary test, therefore no condensation was observed.

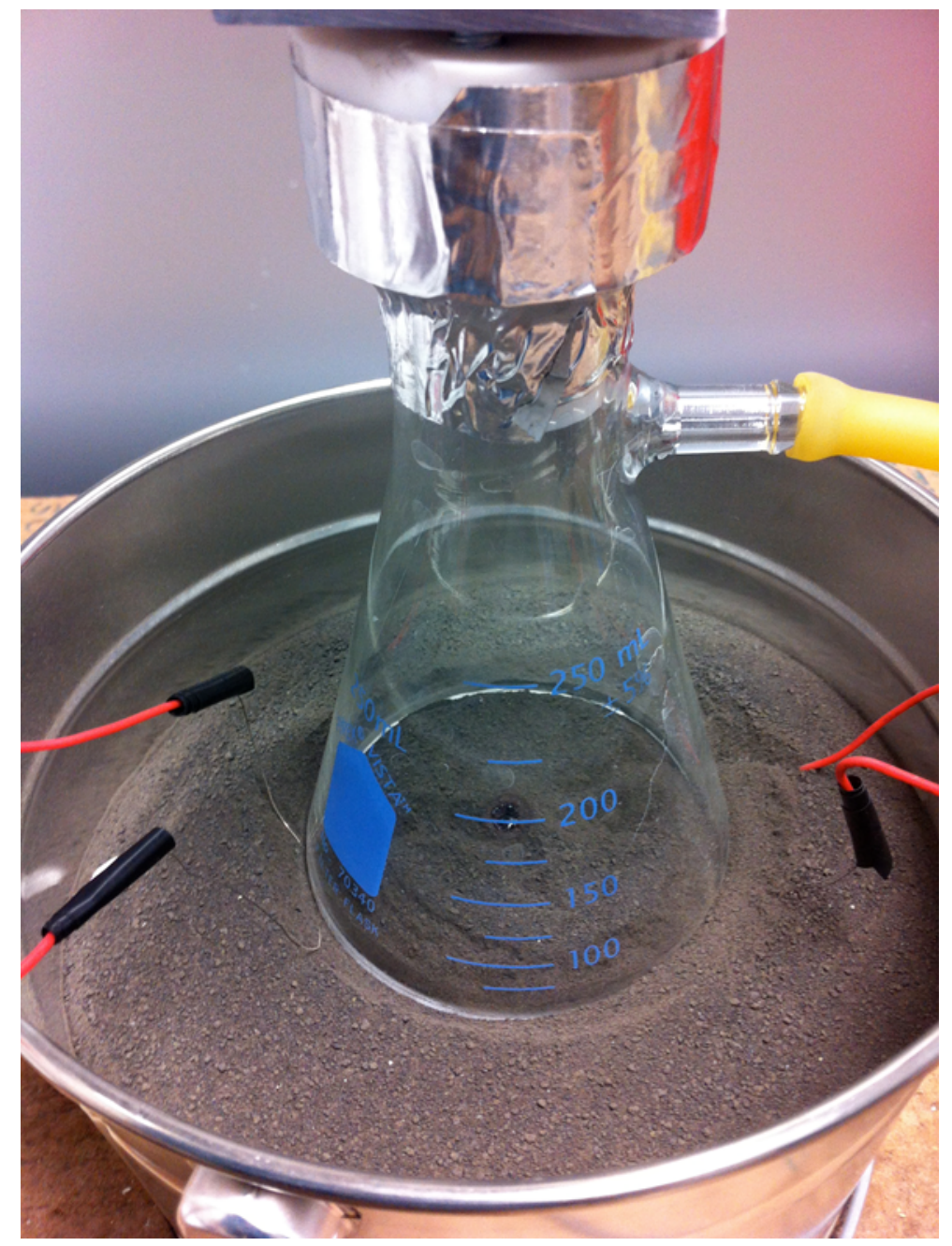

Figure 4.1.7 - Preliminary test

Temperature distribution needed to be measured along the vertical axis following the laser heat flux along the dry and wet regolith. Thermocouples inserted vertically at a certain distance apart allowed 
the software to measure the temperature distribution along the regolith simulant when heat flux was being applied on the surface. A thermocouple setup was designed and manufacturing to allow exact reading of the temperature distribution. Using a data acquisition system from Texas Instruments that allows having up to 16 thermocouples readings at the same time, allowed our system to record the temperature distribution. Figure 4.1.8 shows the thermocouple setup used that consisted of six thermocouples arranged horizontally and separated by $10 \pm 0.3 \mathrm{~mm}$ apart from each other. The thermocouple setup was aligned with the laser using the laser pointer included in the system to allow exact visualization of where the laser was heating.

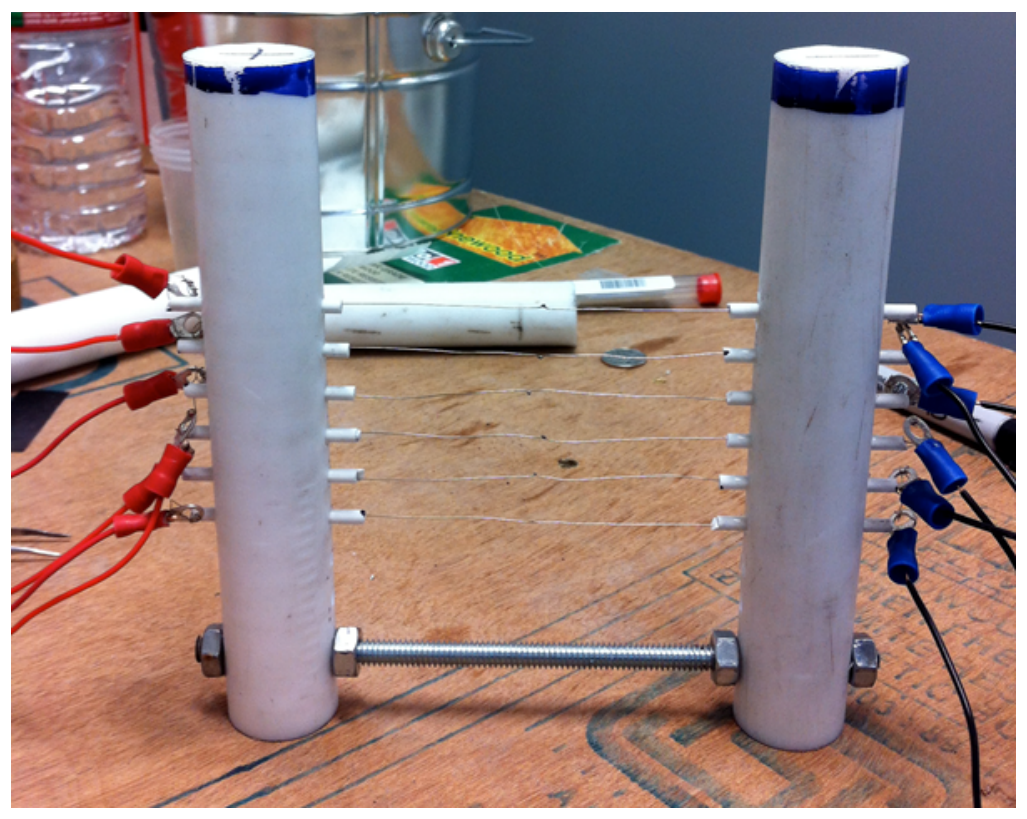

Figure 4.1.8 - Thermocouple setup

Figure 4.1.9 shows a schematic for the thermocouple setup placement. It is important to note that thermocouple 1 is placed $1 \mathrm{~cm}$ deep into the regolith. Each of the six thermocouples used are separated 1 $\mathrm{cm}$ apart from each other. For the results shown in chapter 4.2, thermocouples are going to be named from 1 to 6 in this thesis and it is important to know the exact placement to calculate the most accurate penetration depth. 


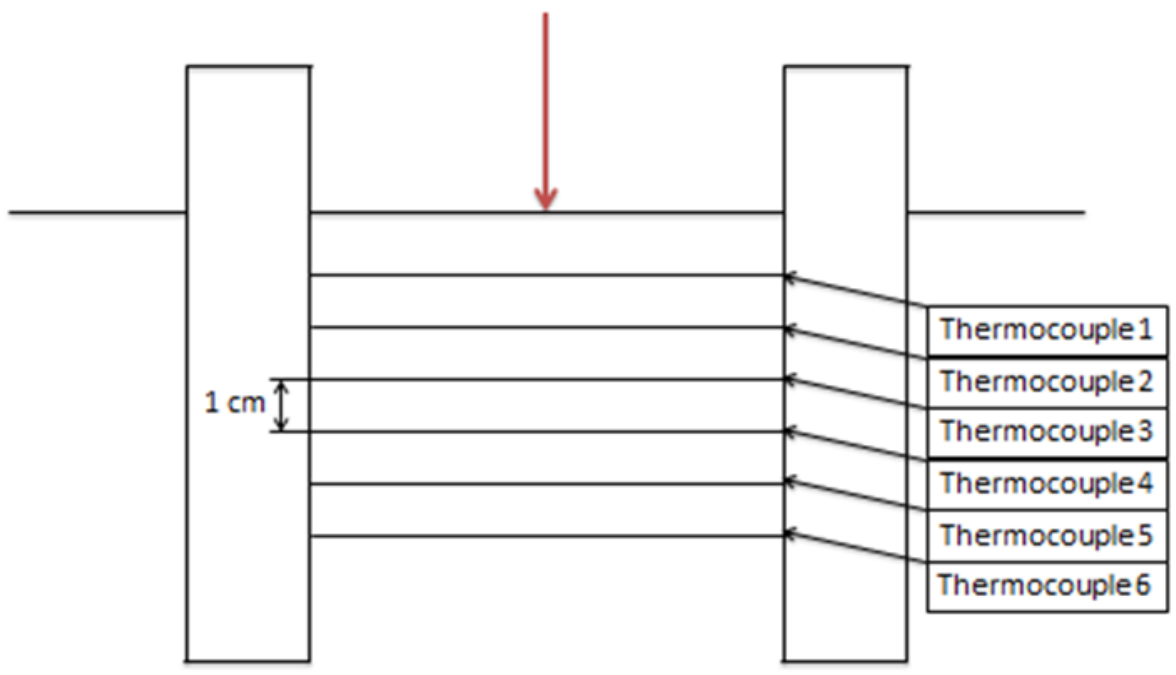

Figure 4.1.9 - Thermocouple setup placement

After several experiments were completed, it was concluded that condensation has occurred inside the flask. The glass container was at a lower temperature than the condensation temperature, therefore condensation inside the flask was being observed before it could separate into a different container passing through the rubber tubing. This posed as a problem because no separation was observed since water vapor was condensing before it could reach the other container. A heating tape from OMEGA Company was purchased to maintain the filter flask at high temperatures to prevent condensation. Figure 4.1.10 shows pictures of both experiments with and without heating tape. 


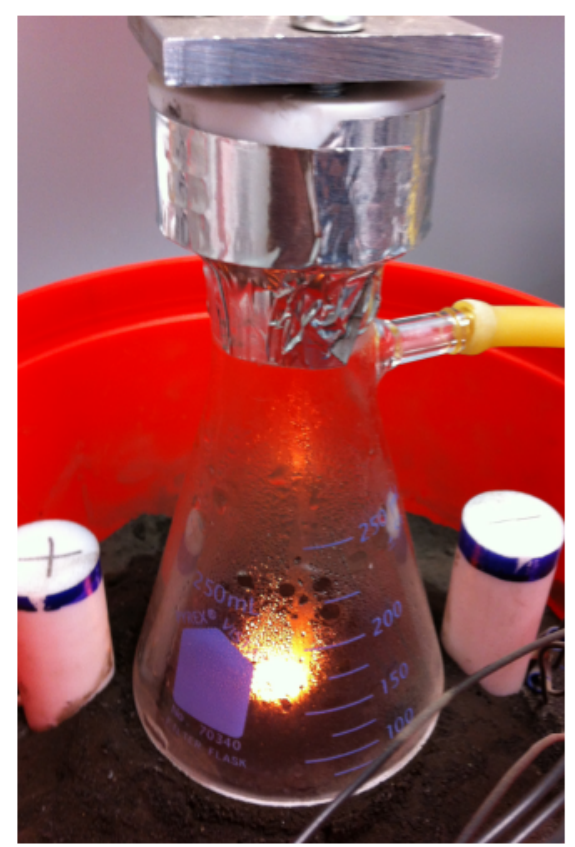

a)

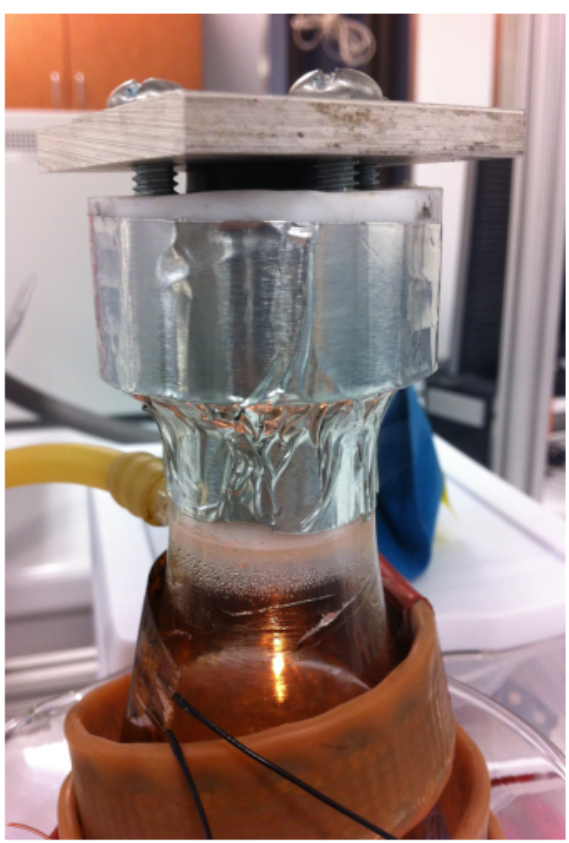

b)

Figure 4.1.10 - Experiment a) without heating tape b) with heating tape

After conducting several tests, water condensation was observed in the system. As experiments consisted of a closed system (no vent), water was condensing inside the rubber tubing and hence was not separated correctly. An experiment where the rubber tubing was not connected to the other container and opened to atmosphere was performed and water droplets were later observed. A major concern with this dilemma was the fact that vapor was escaping into the atmosphere since the system had no mechanism to condense vapor before it could escape into the atmosphere. Figure 4.1.11 shows the schematic and a picture of the final water extraction system. It consisted of the following elements: having the laser passing through the extraction setup, having heating tape to prevent early condensation of the vapor, a separate container with water ice to condensate the vapors, and lastly a small vent into the atmosphere. 

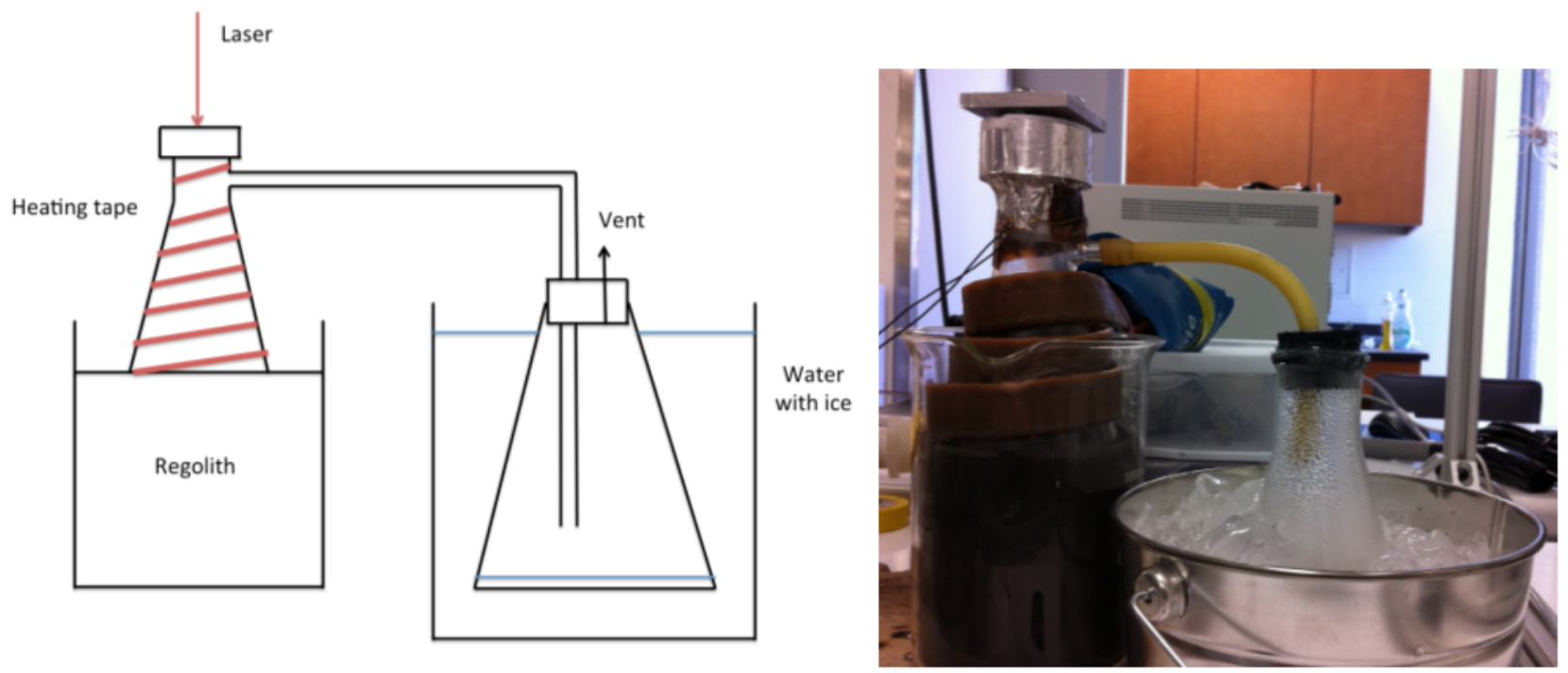

Figure 4.1.11 - Final water extraction system

The system shown in Figure 4.1.11 shows successful results where the laser was used to extract water droplets from the regolith. The laser power percentage used was $80 \%$ for 20 minutes. $80 \%$ of power for our 60 watts $\mathrm{CO}_{2}$ laser is approximately 48 watts. The laser diameter considered was $7 \mathrm{~mm}$; hence the heat flux was approximately $1,263,158 \mathrm{~W} / \mathrm{m}^{2}$.

Moisture in the air was also taken into consideration when extracting water from our system. Atmospheric air can be viewed as a mixture of dry air and water vapor, also referred to as moisture. Air can hold a certain amount of moisture at a given temperature; relative humidity is the amount of moisture the air holds relative to the maximum amount of moisture the air can hold at the same temperature. The specific humidity of air with $100 \%$ humidity (overestimate) and pressure $90 \mathrm{Kpa}$ (average atmospheric pressure in El Paso) was calculated for the temperatures of $25^{\circ} \mathrm{C}$ and $0{ }^{\circ} \mathrm{C}$ using the formulas shown in equation 4.1.1 and 4.1.2

$$
\begin{aligned}
\varnothing & =100 \% \\
w & =\frac{0.622 P_{v}}{P-P_{v}}
\end{aligned}
$$


Where $\varnothing$ is the relative humidity, $P_{v}$ is the saturation pressure at the given temperature, and $P$ is atmospheric pressure. It was obtained that the specific humidity at these temperatures is 0.022 and 0.004 $\mathrm{kg}$ of water per kilograms of dry air respectively. The mass of dry air in the 0.5 -L collector, according to the ideal gas equation, is about $0.64 \mathrm{~g}$. Thus, the mass of water that is condensed in our system from atmospheric air due to its cooling is approximately $11.62 \mathrm{mg}$ at $100 \%$ humidity (at the actual humidity the mass is less of course). 


\subsection{EXPERIMENTAL RESULTS}

Results from experimental testing are summarized in table 4.2.1. As mentioned before, a series of experiments were performed to determine the heat transfer distribution in the regolith using different heat fluxes. These experiments allowed a comparison of heat transfer calculation shown in chapter 3 to the ones obtained from experimental testing. The penetration depth at which we exceed the boiling point of water when the laser was operating at its $80 \%$ during 20 minutes was calculated using engineering software and determined to be approximately $2.3 \mathrm{~cm}$. Table 4.2 .2 shows a comparison between heat transfer calculations and experimental test using thermocouple setup. In the first 10 tests, the temperature distribution along the regolith was measured using a series of thermocouples separated $1 \mathrm{~cm}$ apart from each other. Figure 4.2.1 shows test number 4 where $60 \%$ of the laser was beamed during a time frame of 10 minutes.

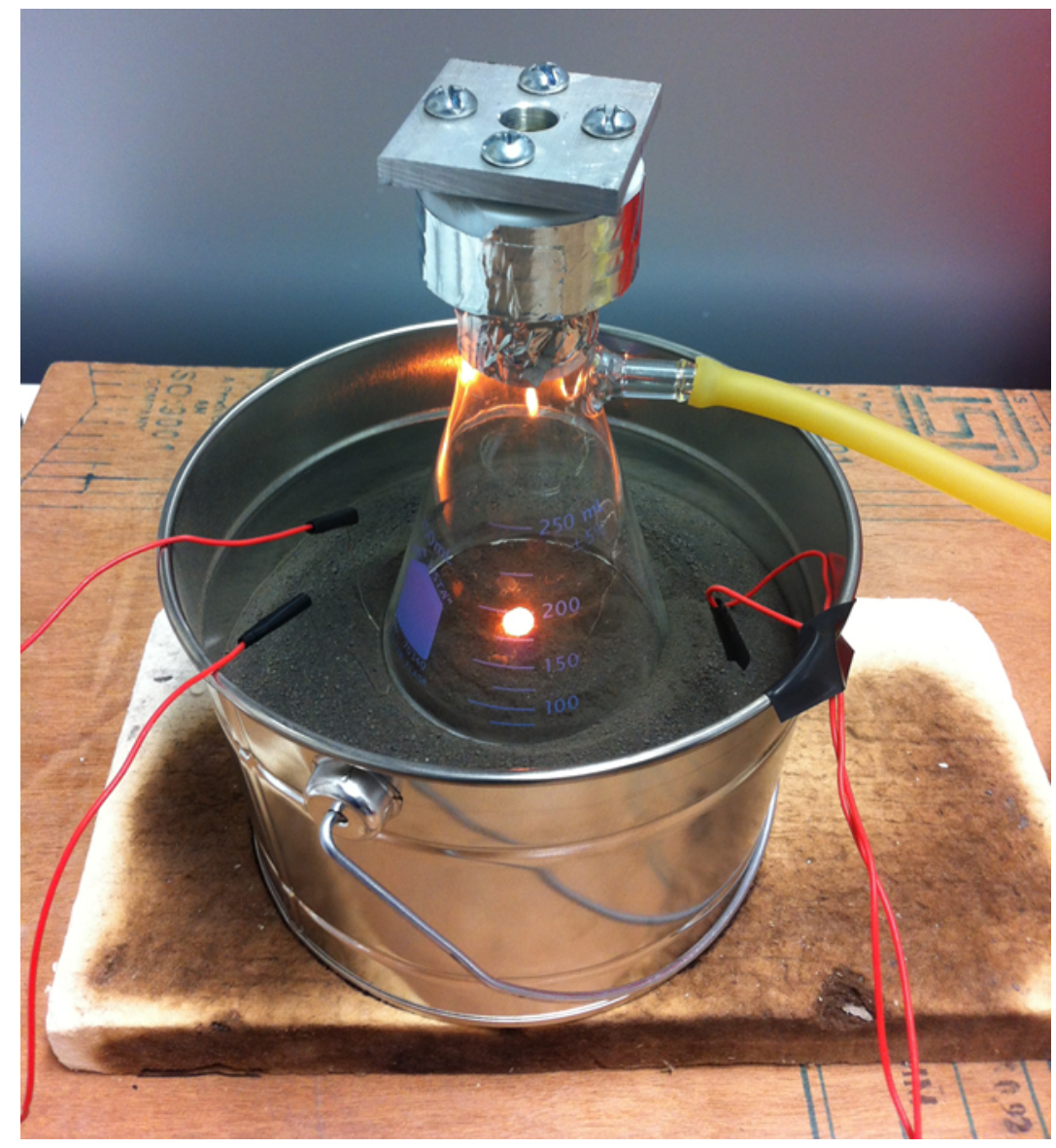

Figure 4.2.1 - Test 4 picture 
Table 4.2.1 - Results from experimental testing summarized

\begin{tabular}{|c|c|c|c|c|c|c|}
\hline Test & $\begin{array}{l}\text { Regolith } \\
\text { (grams) }\end{array}$ & $\begin{array}{l}\text { Water } \\
\text { (mL) }\end{array}$ & $\begin{array}{l}\text { Laser Power } \\
\text { (percentage) }\end{array}$ & $\begin{array}{l}\text { Laser } \\
\text { Power } \\
\text { (watts) }\end{array}$ & $\begin{array}{c}\text { Time } \\
\text { (minutes) }\end{array}$ & Description \\
\hline 1 & 2000 & $\mathrm{n} / \mathrm{a}$ & 20 & 12 & 2 & Initial test \\
\hline 2 & 2000 & $\mathrm{n} / \mathrm{a}$ & 50 & 30 & 2 & $\begin{array}{c}\text { Initial test - } 2 \\
\text { thermocouples placed } \\
\text { randomly }\end{array}$ \\
\hline 3 & 2000 & $\mathrm{n} / \mathrm{a}$ & 50 & 30 & 10 & $\begin{array}{c}\text { Initial test - } 2 \\
\text { thermocouples placed } \\
\text { randomly }\end{array}$ \\
\hline 4 & 2000 & $\mathrm{n} / \mathrm{a}$ & 60 & 36 & 10 & $\begin{array}{l}2 \text { thermocouples placed } \\
1 \mathrm{~cm} \text { apart }\end{array}$ \\
\hline 5 & 2000 & $\mathrm{n} / \mathrm{a}$ & 60 & 36 & 15 & $\begin{array}{l}2 \text { thermocouples placed } \\
1 \mathrm{~cm} \text { apart }\end{array}$ \\
\hline 6 & $\mathrm{n} / \mathrm{a}$ & $\mathrm{n} / \mathrm{a}$ & $\mathrm{n} / \mathrm{a}$ & $\mathrm{n} / \mathrm{a}$ & $\mathrm{n} / \mathrm{a}$ & $\begin{array}{c}\text { Thermocouple setup } \\
\text { tested }\end{array}$ \\
\hline 7 & 4000 & $\mathrm{n} / \mathrm{a}$ & 60 & 36 & 20 & $\begin{array}{c}\text { Problems with laser - no } \\
\text { data }\end{array}$ \\
\hline 8 & 4000 & $\mathrm{n} / \mathrm{a}$ & 60 & 36 & 20 & $\begin{array}{c}\text { Cool down for } 6 \\
\text { minutes }\end{array}$ \\
\hline 9 & 4000 & $\mathrm{n} / \mathrm{a}$ & 80 & 48 & 20 & $\begin{array}{c}\text { Temperature } \\
\text { distribution plotted }\end{array}$ \\
\hline 10 & 4000 & $\mathrm{n} / \mathrm{a}$ & 80 & 48 & 30 & $\begin{array}{c}\text { Temperature } \\
\text { distribution plotted }\end{array}$ \\
\hline 11 & 4200 & 250 & 80 & 48 & 20 & $\begin{array}{l}\text { Vapor condensed in } \\
\text { filter flask }\end{array}$ \\
\hline 12 & 1000 & 60 & 80 & 48 & 10 & Heating tape used \\
\hline 13 & 1000 & 20 & 80 & 48 & 8 & $\begin{array}{c}\text { Heating tape on top } \\
\text { part of flask }\end{array}$ \\
\hline 14 & 1000 & 10 & 80 & 48 & 15 & $\begin{array}{c}\text { Heating tape on bottom } \\
\text { part of flask }\end{array}$ \\
\hline 15 & 1000 & 60 & 80 & 48 & 15 & $\begin{array}{c}\text { Water droplets } \\
\text { obtained }\end{array}$ \\
\hline 16 & 1000 & 20 & 80 & 48 & 15 & $\begin{array}{c}1.88 \mathrm{~mL} \text { of water } \\
\text { extracted }\end{array}$ \\
\hline 17 & 1000 & 20 & 80 & 48 & 20 & $\begin{array}{c}5.54 \mathrm{~mL} \text { of water } \\
\text { extracted }\end{array}$ \\
\hline 18 & 1000 & 60 & 80 & 48 & 20 & $\begin{array}{l}0.645 \mathrm{~mL} \text { of water } \\
\text { extracted. Rubber } \\
\text { tubing to long }\end{array}$ \\
\hline 19 & 1000 & 10 & 80 & 48 & 20 & $\begin{array}{c}1.976 \mathrm{~mL} \text { of water } \\
\text { extracted }\end{array}$ \\
\hline
\end{tabular}


Table 4.2.2 Comparison between heat transfer simulation and experimental testing

\begin{tabular}{|c|c|c|c|}
\hline & $\begin{array}{c}\text { Heat Flux } \\
\left(\mathbf{W} / \mathbf{m}^{2}\right)\end{array}$ & $\begin{array}{c}\text { Time } \\
(\mathbf{m i n})\end{array}$ & $\begin{array}{c}\text { Penetration } \\
\text { Depth }(\mathbf{c m})\end{array}$ \\
\hline $\begin{array}{c}\text { Gambit Fluent } \\
\text { Simulation }\end{array}$ & 1200000 & 20 & 2.3 \\
\hline $\begin{array}{c}\text { Gambit Fluent } \\
\text { Simulation }\end{array}$ & 1200000 & 30 & 2.6 \\
\hline $\begin{array}{c}\text { Thermocouple } \\
\text { Setup Testing }\end{array}$ & 1263000 & 20 & $\sim 2.5$ \\
\hline
\end{tabular}

The following section will include graphs obtained for the temperature distribution experiments. A brief description will be mentioned before each figure. The first test performed consisted of testing the functionality of the laser. The laser was turned on at $20 \%$ during 2 minutes and two thermocouples were placed at random distances in order to observe any raise in temperatures along the regolith. Figure 4.2.2 shows the graph of the results of test 1 . Test 1 did not exceeded temperatures above $29{ }^{\circ} \mathrm{C}$ because thermocouples were misplaced too deep into the regolith.

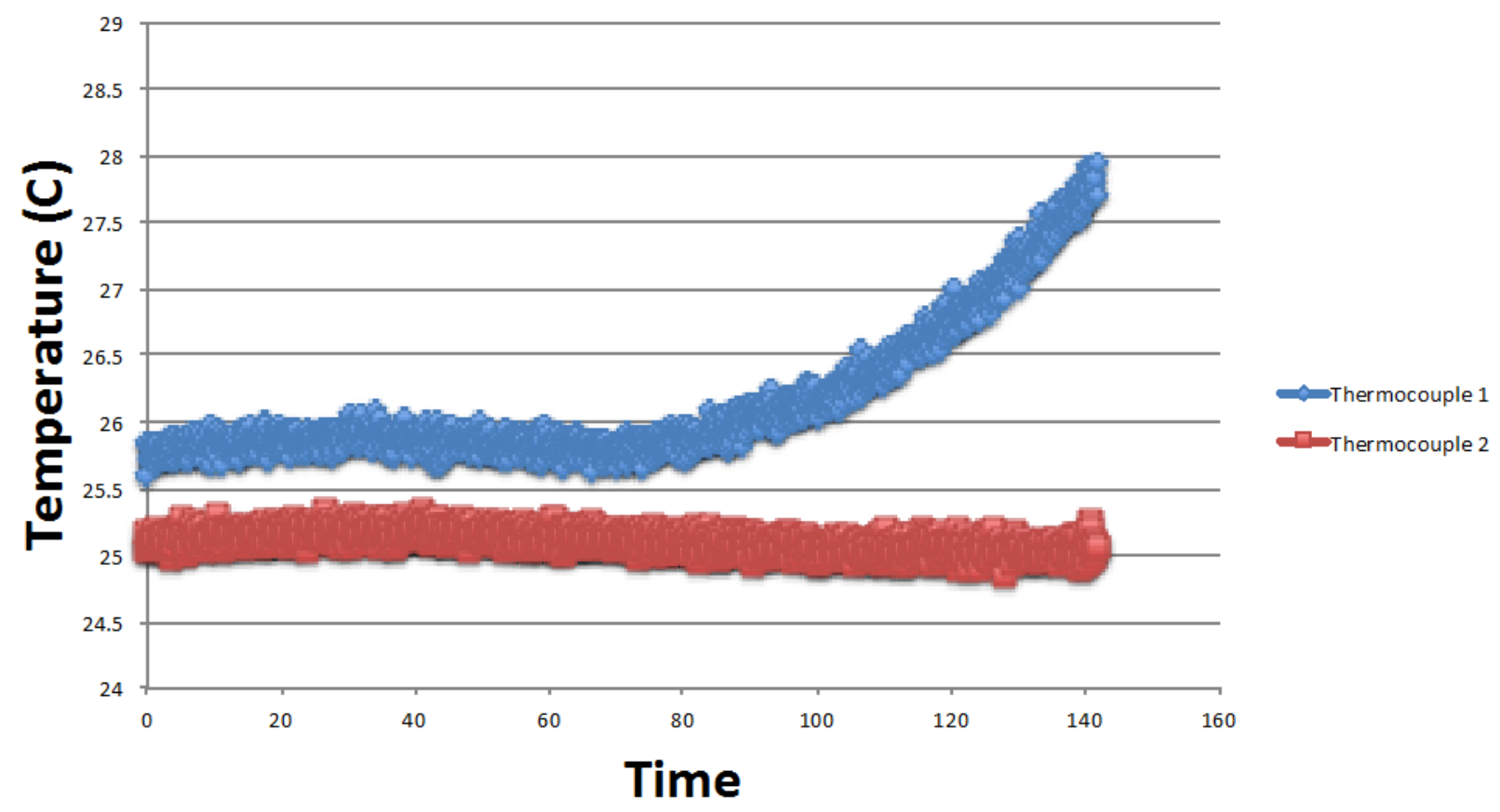

Figure 4.2.2 - Test $1.20 \%$ power for 2 minutes 
Test 1 through 5 consisted of increasing the power percentage and observing temperature increase. It was determined that to obtain more precise results, a thermocouple setup needed to be implemented into the experiments. Figure 4.2.3 shows the initial thermocouple setup used to measure the temperature. This preliminary system consisted of two thermocouples placed inside ceramic tubes for protection and separated $\sim 1 \mathrm{~cm}$ apart from each other. Then a new thermocouple setup was designed and built consisting of six thermocouples aligned vertically in the same axis.

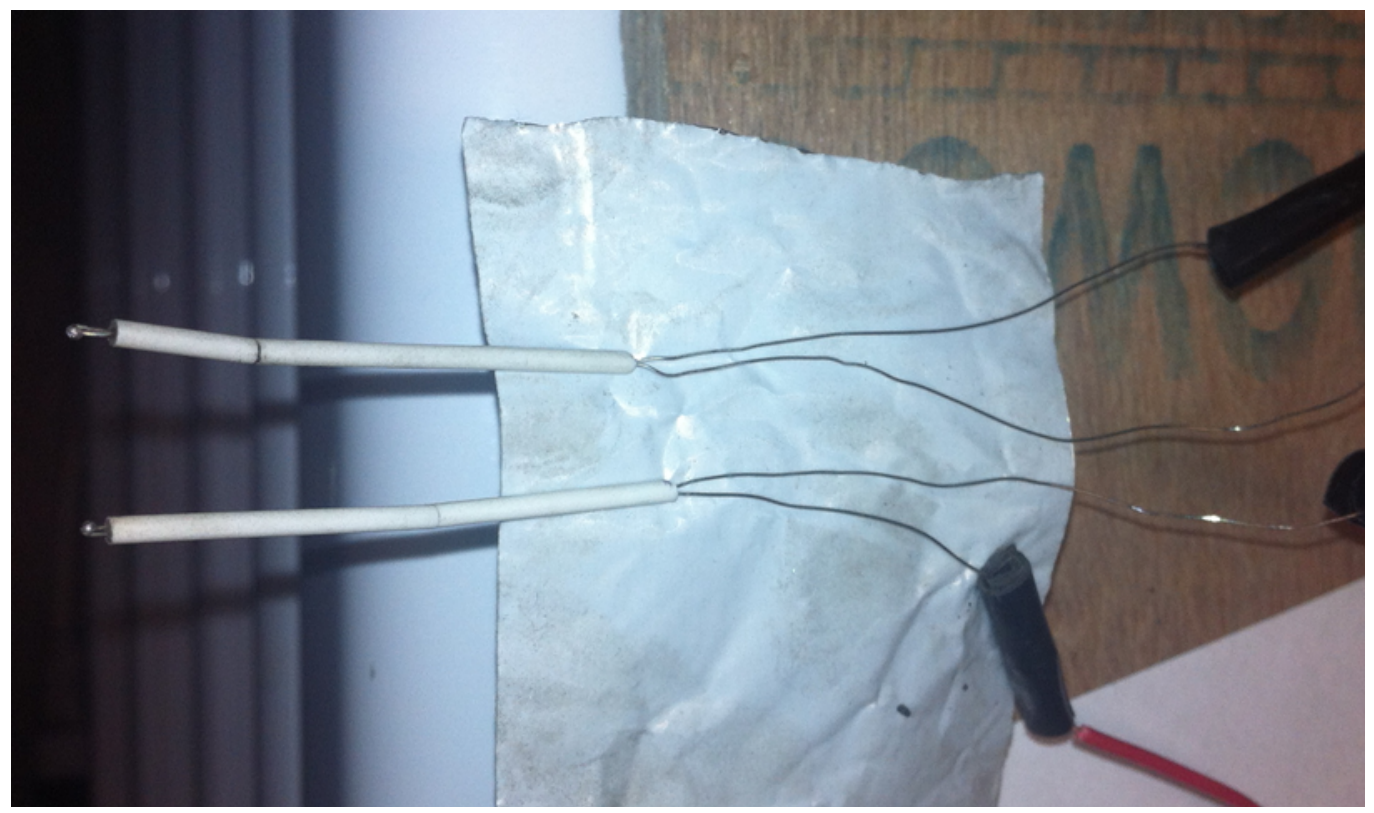

Figure 4.2.3 - Initial thermocouple setup

The following figures show results obtained when the heat flux and time were increased. It is shown that after test 3 , which had $50 \%$ of the laser power during 10 minutes, temperature achieved 100 ${ }^{\circ} \mathrm{C}$ necessary to boil water. 


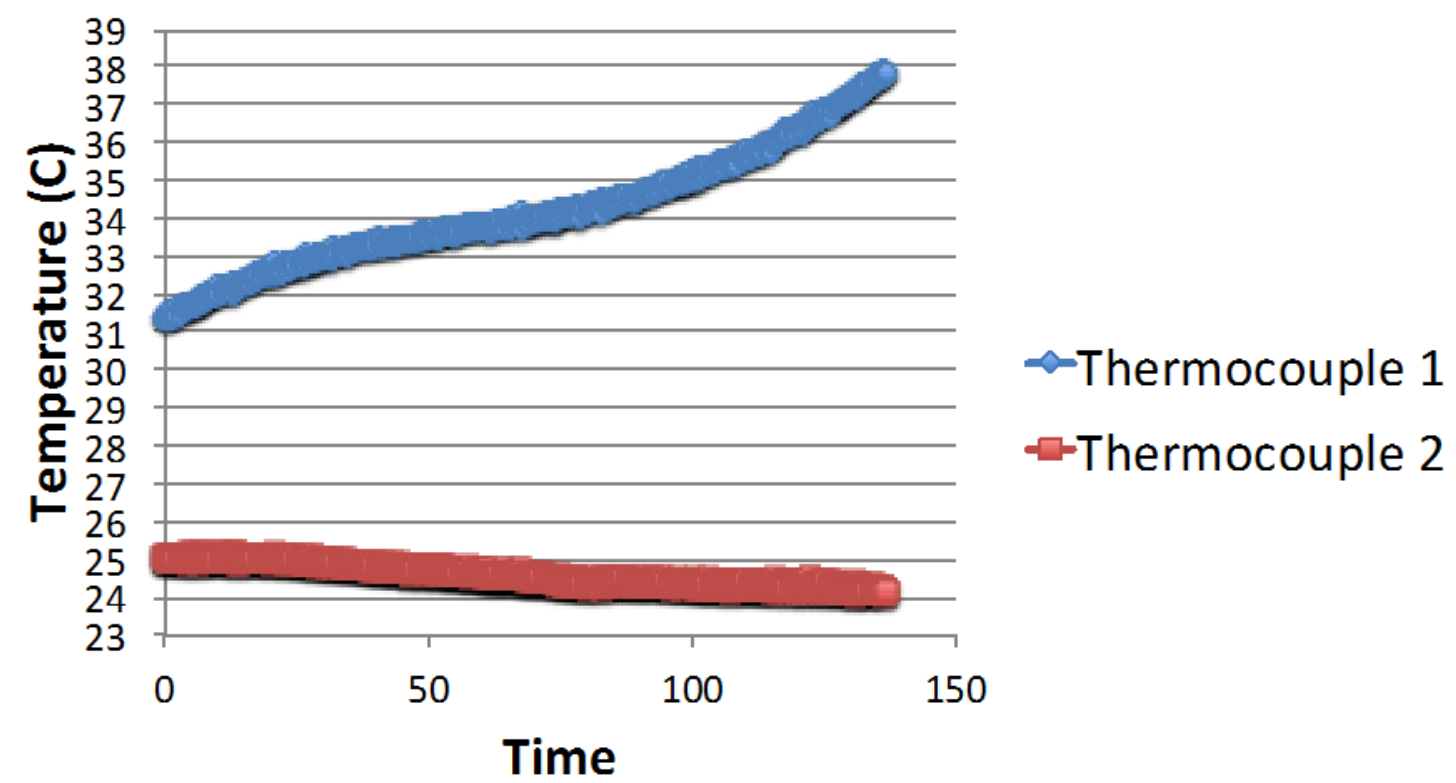

Figure 4.2 .4 - Test $2.50 \%$ power for 2 minutes

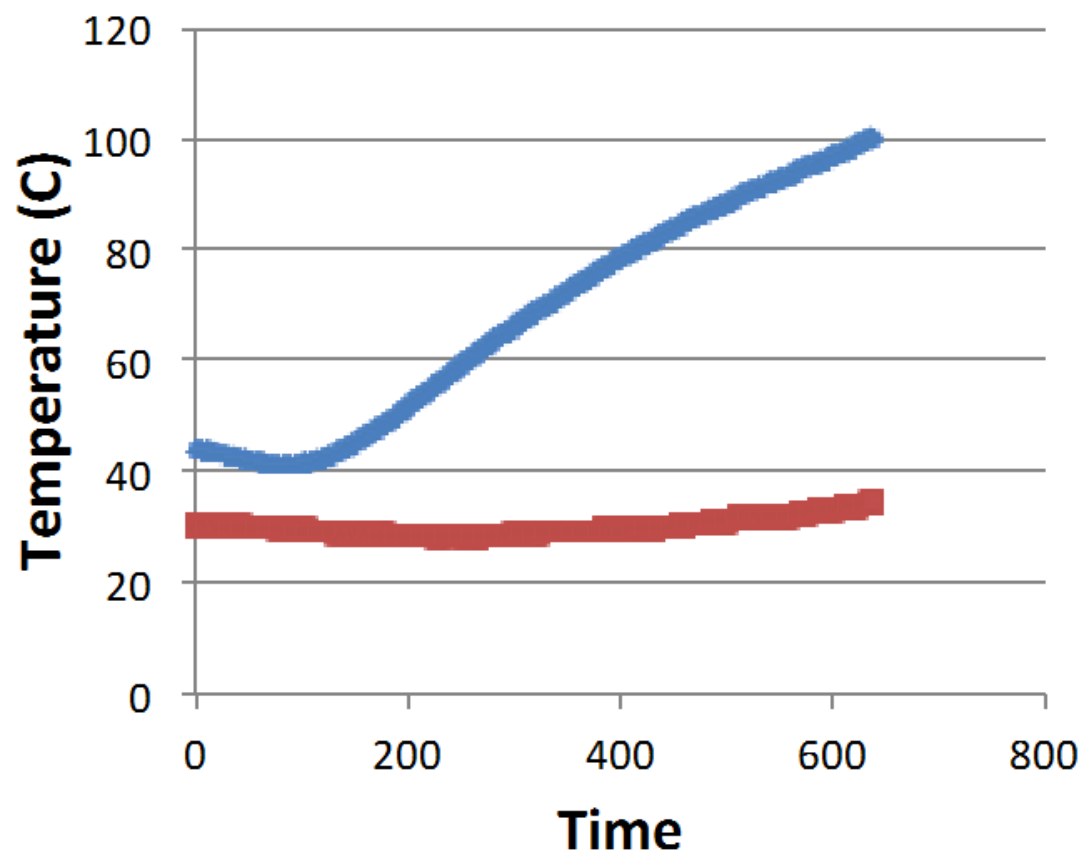

$\rightarrow$ Thermocouple 1

-Thermocouple 2

Figure 4.2.5 - Test 3.50\% power for 10 minutes 


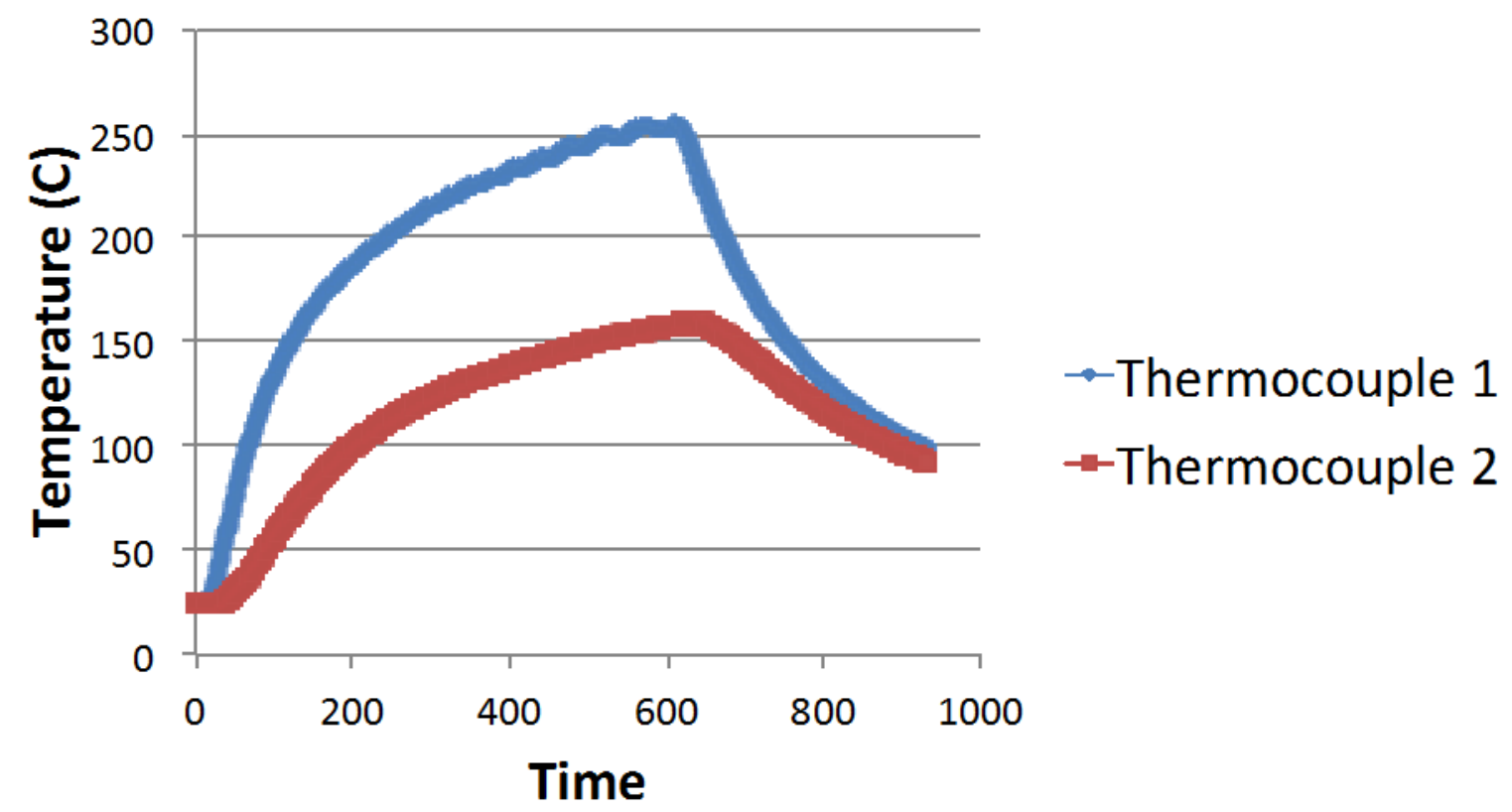

Figure 4.2 .6 - Test $4.60 \%$ power for 10 minutes

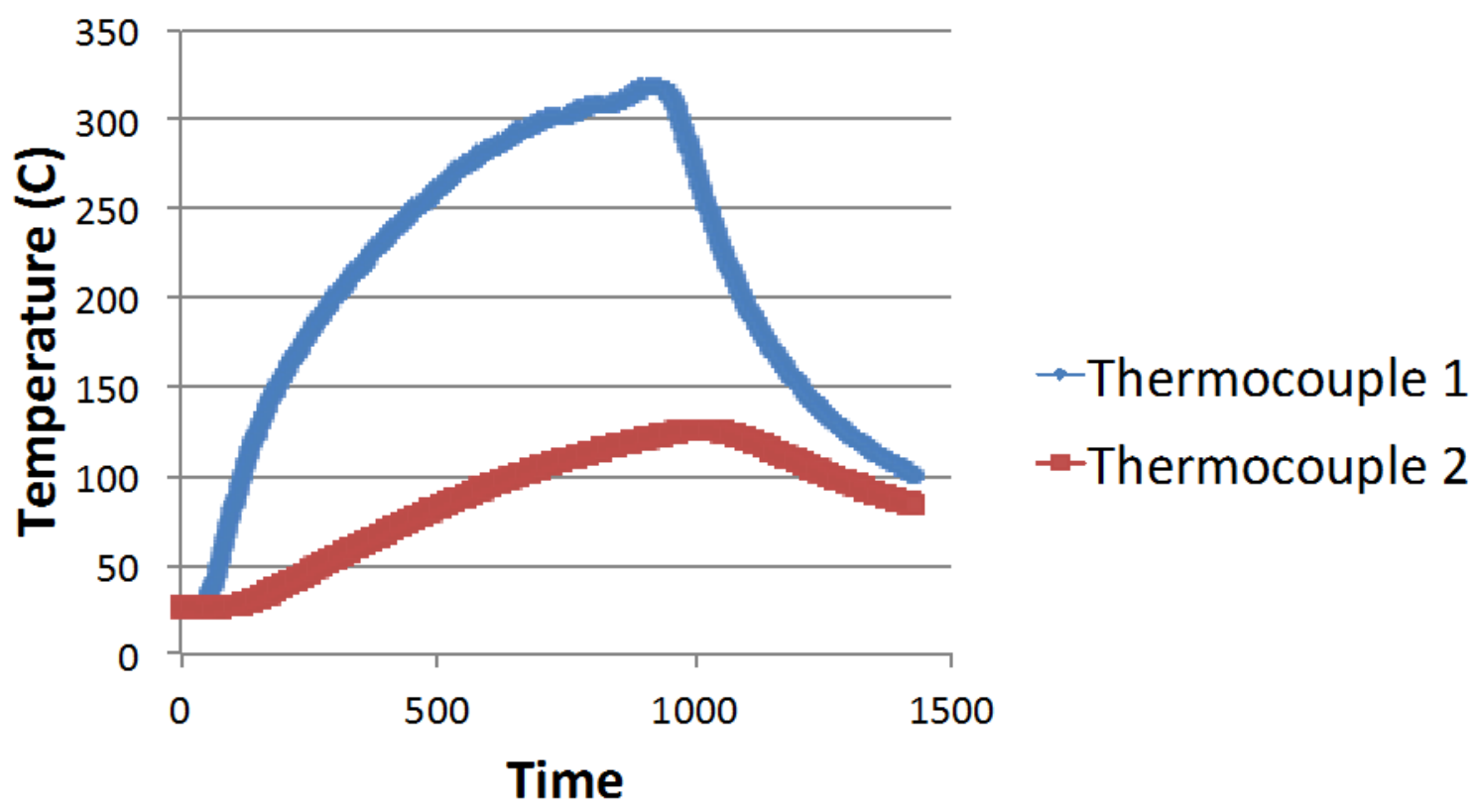

Figure 4.2.7 - Test 5.60\% power for 15 minutes

After each test was performed, a cool down process of approximately 5 minutes was also recorded to determine if heat was still increasing after the laser was turned off due to heat transfer from a vitrified regolith slag formed in the surface. No increase was found or recorded in any experiment. 
Test 6 consisted of examining the functionality of the thermocouple setup design. Test 6 involved connecting the thermocouple setup to the DAQ and by simply touching the thermocouple welds without any regolith or laser functionality; a small increase in the temperature was recorded. The small increase in temperature proved that the thermocouple setup was properly working. Results are shown in Figure 4.2.8.

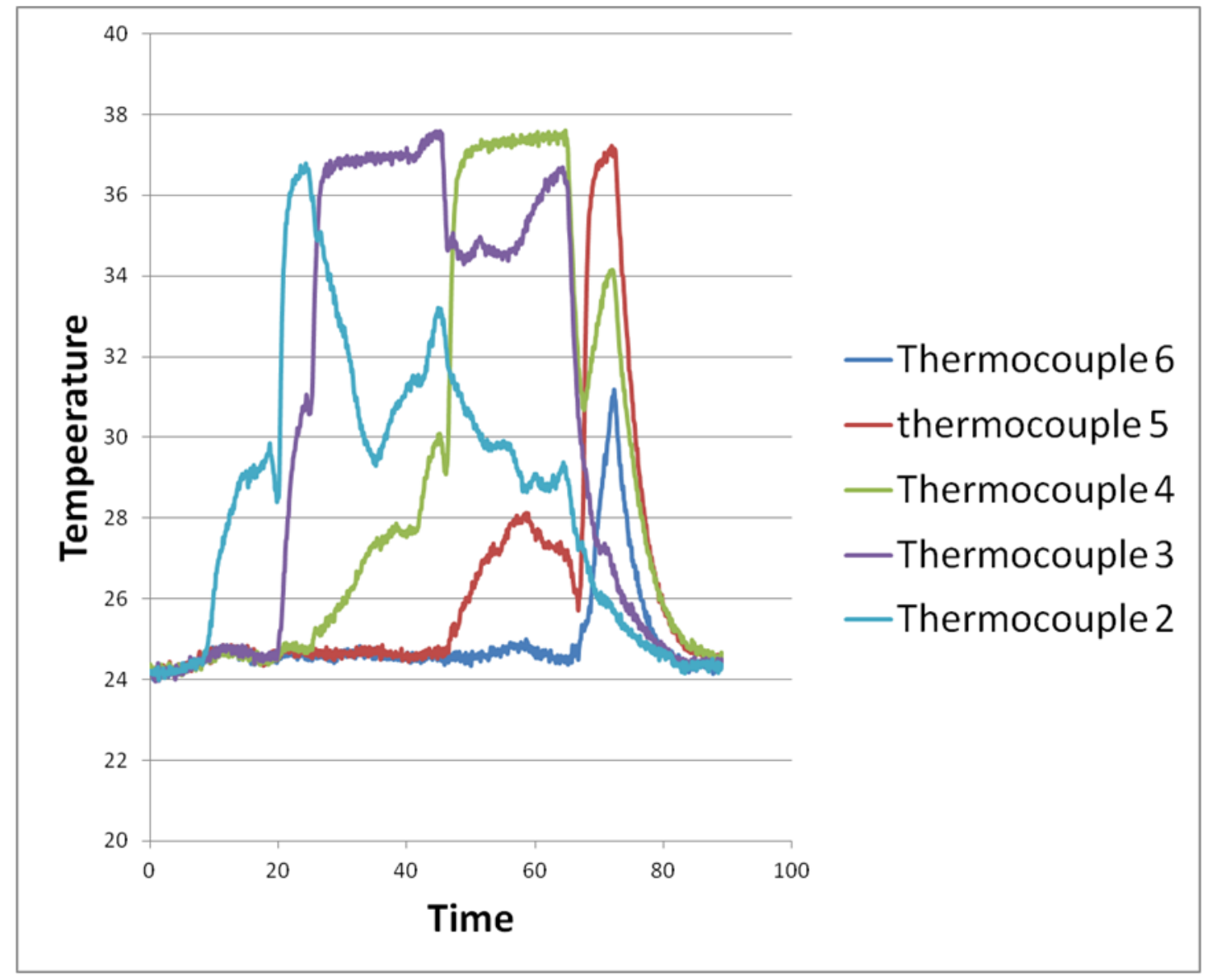

Figure 4.2.8 - Thermocouple setup testing

Test 8 through 11 consisted of obtaining more accurate readings including the thermocouple setup. Experiments consisted of using the laser above $60 \%$ of its maximum operation for 20 and 30 minutes intervals. Readings showed similar results as the simulations were performed using engineering software. It is important to note that thermocouple 1 was $1 \mathrm{~cm}$ below the top surface. Therefore, experiments presented a penetration depth exceeding the $2 \mathrm{~cm}$. 


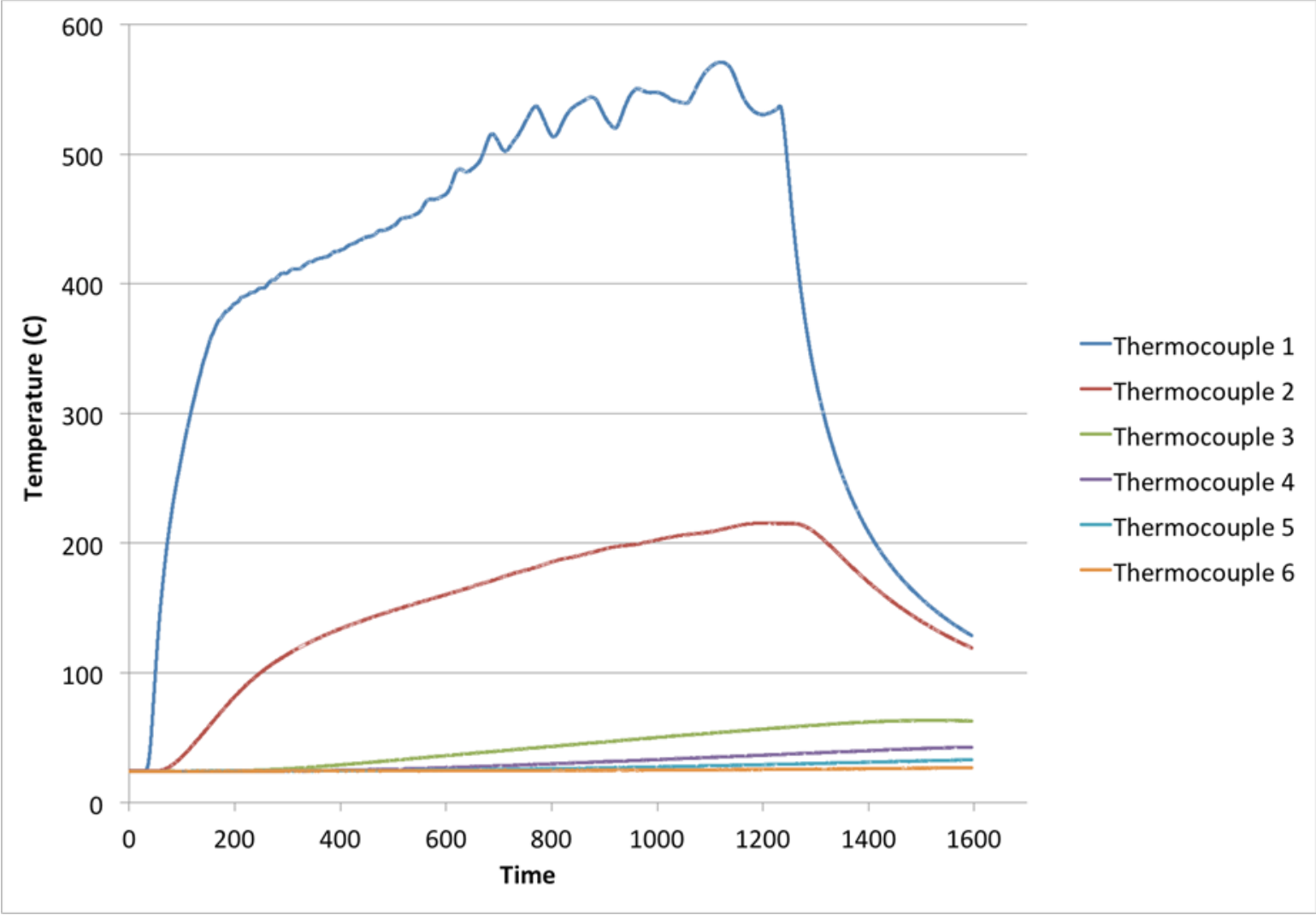

Figure 4.2 .9 - Test $8.60 \%$ power for 20 minutes

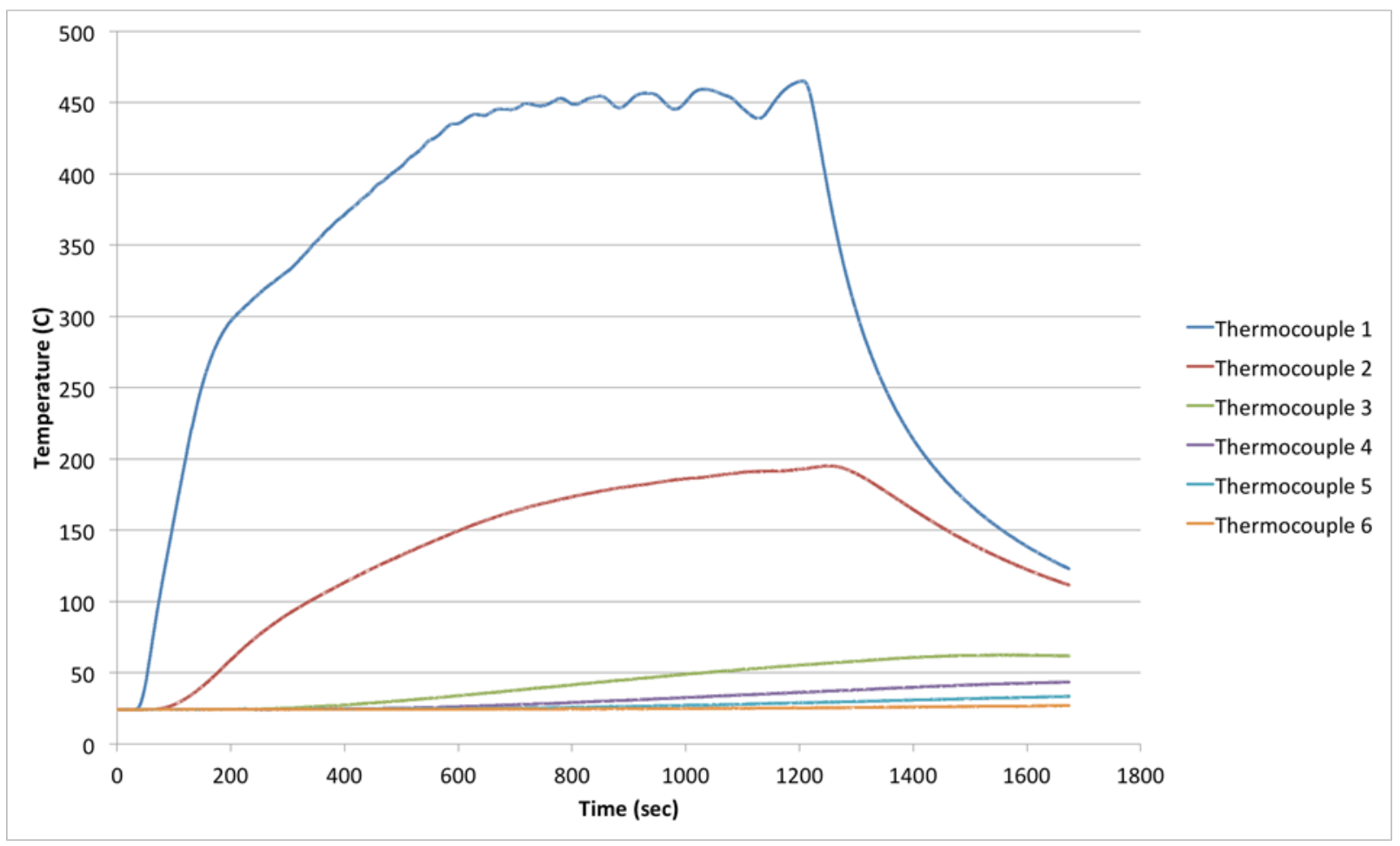

Figure 4.2.10 - Test $9.80 \%$ power for 20 minutes 
So far, experimental results figures have shown a temperature-time curve for a number of six thermocouples placed within the regolith. Figure 4.2.11 shows a temperature-distance dependencies graph for a series of time of 0, $5 \mathrm{~min}(300 \mathrm{sec}), 10 \mathrm{~min}(600 \mathrm{sec}), 15 \mathrm{~min}(900 \mathrm{sec})$, and $20 \mathrm{~min}(1200$ sec). X-axis shows the distance from the top surface (i.e. the penetration depth) and the Y-axis shows the temperature. Results show that the penetration depth exceeds the $2.5 \mathrm{~cm}$ after the 20 minutes laser has been beamed.

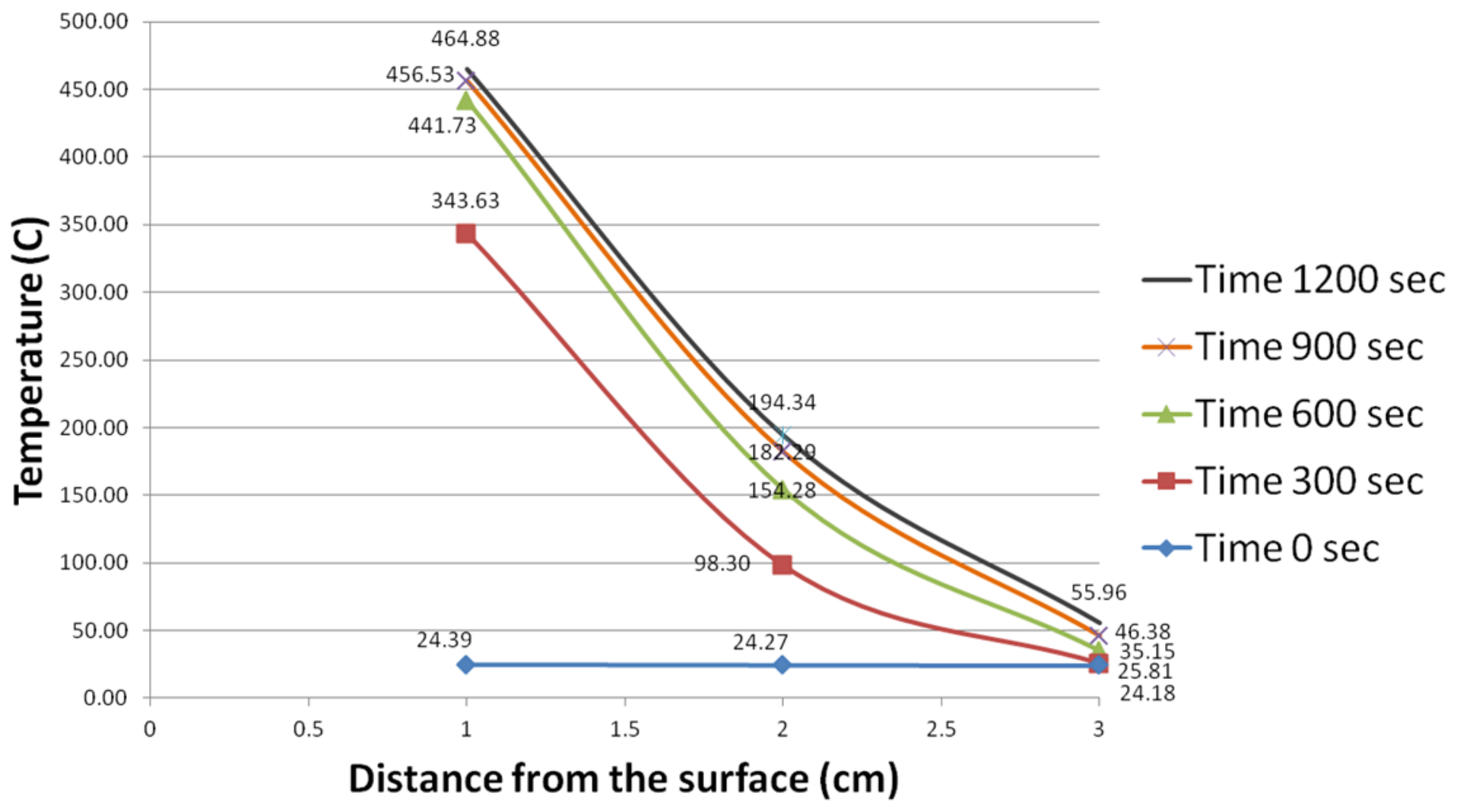

Figure 4.2.11 - Temperature vs. distance graph 


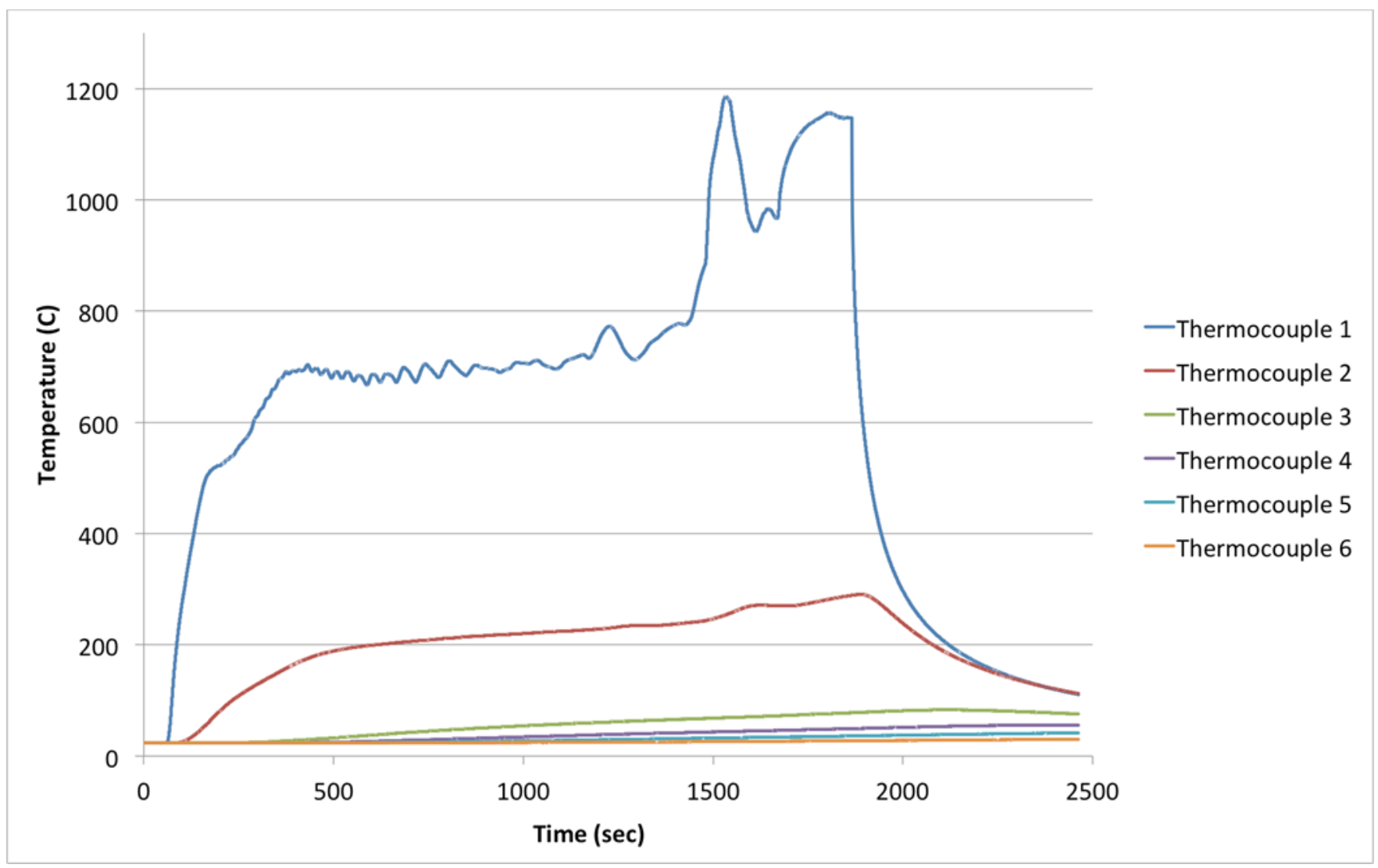

Figure 4.2 .12 - Test $10.80 \%$ power for 30 minutes

Figure 4.2.13 shows a close-up section of the four thermocouples placed deeper into the regolith. We are focusing mainly on a temperature to pass the $100 \mathrm{C}$ necessary to evaporate water. The test consisted of applying a heat flux with $80 \%$ of the laser power for 30 minutes and neither of them exceeded the necessary temperature. It is important to note that thermocouple 3 was placed $4 \mathrm{~cm}$ into the regolith. 


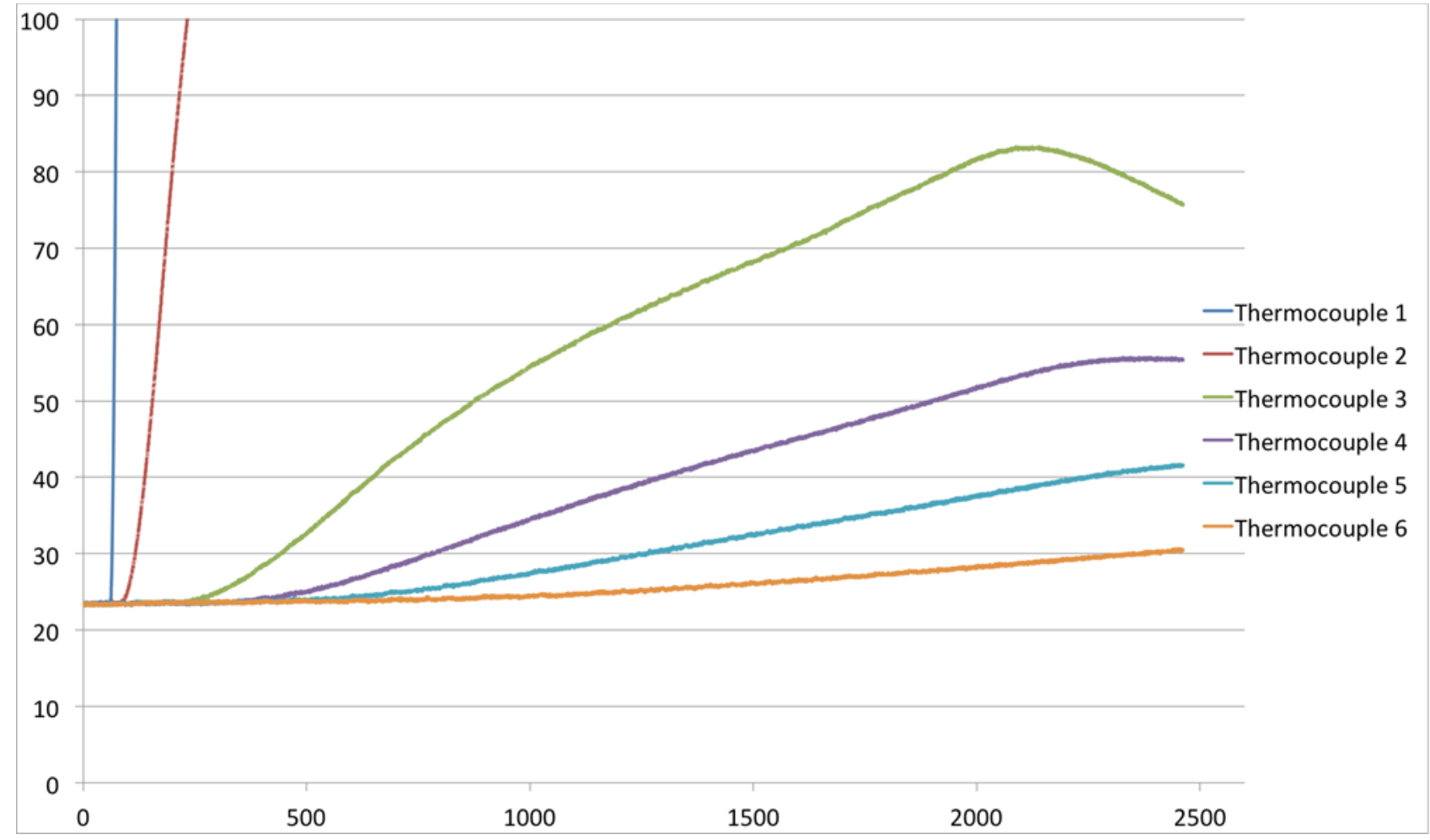

Figure 4.2 .13 - Test $10.80 \%$ power for 30 minutes close-up

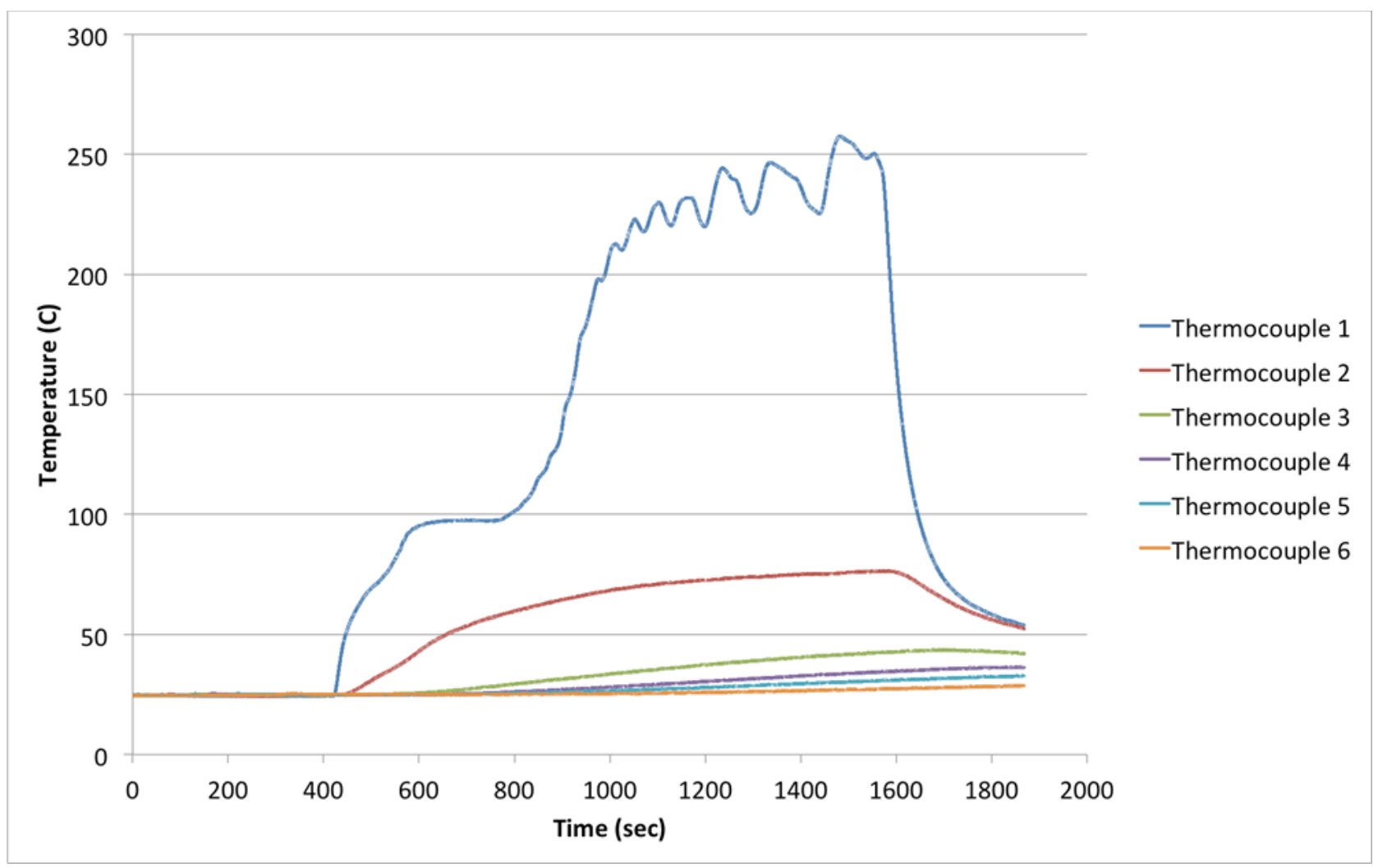

Figure 4.2.14 - Test $11.80 \%$ power for 20 minutes 
A comparison between modeling and experimental results is shown in Figure 4.2.15. The unsteady model provides the temperature field for a $30 \mathrm{~min}$ simulation and compared to test 10 , also to this time frame. A higher temperature was observed in the first centimeter for the modeling since model was calculated without any external conditions. During experimental testing, a vitrified melt zone was observed in the regolith. This zone may affect the heat transfer distribution into the regolith when heat source is applied for a long period of time. The penetration depth exceeding the $100{ }^{\circ} \mathrm{C}$ is approximately $2.5 \mathrm{~cm}$ in both cases.

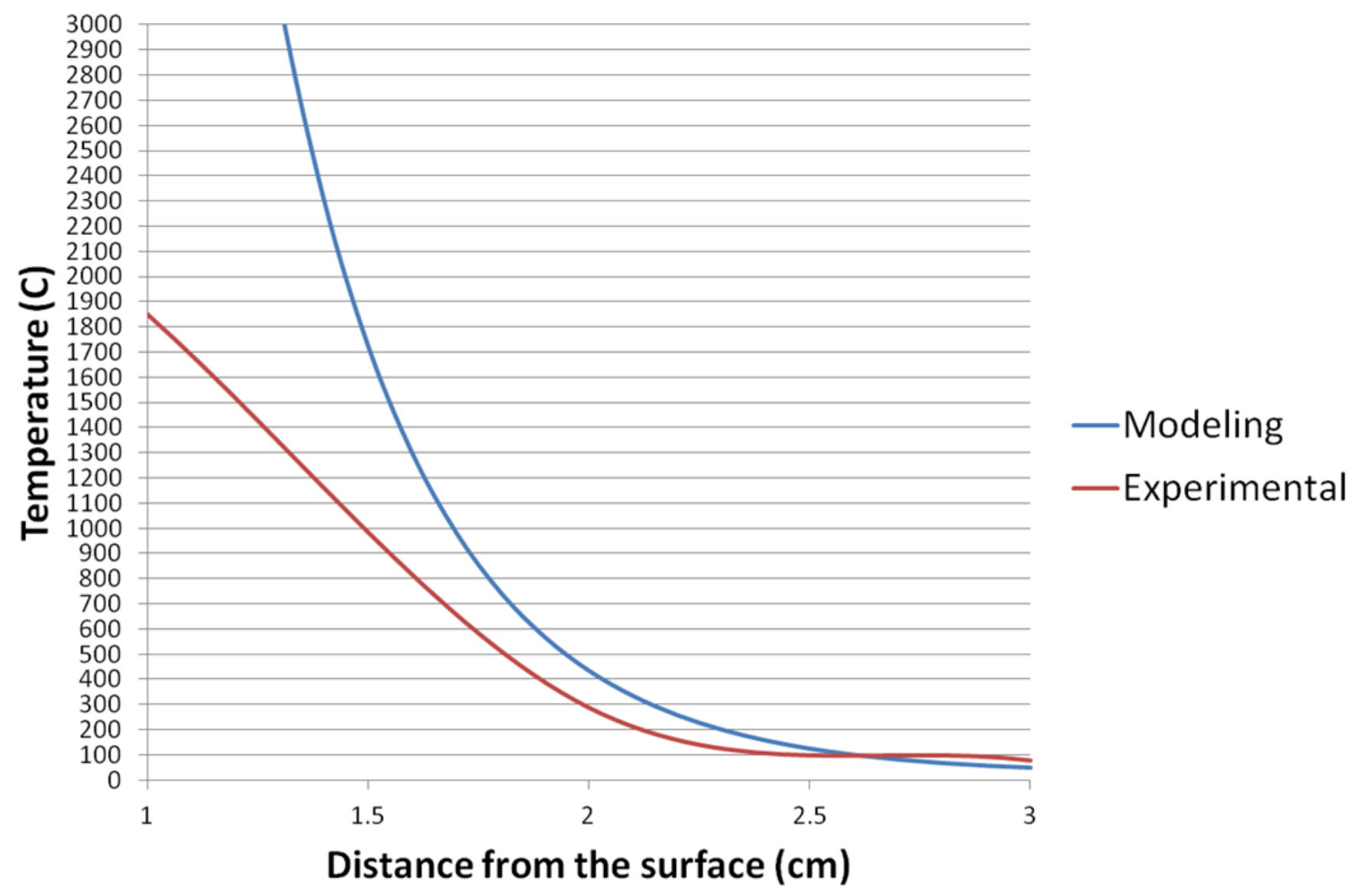

Figure 4.2.15 - Comparison between modeling and experimental results 
In conducting the regolith melting experiment and measuring the temperature distribution, we consider the system for the balance within the lunar simulant. Within the melt zone below the surface, the conduction of the molten regolith will make the temperature more uniform. At the edge of the melt zone and through the sample, heat propagates into the regolith via heat conduction and the temperature becomes steeper. Figure 4.2.16 shows the vitrified regolith melt obtained in the surface after each experiment conducted.

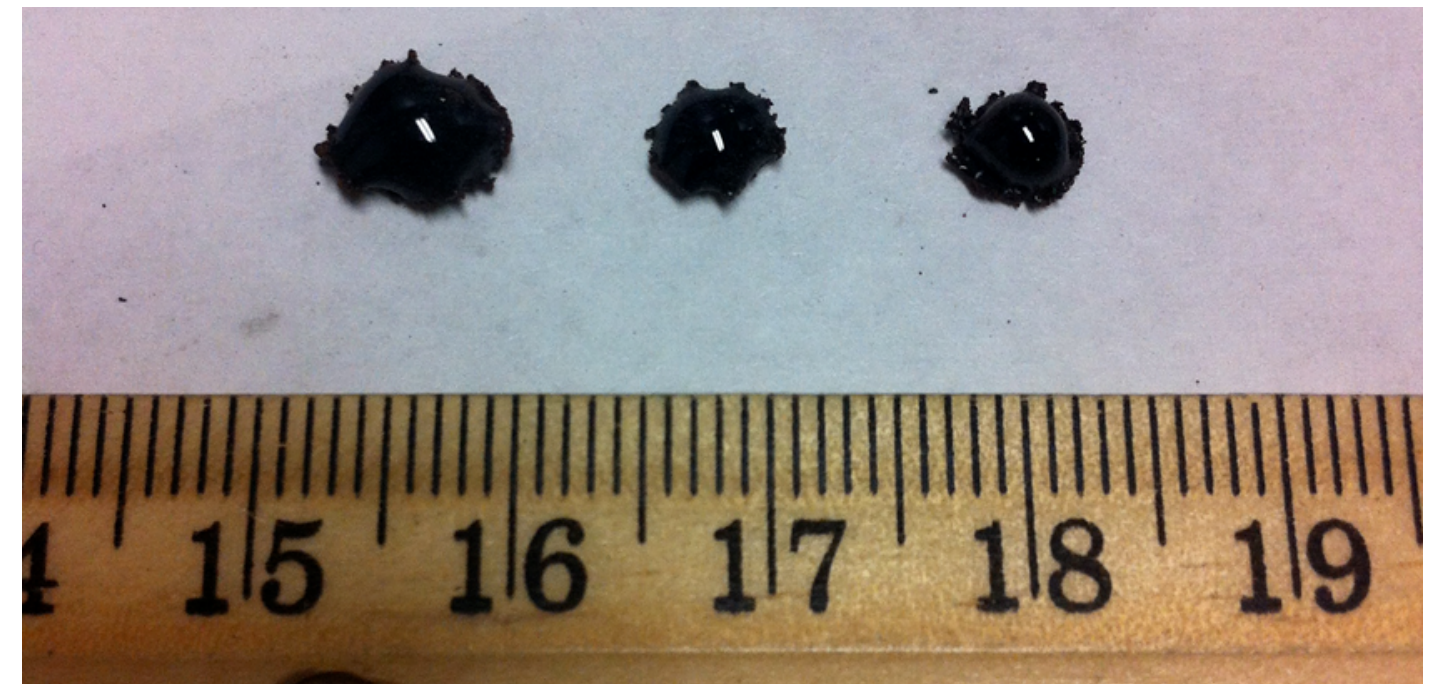

Figure 4.2.16 - Vitrified regolith

In conclusion for experimental results, by using our $60-\mathrm{Watt} \mathrm{CO}_{2}$ laser at $80 \%$ of its maximum power during 20 minutes, we could reach a penetration depth of approximately $2.5 \mathrm{~cm}$ (close to the 2.3 $\mathrm{cm}$ obtained from modeling). If the heat transfer into the regolith is considered to propagate in a hemisphere shape into the regolith, and by using a radius of $2.5 \mathrm{~cm}$, a volume of $0.000025 \mathrm{~m}^{2}$ of heated regolith was calculated. This value is compared to experimental results from the water extracted using the $\mathrm{CO}_{2}$ laser. An average of $2 \mathrm{~g}$ of water was extracted from the wet regolith $(60 \mathrm{~g}$ of water by $1000 \mathrm{~g}$ of regolith). $33 \mathrm{~g}$ of regolith was heated to our desired temperature, and by using the density of the regolith, an estimated volume of $0.000022 \mathrm{~m}^{3}$ of regolith was heated in the experimental analysis. We may compare this value to the model analysis by multiplying the obtained $0.000025 \mathrm{~m}^{3}$ volume by the density which gives us $37 \mathrm{~g}$ of regolith heated on the model. 


\section{Chapter 5 Conclusions}

To develop the extraction equipment, the amount of power required for sublimation of frozen volatiles in the lunar regolith was determined. The objective of this thesis is to study extraction methods of volatiles from the lunar regolith within the shadowed craters of the Moon using solar power and validate the feasibility of the system. Preliminary test will enable researchers to better understand the process of extraction and compare simulations with experiments. Simulations using laboratory conditions were performed and compared with experimental testing to validate the effectiveness of our design. Table 5.1 shows results obtained from modeling and experimental results for laboratory and lunar conditions.

Table 5.1 - Comparison of modeling with experimental results

\begin{tabular}{|c|c|c|c|}
\hline & $\begin{array}{l}\text { Heat Flux } \\
\left(\mathrm{W} / \mathrm{m}^{2}\right)\end{array}$ & $\begin{array}{l}\text { Time } \\
\text { (min) }\end{array}$ & $\begin{array}{l}\text { Penetration } \\
\text { Depth }(\mathrm{cm})\end{array}$ \\
\hline $\begin{array}{c}\text { Gambit Fluent } \\
\text { Simulation } \\
\text { (Laboratory } \\
\text { conditions) }\end{array}$ & 1200000 & 20 & 2.3 \\
\hline $\begin{array}{l}\text { Gambit Fluent } \\
\text { Simulation } \\
\text { (Laboratory } \\
\text { conditions) } \\
\end{array}$ & 1200000 & 30 & 2.6 \\
\hline $\begin{array}{l}\text { Thermocouple } \\
\text { Setup Testing }\end{array}$ & 1263000 & 20 & $\sim 2.5$ \\
\hline $\begin{array}{c}\text { Gambit Fluent } \\
\text { Simulation } \\
\text { (Lunar conditions) }\end{array}$ & 1200000 & 20 & 2.0 \\
\hline $\begin{array}{c}\text { Gambit Fluent } \\
\text { Simulation } \\
\text { (Lunar conditions) }\end{array}$ & 1200000 & 30 & 2.3 \\
\hline
\end{tabular}


Two different approaches to the heat transfer modeling were demonstrated and compared to the experimental testing. The first approach was to simulate a given area by using Gambit and Fluent and by transient heat conduction obtaining an estimate on the penetration depth. The second approach was to use the Engineering Equation Solver and by using the transient heat conduction in a semi-infinite solid we obtained the penetration depth. These two approaches were compared to the experimental results and are shown in table 5.2.

Table 5.3 - Laboratory conditions results

\begin{tabular}{|c|c|c|c|}
\hline & $\begin{array}{c}\text { Heat Flux } \\
\left(\mathbf{W} / \mathbf{m}^{\mathbf{2}}\right)\end{array}$ & $\begin{array}{c}\text { Time } \\
(\mathbf{m i n})\end{array}$ & $\begin{array}{c}\text { Penetration } \\
\text { Depth }(\mathbf{c m})\end{array}$ \\
\hline $\begin{array}{c}\text { Gambit Fluent } \\
\text { Simulation } \\
\text { (Laboratory } \\
\text { conditions) }\end{array}$ & 1200000 & 20 & 2.3 \\
\hline $\begin{array}{c}\text { EES } \\
\text { (Laboratory } \\
\text { conditions) }\end{array}$ & 1200000 & 20 & 1.5 \\
\hline $\begin{array}{c}\text { Thermocouple } \\
\text { Setup Testing }\end{array}$ & 1263000 & 20 & $\sim 2.5$ \\
\hline
\end{tabular}

The most feasible approach obtained was that obtained in our Gambit-Fluent simulation. Simulations were also made using lunar conditions and are shown in table 5.3. By modeling and estimating a possible penetration depth in the Moon researchers can estimate the amount of energy required to extract the volatiles. In the Moon, conditions are more extreme and researchers need the have a good idea of the amount of energy required to complete the mission. An approximated penetration depth of $2.3 \mathrm{~cm}$ was observed when lunar conditions were implemented into our simulation. 
Table 5.3 - Lunar conditions results

\begin{tabular}{|c|c|c|c|}
\hline & $\begin{array}{l}\text { Heat Flux } \\
\left(\mathrm{W} / \mathrm{m}^{2}\right)\end{array}$ & $\begin{array}{l}\text { Time } \\
(\min )\end{array}$ & $\begin{array}{l}\text { Penetration } \\
\text { Depth }(\mathrm{cm})\end{array}$ \\
\hline $\begin{array}{l}\text { Gambit Fluent } \\
\text { Simulation } \\
\text { (Lunar conditions) }\end{array}$ & 1200000 & 30 & 2.3 \\
\hline $\begin{array}{c}\text { EES } \\
\text { (Lunar conditions) }\end{array}$ & 1200000 & 30 & 1.8 \\
\hline
\end{tabular}

According to calculations obtained from experimental testing, $57.6 \mathrm{KJ}$ (48 watts * $1200 \mathrm{sec}$ ) are required to extract 2 grams of water in laboratory conditions. If $10 \mathrm{~kg}$ of water wanted to be extracted for laboratory conditions, an approximation of the total energy required to achieve this would be 288000 $\mathrm{kJ}$. In the other hand, for lunar conditions, if we wanted to extract $10 \mathrm{~kg}$ of water an estimated total energy would be $402800 \mathrm{KJ}$. 


\section{Bibliography}

Alvarez, Francisco, Christopher White, Ashvin Kumar, and Evgeny Shafirovich. "Combustion wave propagation in mixtures of JSC-1A lunar regolith simulant with magnesium." Proceedings of the Combustion Institute, 2012.

Askew, Jim. The Internet Science Room. n.d.

http://crescentok.com/staff/jaskew/ISR/chemistry/class16.htm (accessed 11 14, 2012).

B. Dabrowski, M. Banaszkiewics. Measurments of Lunar and Martian Regolith Thermal Properties using Subsurface Robotic Teams. Bartycka, Warsaw: Space Research Center PAS, 2006.

C. Ray, S. Reis, S. Sen and J. O'Dell. "JSC-1A Lunar Soil Simulant: Characterization, Glass Formation, and Selected Glass Properties ." Journal of Non-Crystalline Solids vol. 356, no. 44-49 (2010): pp. 2369-2374 .

C. Schrader, D. Rickmann, C. McLemore, J. Fikes, S. Wilson, D. Stoeser, A. Butcher and P. Botha. "Extant and Extinct Lunar Regolith Simulants: Modal Analyses of NU-LHT-1M and - 2M, OB1, JSC-1, JSC-1A and -1AF, FJS-1, and MLS-1,." Online. 12 12, 2008. . http://isru.msfc.nasa.gov/lib/Documents/PDF\%20Files/conf_pres_PTMSS2008_Schrader.p df. (accessed 11 15, 2012).

Colaprete, Anthony. "Detection of Water in the LCROSS Ejecta Plume ." Science, 2010: 463.

E. Hill, M. Mellin, B. Deane, Y. Liu and L. and Taylor. "Apollo sample 70051 and high and low-Ti soil simulants MLS-1A and JSC-1A: Implications for future lunar exploration ." Journal of Geophysical Research 112 (2007): p. E02006, .

Gladstone, G. Randall. "LRO-LAMP Observations of the LCROSS Impact Plume ." Science 330, 2010: 472.

Goodrich. Goodrich. November 13, 2009. http://www.goodrich.com/Goodrich (accessed 11 13, 2012). 
Hayne, Paul O. "Diviner Lunar Radiometer Observations of the LCROSS Impact." Science 330, 2010: 477.

Heiken, G.H., Vaniman, D.T., and French, B.M. The Lunar Sourcebook - A User's Guide to the Moon. Cambridge : University Press , 1993.

Landau, L.D., Lifschitz, E.M. Statistische Physik. Berlin: Akademie-Verlag, 1966.

Landis, G. A. "Materials Refining on the Moon ." cta Astronautica, vol. 60, no. 10-11, 2007: 906-915.

Lluís Acero, Àngela Aragón, Xavier Giró, Xavier Prats. "THE MOON ORBITAL MIRROR."

Universistat Politècnica de Catalunya. Barcelona, CATALONIA, n.d.

Lucas, John W. Thermal Characteristics of the Moon. Cambridge, Massachusetts: The Massachusetts Institute of Technology, 1972.

Mitrofanov, I. G. "Hydrogen Mapping of the Lunar South Pole Using the LRO Neutron Detector Experiment LEND ." Science 330, 2010: 483.

Nakamura, T., and Case, J. A. Optical Waveguide Solar Energy System for Lunar Material Processing. SBIR Phase II: NAAS9-19105, 1996.

Nakamura, Takashi. "Solar Power System for Lunar ISRU Aplications." 48th AIAA Aerospace Science Meeting Including the New Horizons Forum and Aerospace Exposition. Orlando: AIAA, 2010. AIAA 2010 - 1162.

—. "Solar Thermal System for Lunar ISRU Applications: Development and Field OPerations at Mauna Kea, HI." 49th AIAA Aerospace Science Meeting Including the New Horizon Forum and Aerospcae Exposition. Orlando: AIAA, 2011. AIAA 2011-433.

ORBITEC. Characterization Summary of JSC-1AF Lunar Mare Regolith Simulant . 12 12, 2006. http://www.orbitec.com/store/JSC-1AF_Characterization.pdf. (accessed 11 14, 2012).

Paige, David A. "Diviner Lunar Radiometer Observations of Cold Traps in the Moon's South Polar Region ." Science, 2010: 479. 
R. Balasubramaniam, R. Wegeng, S. Gokoglu, N. Suzuki and K. Sacksteder. "Analysis of Solar-Heated Thermal Wadis to Support Extended-Duration Lunar Exploration." Orlando: 47th AIAA Aerospace Sciences Meeting Including The New Horizons Forum and Aerospace Exposition , 2009.

Rainer Feistel, Wolfgang Wagner. Sublimation pressure and sublimation enthalphy of H2O ice Ih between 0 and 273.16 K. Bochum: ScienceDirect, 2007.

Schultz, Peter H. "The LCROSS Cratering Experiment ." Science , 2010: 468.

Spudis, P. D. The Clementine Mission - Initial Results from Lunar Mapping. Houston, TX: Lunar and Planetary Institute, 2004.

Takashi Nakamura, Aaron D. Van Pelt, Robert J. Gustafon, Larry Clark. "Solar Thermal Power System for Oxygen Production from Lunar Regolith." Space Technology and Applications International Forum, 2008: PSI-SR-1311.

Woolley, H.W. "Thermodynamics properties for $\mathrm{H} 2 \mathrm{O}$ in the ideal gas state." water and steam proceedings of the 9th International Conference on the Properties of Steam (Pergamon Press), 1980: pp. 166-175. 


\section{Vita}

Jorge Alberto Frias was born in El Paso, Texas in 1987. He is the son of Norberto Frias and Elizabeth Acosta. He finished his high-school education in Preparatoria el Chamizal in Ciudad Juarez, Mexico, graduating in 2006. He attended The University of Texas at El Paso and received a Bachelor of Science degree in Mechanical Engineering in 2010. In November 2009, he started working for the InSitu Resource Utilization (ISRU) team at the NASA-sponsored Center for Space Exploration Technology Research under the supervision of Dr. Evgeny Shafirovich. The research performed at the center led to the publication of "Microgravity Combustion of Thermite Mixtures for Welding in Space and for Production of Structural Materials from Lunar Regolith” by Francisco Alvarez, Armando Delgado, Jorge Frias, Mario Rubio, Christopher White, Ashvin Kumar Narayana Swamy, and Evgeny Shafirovich (AIAA-2012-1119). This also led to the publication of "Combustion of JSC-1A Lunar Regolith Simulant Mixed with Magnesium" by Francisco Alvarez, Christopher White, Armando Delgado, Jorge Frias, Ashvin Kumar Narayana Swamy, and Evgeny Shafirovich (AIAA-2012-4092). During the summer of 2010, he participated in research internship at NASA Johnson Space Center (JSC) where he worked in the ISRU department under mentorship of Aaron Paz. He was a member of three student teams conducted microgravity experiments onboard reduced gravity research aircraft at JSC (April 2011 - Team Leader and Flyer, June 2011 - Flyer, and June 2012 - Ground Crew).

Permanent address: 7528 Luz de Lumbre Av.

El Paso, TX 79912

This thesis was typed by Jorge Frias. 